Florida International University FIU Digital Commons

5-20-2013

\title{
Analyzing Tidal Fluctuations in the Big Pine Key Freshwater Lens with Time-Lapse Resistivity
}

Nicole M. Tucker

Florida International University, ntuck003@fiu.edu

DOI: $10.25148 /$ etd.FI13080512

Follow this and additional works at: https://digitalcommons.fiu.edu/etd

Part of the Geology Commons, Geophysics and Seismology Commons, and the Hydrology Commons

\section{Recommended Citation}

Tucker, Nicole M., "Analyzing Tidal Fluctuations in the Big Pine Key Freshwater Lens with Time-Lapse Resistivity" (2013). FIU Electronic Theses and Dissertations. 947.

https://digitalcommons.fiu.edu/etd/947 


\title{
FLORIDA INTERNATIONAL UNIVERSITY
}

Miami, Florida

\section{ANALYZING TIDAL FLUCTUATIONS IN THE BIG PINE KEY FRESHWATER LENS WITH TIME-LAPSE RESISTIVITY}

\author{
A thesis submitted in partial fulfillment of \\ the requirements for the degree of \\ MASTER OF SCIENCE \\ in \\ GEOSCIENCE
}

by

Nicole M. Tucker 
To: $\quad$ Dean Kenneth G. Furton

College of Arts and Sciences

This thesis, written by Nicole M. Tucker, and entitled Analyzing Tidal Fluctuations in the Big Pine Key Freshwater Lens with Time-lapse Resistivity, having been approved in respect to style and intellectual content, is referred to you for judgment.

We have read this thesis and recommend that it be approved.

Michael Sukop

Florentin Maurrasse

Dean Whitman, Major Professor

Date of Defense: May 20, 2013

The Thesis of Nicole M. Tucker is approved.

Dean Kenneth G. Furton
College of Arts and Sciences

Dean Lakshmi N. Reddi University Graduate School

Florida International University, 2013 


\begin{abstract}
OF THE THESIS
ANALYZING TIDAL FLUCTUATIONS IN THE BIG PINE KEY FRESHWATER

LENS WITH TIME-LAPSE RESISTIVITY
\end{abstract}

by

Nicole M. Tucker

Florida International University, 2013

Miami, Florida

Professor Dean Whitman, Major Professor

The tidal influence on the Big Pine Key saltwater/freshwater interface was analyzed using time-lapse electrical resistivity imaging and shallow well measurements. The transition zone at the saltwater/freshwater interface was measured over part of a tidal cycle along three profiles. The resistivity was converted to salinity by deriving a formation factor for the Miami Oolite. A SEAWAT model was created to attempt to recreate the field measurements and test previously established hydrogeologic parameters. The results imply that the tide only affects the groundwater within 20 to $30 \mathrm{~m}$ of the coast. The effect is small and caused by flooding from the high tide. The low relief of the island means this effect is very sensitive to small changes in the magnitude. The SEAWAT model proved to be insufficient in modeling this effect. The study suggests that the extent of flooding is the largest influence on the salinity of the groundwater. 


\section{TABLE OF CONTENTS}

CHAPTER

PAGE

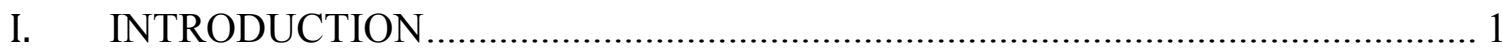

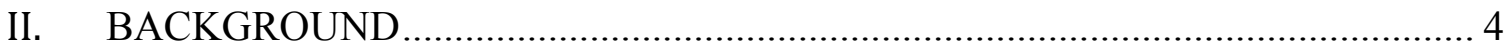

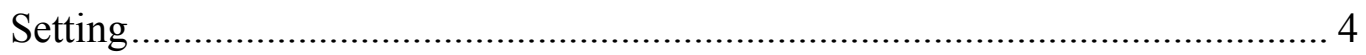

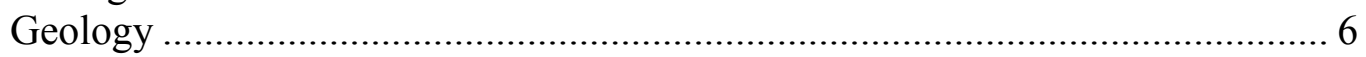

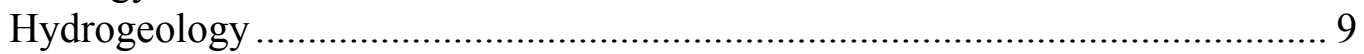

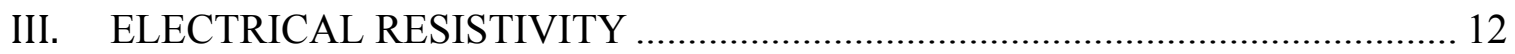

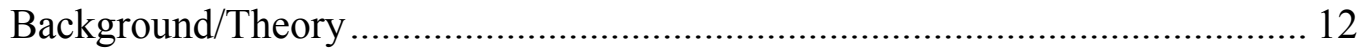

Electrical Resistivity Tomography (ERT) …………................................. 13

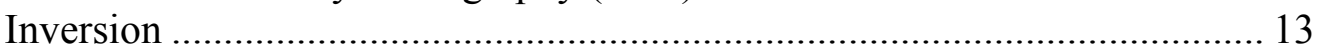

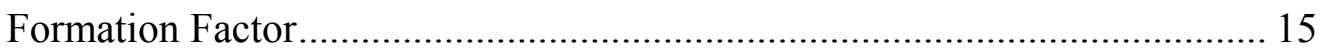

Data and Method of Analysis ...................................................................... 16

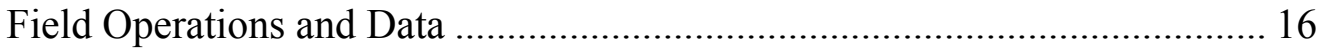

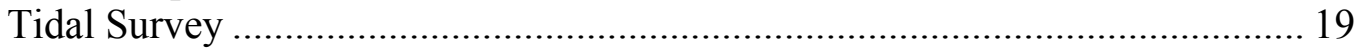

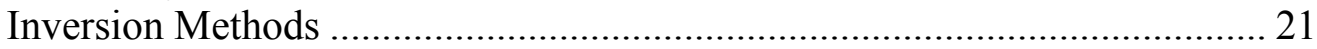

Estimation of Formation Factor and Salinity .................................................. 22

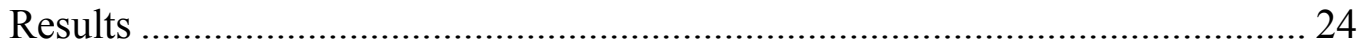

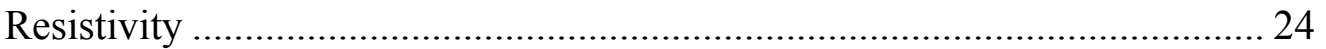

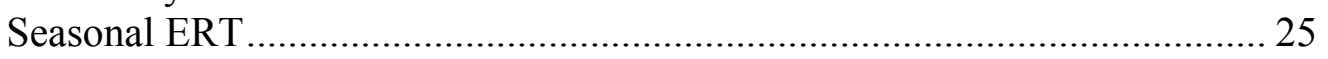

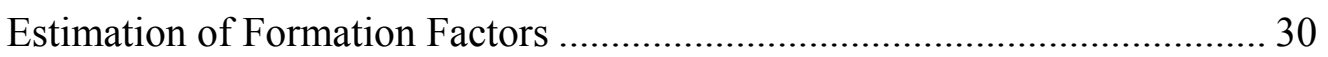

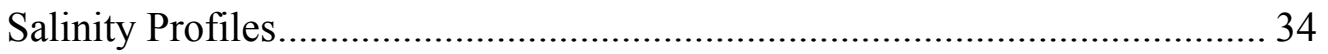

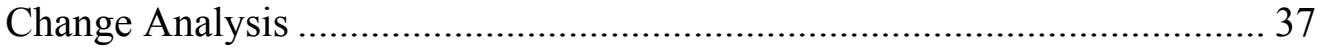

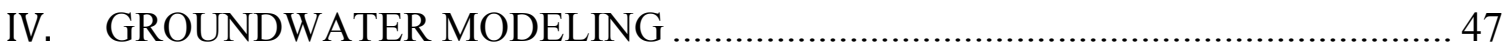

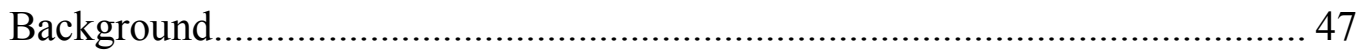

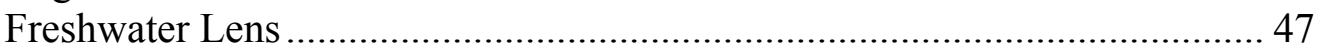

Variable-Density Groundwater Modeling ..................................................... 48

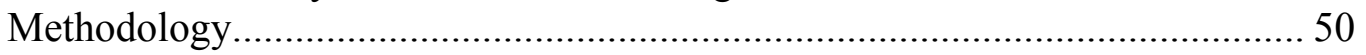

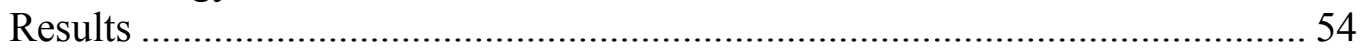

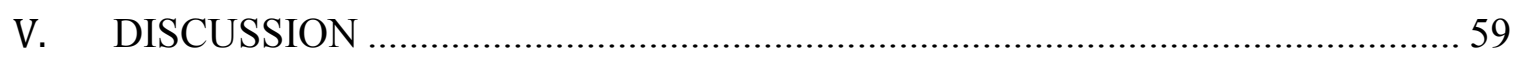

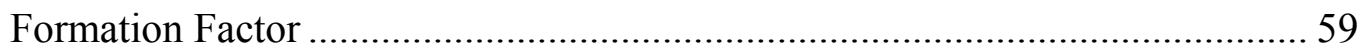

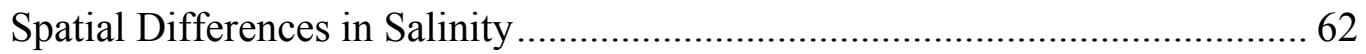

Comparison of Groundwater Model to ERT salinity results ............................ 65

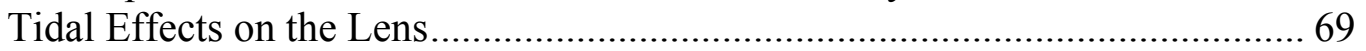

Comparison of Separate Inversion and Difference Inversion ............................. 74

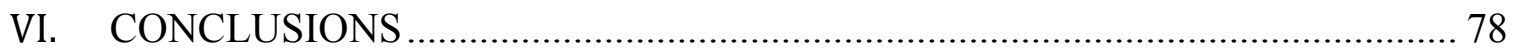

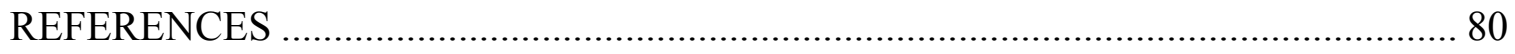

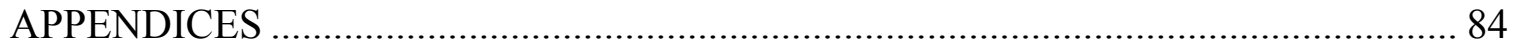




\section{TABLE OF FIGURES}

FIGURE

PAGE

1. South Florida and the Florida Keys 5

2. Geology of Big Pine Key. Map of island indicates the outcropping formations, Miami Oolite and Key Largo Limestone, based on Coniglio and Harrison (1983). The profile indicated by the orange line is in the top right hand corner showing the depth to contact between the Miami Oolite and Key Largo Limestone. 8

3. "Bahama-type" island based on Vacher and Wallis (1992). If hydraulic conductivity, $\mathrm{K} 1$, is less then $\mathrm{K} 2$, then freshwater lens depth is truncated

4. Electrical resistivity array where $\mathrm{r} 1, \mathrm{r} 2, \mathrm{r} 3$, and $\mathrm{r} 4$ represent the lengths with respect to the current and potential electrodes.

5. The seasonal ERT profiles, red dashed lines, and shallow wells, green dots, for the Ogurcak study on Big Pine Key and Sugarloaf. The data collected along these lines will be used for formation factor determination.

6. Tidal profiles (yellow lines) referenced to their locations on the seasonal profiles (red lines) from Figure 6. Green dot represent wells. The B1 site has a coastal boundary of mangroves and a salt marsh. The B3 site is on the edge of a large tidal flat with a network of mosquito ditches in the area.

7. High tide ERT results for B1WE at $15: 20$ on $5 / 7 / 12$. The color scale is in log 10 with the real resistivity labeled below.

8. ERT results for the seasonal line B1. Both inversion methods produce similar percent differences in resistivity over the season. There is a clear increase in resistivity caused by the increase in freshwater to the lens over the wet season. . 26

9. ERT results for the seasonal line B2. Large changes observed in the percent change of the seperate inversion are caused by a variation on the modeled resistivity for the December results. The water table at this site is deeper than the others due to the higher elevation. The top meter is the vadose zone, which explains the presence of the high resistivity $(>1000 \mathrm{ohm}-\mathrm{m})$.

10. ERT results for the seasonal B3 line. The color scale of the percent change plot had to be lowered compared to the other seasonal plots. The seasonal change in precipitation and recharge appears to have little effect on the groundwater. ....... 28

11. ERT results for seasonal line S2. Due to high tide flooding, the beginning of the November 2011 measurement had to be shifted up. Changes are not very large 
over the season but the overall increase in resistivity suggests an increase in freshwater recharge.

12. ERT results for seasonal line S3. The May 2011 measurement has a number of artifacts causing the percent change plot to be difficult to interpret. Overall, there appears to be an increase in resistivity

13. Scatter plot of bulk rock resistivity vs. pore water resistivity of all measured wells on seasonal profile lines.

14. Formation Factor for each line determined by the data points obtained on each, separated by island.

15. Formation Factor of each island determined by the combined data points of each. Both formation factors determined are within each other's uncertainties. The error increases with higher resistivity.

17. B1WE high tide ERT converted to salinity using the formation factor. Middle profile shows the formation factor used for all conversions. Top and bottom profiles illustrate difference between upper and lower bounds of the uncertainty.

18. Salinity profiles for B1NS from $7 / 29 / 11$ and B3 from $5 / 8 / 12$.

19. B1WE high and low tide salinity results from $5 / 7 / 12$. The bottom plot is the percent change in salinity over this time period. The overland flow of the saltwater during high tide is noted by the surficial high salinity and the percent change plot. An increase in salinity occurs in the groundwater closest to the region flooded by low tide. The eastern half shows a small decrease in overall salinity.

20. Well and tide gauge measurements collected during B1WE tidal survey on 5/7/12. The temperature and electrical conductivity measurements are from Well B11. Well B12 water level measurements were conducted manually once an hour. The tide measurements are from the temporary gauge set up near the site and the Vaca Key measurements are from NOAA/NOS chart \#11453.

21. High and low tide results from B1WE tidal survey on $7 / 28 / 11$. The percent difference scale is smaller than the 5/7/12 plot. Tidal changes were much smaller over this survey.

22. B11 well measurements and Vaca Key tide level collected during the 7/28/11 survey. The conductivity follows the trend of the water level until mid-tide where 
it begins to increase again while the water level drops. The temperature increases as the water level recedes, inversely following the trend of the water level. ....... 42

23. B1NS high and low tide results from $7 / 29 / 11$. The percent change between high and low tide shows a small decrease in salinity for the majority of the profile.... 43

24. Well B11 and Vaca Key tidal results during the B1NS survey on 7/29/11. The electrical conductivity and temperature follow the same pattern as measurements

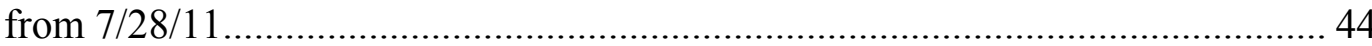

25. High and low tide salinity results from B3 tidal survey on 5/8/12. Areas of high salinity near the surface are likely casued by marl, which has a lower salinity than the limestone. Similar to the B1WE and B1NS surveys in 2011, tidal changes were very small.

26. Well and tide measurements during the B3 tidal survey. While temperature follows the same pattern as the measurements at the B11 well, the conductivity shows no pattern and changes little over the survey.............................................. 46

27. Groundwater model boundary conditions created in Groundwater Vistas 6 , showing. Red cells represent high hydraulic conductivity ocean boundary. Green cells represent Miami Oolite and orange cells are Key Largo Limestone.

28. Starting model for the tidal simulation with boundary conditions. Solid black line is Ghyben-Herzberg line based on head of the starting model. Salinity scale is set to the same bounds as the salinity distribution from ERT data. Vertical exaggeration is 5.3 .

29. Groundwater model results using the tide data from July 28th, 2011 corresponding to ERT measurement at B1WE. Tide level input came form the Vaca Key tide station. 56

30. Groundwater model results with the tide data from May 7th, 2012 corresponding to the tidal measurement at B1WE. Tide level input came from temporary tidal station set up at the site.

31. Comparison of spatial differences in the salinity of each tidal profile. The A plot is from $5 / 7 / 12$ survey, $B$ is from $7 / 29 / 11$, and $C$ is from $5 / 8 / 12$. Freshwater is denoted in black, $<1$ ppt. The oligohaline zone is light in salinity $(1-5 \mathrm{ppt})$. Mesohaline is moderate in salinity $(5-18 \mathrm{ppt})$. Polyhaline is high in salinity (18$30 \mathrm{ppt}$ ). Hypersaline areas indicated in grey are due to marl not increased salinity.

32. Topographic relief of the B1WE and B3 tidal profiles. B3 has a relief .2 m smaller than the B1WE profile. The lower elevation would cause more flooding and saltwater infiltration into the groundwater. 64 
33. Comparison of the measured salinity results from B1WE and the groundwater model result from SEAWAT after the tidal simulation.

34. Possible formation factors for the Key Largo Limestone. Two resistivity points from B1WE 5/8/12 at 01:20 were picked, at $25 \mathrm{~m}$ and $10 \mathrm{~m}$ at a depth of $7.5 \mathrm{~m}$, to match the SEAWAT salinity results by recalculating the formation factors. The salinity results based on those formation factors are displayed below.

35. Comparison of tidal ERT results, the original groundwater model results and new groundwater model with an even hydraulic conductivity of the Miami Oolite for all layers.

36. $\mathrm{A}$ is the percent change over the two hours leading up to high tide at 15:20 and B is the percent change from high tide to low tide on 5/7/12 on B1WE.

37. A comparison of the tide and well water level results for the two B1WE tidal surveys. The tidal range increased for the May 2012 survey by $30 \%$ and the well water level increased $\sim 0.15 \mathrm{~m}$.

38. Well and tide level measurements during the May 2012 tidal survey. The salinity is converted from the conductivity measurements from Well B11.

39. High tide comparison of the two SEAWAT simulations of the B1WE tide measurements.

40. Comparison of the two ERT inversion results leading up to high tide from 12:20 to $15: 20$. The separate inversions produce different models which makes smaller changes difficult to see. 


\section{INTRODUCTION}

Freshwater resources are vital to island communities, both anthropogenic and biota. Fresh groundwater is stored as a lens beneath the surface that floats on top of the denser saltwater and its only source of recharge is the precipitation that the island receives. The groundwater interactions between the freshwater and seawater are complex, with daily to seasonal and long term effects all playing a role. The lens is highly vulnerable to saltwater contamination, made worse because of the threat of sea level rise. Understanding the lens and what affects it are crucial to predicting future problems and optimal water management.

Big Pine Key is one of the few Florida Keys that retains a freshwater lens yearlong (Halley, Vacher, \& Shinn, 1997). Big Pine Key has a dual-layer aquifer, with less permeable Miami Oolite at the surface and more permeable Key Largo Limestone below about $5 \mathrm{~m}$, causing a truncated lens similar to lenses measured in the Bahamas (Vacher 1997). The lens is split in two with a smaller lens to the south and a larger lens in the northern half of the island (Hanson 1980; Wightman 1990). Factors that affect the extent of the lenses include seasonal variation in recharge from precipitation, wells, pavement, calcrete, canals, and tides (Hanson 1980, Wightman 1990, Beaudoin 1990).

Electrical geophysical methods such as electromagnetic (EM) and DC resistivity profiling have proven to be an effective way to measure island lenses. EM profiles have been used in the past to measure the depth to the saltwater/freshwater interface of the lens (Stewart 1988; Beaudoin 1990; Wightman 1990; Cabellero 2004). Electrical resistivity tomography (ERT), widely used in hydrogeophysics (Binley \& Kemna 2005), resolves more detail of the spatial distribution of resistive properties of the subsurface. In addition 
to static measurements, time-lapsed resistivity measurements have been used for interface and saltwater intrusion monitoring (Swarzenski et al. 2006; de Franco et al. 2009; Morrow et al. 2010). With the amount of data provided with ERT, there is no unique inverse solution to the resistivity distribution. Therefore, the goal when conducting a geophysical analysis is finding the best-fit model with the least error that remains geologically sensible. When monitoring changes, constraining or weighting the model on the basis of the previous model can reduce noise and help to resolve small changes in the resistivity (Binley \& Kemna 2005).

Previous studies by Wightman (1990), Beaudoin (1990), and Wightman (2010) utilized geophysical methods for the freshwater lenses of Big Pine Key. The studies focused on the general geometry and extent of the freshwater lens and relied primarily on EM with a few ERT profiles conducted in the most recent study. Due to the lower resolution of EM and larger extent of these studies, a sharp saltwater-freshwater interface was assumed and the measurements were conducted once for each dry and wet season. According to a USGS report by Hanson (1980), the interface, which can be 1 to $6 \mathrm{~m}$ below the surface, is not sharp but transitional, at least $3 \mathrm{~m}$ thick and there are hourly changes in the water table height as a result of the tides.

The transition zone and tidal influences on the groundwater are not well understood because of the low resolution of EM and limited information provided by well measurements. The purpose of this study was to investigate the tidal changes at the edge of the Big Pine Key freshwater lens with time-lapse ERT, utilizing a difference inversion scheme (Labrecque and Yang 2001) to resolve smaller changes in resistivity. To analyze the data with respect to salinity, a formation factor was determined to convert 
the resistivity to salinity. A numerical groundwater model was created to test parameters from previous studies and replicate the tidal results of the ERT data. 


\section{BACKGROUND}

\section{Setting}

Big Pine Key is a part of the Florida Keys. The Florida Keys extend in a chain of islands $240 \mathrm{~km}$ long from Elliot Key, southeast of Miami, to Key West along the southern edge of the Florida Platform (Halley et al. 1997) (Figure 1). They are divided into the Upper and Lower Keys, according to the change in the shape of the islands and their geology. From Soldier Key to Bahia Honda, the Upper Keys align parallel with the Florida Platform in long thin islands. The Lower Keys, from Big Pine Key to Key West, align somewhat perpendicular to the platform as wider, larger, more irregularly shaped islands. Big Pine Key is the largest of the Lower Keys.

The topography of Big Pine Key is low and flat with a relief no more than 2 meters. The average width of the island is around $2 \mathrm{~km}$ towards the north and $3 \mathrm{~km}$ to the south with a length of about $10 \mathrm{~km}$. The island has a pine rockland ecosystem which hosts a number of critically listed species. Close to $50 \%$ of the island is a part of the Key Deer Refuge, lying primarily in the Northern half of the island. The Key Deer Refuge, established in 1957, has limited further development of the island. The northern part of the island is ideal for study since it is less impacted by human development. 


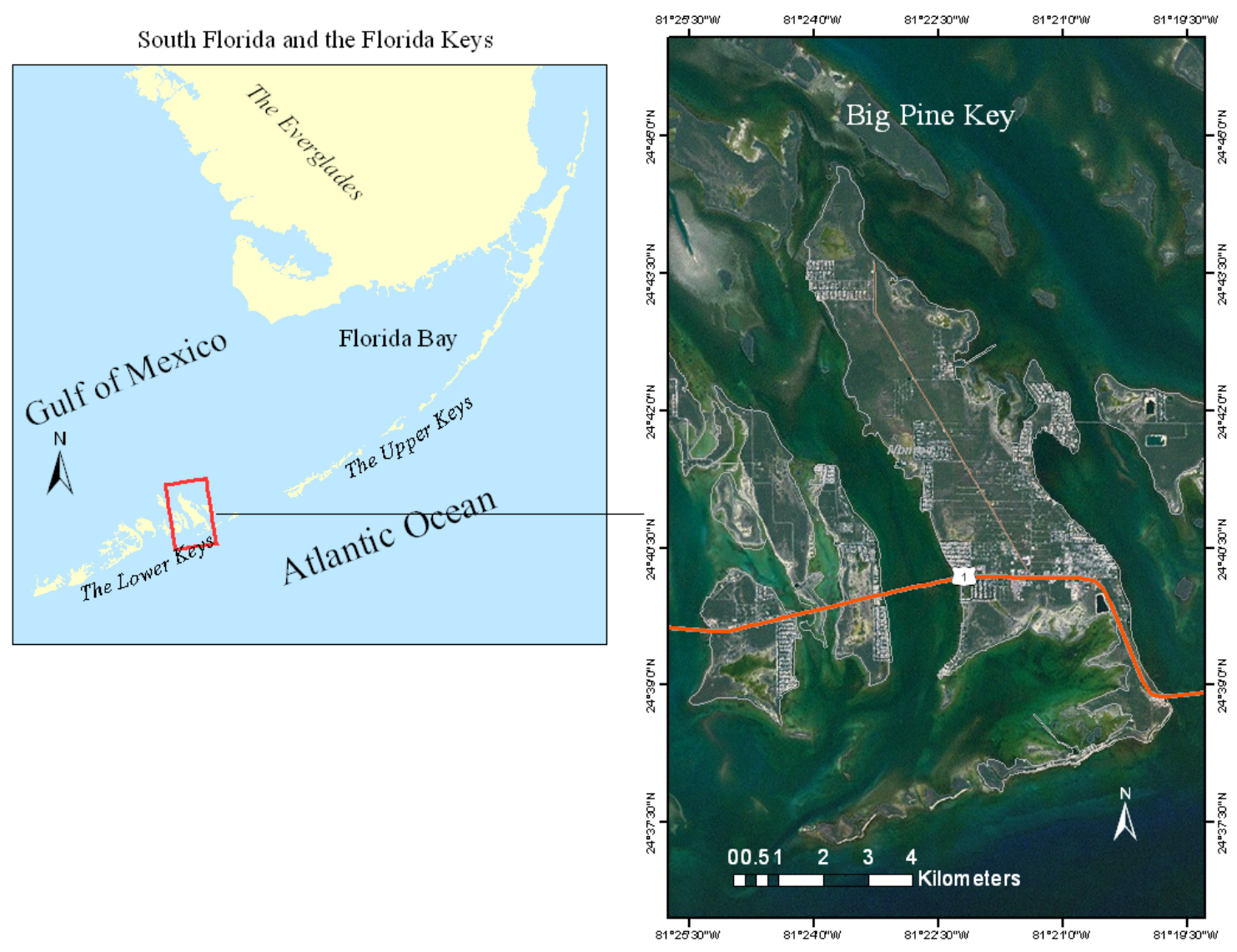

Figure 1 - South Florida and the Florida Keys.

Freshwater resources on the island are affected by a host of natural and man-made causes. Annual precipitation averages about $1.18 \mathrm{~m}$ (Hanson 1980) but around 75\% of the precipitation occurs in the wet season, from early May to the end of October. Many canals were dredged on the island for boat access and to create more waterfront property. Dredging has resulted in saltwater intrusion inland, causing at least a $20 \%$ loss of freshwater in the lens (Langevin et. al. 1998). Potable water for residents is provided by the Florida Keys Aqueduct Authority, the primary source of freshwater coming from the Biscayne Aquifer on the mainland. Some residents still utilize wells on the island primarily for landscape use, which can cause some loss of freshwater but may be 
balanced out by those who use the aqueduct water for landscape purposes. Other factors affecting the amount of freshwater include paved surfaces that reduce recharge to the groundwater, mosquito ditches that increase seawater intrusion, and storm surges from tropical storms that carries saltwater inland. The encroachment of salt tolerant plant species and loss in area of freshwater reliant plant species in recent years highlights the effect of sea level rise. As sea levels rise, the extent of the freshwater lens will continue to shrink, which is estimated to speed up as a result the effects of climate change.

\section{Geology}

Two late Pleistocene formations dominate the geology of the Florida Keys: the Key Largo Limestone and the Miami Oolite. The Key Largo Limestone is a remnant of the ancient reef tract that once extended from Miami past Key West. It is composed of hermatypic corals with interbedded calcarenites and thin beds of quartz sand (Halley et al. 1997). The Key Largo Limestone can be found at the surface in the Upper Keys, creating the thin linear trend of the islands. The Miami Oolite Limestone is an ooid grainstone-packstone. It is composed of well-sorted ooids, skeletal material, and some quartz sand and found at the surface of the Lower Keys (Halley et al. 1997; Coniglio and Harrison 1983). It varies in thickness throughout with a maximum thickness recorded on Key West of $10.7 \mathrm{~m}$ (Hoffmeister 1974). The Miami Oolite originated as a shallow marine ooid shoal that deposited laterally with the youngest Key Largo Limestone, Q5, unit and on top of the older Q4 unit (Figure 2). The larger, wider island shape of the Lower Keys and the paleo-tidal channels between them reflect this deposition (Randazzo and Halley, 1997). 
Big Pine Key starts the Lower Keys from the East. Therefore, the majority of the outcropping formation is the Miami Oolite while the Key Largo Limestone outcrops just on the southern end of the island (Figure 2). The Miami Oolite averages about 5 meters thick but thins out towards the southern end of the island until the Key Largo Limestone outcrops near the coast (Hanson 1980). The Key Largo Limestone has an unknown thickness since the deepest core drilling on Big Pine Key reached a thickness of 52 meters without reaching the base (Hoffmeister 1974). 


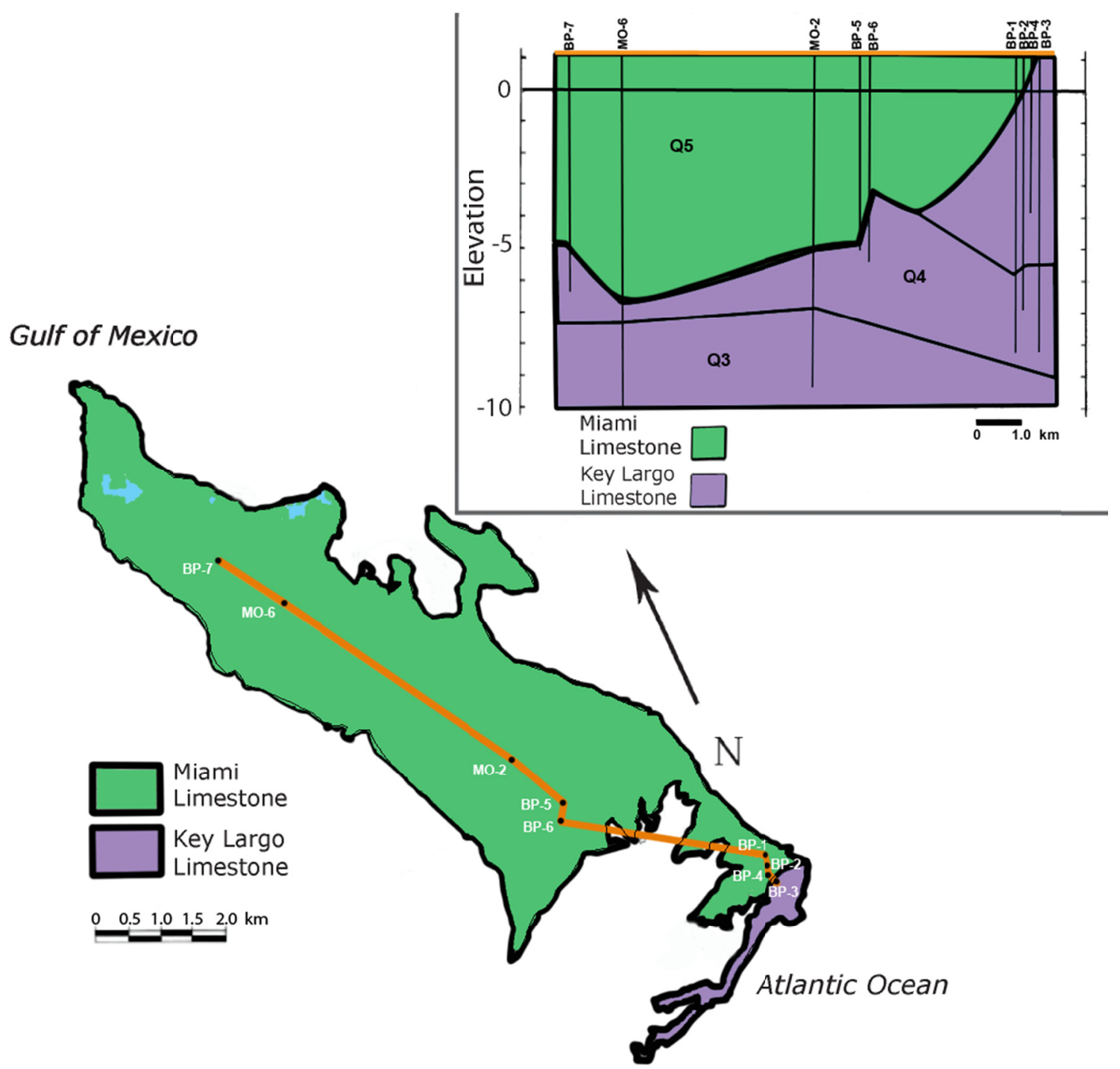

Figure 2 - Geology of Big Pine Key. Map of island indicates the outcropping formations, Miami Oolite and Key Largo Limestone, based on Coniglio and Harrison (1983). The profile indicated by the orange line is in the top right hand corner showing the depth to contact between the Miami Oolite and Key Largo Limestone.

Both formations have been subjected to some alteration since deposition. A laminated crust, referred to as calcrete, can be found at the surface and at other depths within the Miami Oolite in much of the Keys including Big Pine Key. These typically reddish-brown crusts form during subaerial exposure and have been used for stratigraphy and determining past sea levels (Robin and Stipp 1979; Halley et al. 1997). Weathering 
of these marine carbonates has also caused minor karstification throughout the Keys along with the development of vug and channel porosity (Halley et al. 1997). The result is similar to what is found in Southeast Florida and the Bahamas, with high permeability that varies laterally and with depth (Hanson 1980; Halley et al. 1997; Cunningham et al. 2009).

\section{Hydrogeology}

Both formations have similar porosities but significantly different permeability. According to Coniglio and Harrison (1983), both limestone formations have an average matrix porosity of $15 \%$ and a total porosity reaching up to $40 \%$ but the pore space of the Key Largo Limestone is much better connected. Since the Key Largo Limestone is older, the pore fabric of the rock had more time to change from primary to secondary porosity than that of the Miami Oolite. An effective and average porosity was determined in studies of these rock formations in other areas such as Key Largo and Miami-Dade. DiFrenna et al. (2007) determined the effective porosity of Key Largo Limestone from Key Largo, Florida, to be 33\%. Robinson (1967) determined the porosity of the Miami Oolite collected from road cuts in Miami, Florida, to be in a range between 20 and 40\% but the majority was over $30 \%$. In all studies the porosity was found to vary considerably from place to place.

The permeability of the two formations plays an important role on the freshwater lenses. A study done by Wightman (1990) on Big Pine Key determined the hydraulic conductivity of the Miami Oolite ranges from 100-140 m/day and the Key Largo Limestone ranges from 1200-1600 m/day. This dual aquifer relationship has been 
observed on other carbonate atoll and reef islands, causing the freshwater lens to be truncated (Vacher 1997). The depth of the freshwater lens corresponds to about 40 times the hydraulic head. In the case of an underlying higher conductivity formation, the flow lines are refracted when the water reaches the contact and the tidal mixing increases in the lower more permeable formation. When the freshwater depth reaches the lower layer, the freshwater head and interface depth increases very little and the interface has a thicker transition zone. A study by Vacher and Wallis (1992) compared the hydrogeology of Bermuda and the Bahamas, classifying islands with the same truncated lens as Big Pine Key as a "Bahama-Type" island (Figure 3).

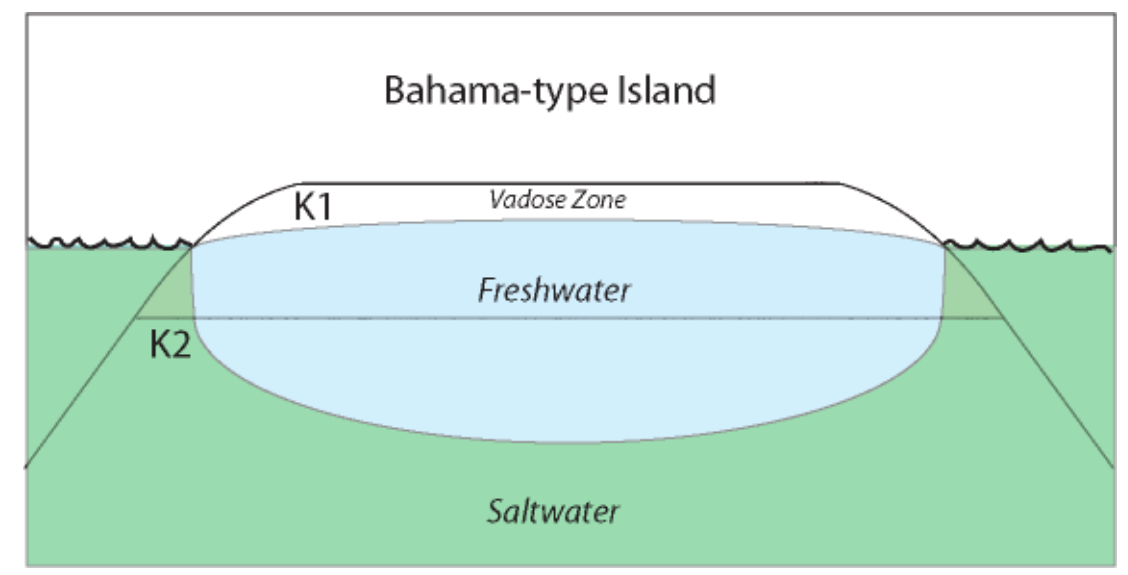

Figure 3 - "Bahama-type" island based on Vacher and Wallis (1992). If hydraulic conductivity, K1, is less then $\mathrm{K} 2$, then freshwater lens depth is truncated.

The lens shape and extent is controlled by a few permanent and fluctuating factors. The lens is split in two by a topographic low in the middle of the island, which corresponds with a large area of outcropping calcrete that may retard infiltration. The Northern lens is larger than the Southern lens because of the larger areas of paved surfaces that decrease groundwater recharge and a shallower depth to contact between Miami Oolite and Key Largo Limestone in the South. The coastline and canals primarily 
shape the horizontal extent while the depth to the contact and the topography shape the vertical extent. The seasonal difference in precipitation, the only source of recharge, causes a change in lateral extent but not much with depth as observed by Hanson (1980) and Wightman (1990). Meadows, Caballero, Kruse, and Vacher (2004) conducted a study with respect to the brackish zones for two nearby islands, Sugarloaf and Little Torch Key, since they retain no freshwater lens. The two islands, geologically similar to Big Pine Key but smaller in size, retain a brackish lens that varies in salinity with respect to distance from the center and with the wet and dry seasons.

Tides are another factor affecting the groundwater but it has not been well studied for Big Pine Key. The tides are mixed and semi-diurnal around Big Pine Key, coming from the Atlantic Ocean, the Gulf of Mexico, and Florida Bay. On average the tidal range of one day is around $0.33 \mathrm{~m}$ but can be upwards of $0.6 \mathrm{~m}$ during spring tide. To the east and west of the island, separating it from the other islands, lie shallow paleo-tidal channels. With the variable tides from both ends of the island and the shallow channels on either side, the tides can be different depending on location. Hanson (1980) observed a lag of a couple of hours between the tides in Bogie Channel, on the eastern side of the island, and Pine Channel, on western side. Hanson found that the tidal amplitudes and times were influenced by local winds and offshore weather systems. The tide was observed as the overriding influence on the groundwater in the dry season. The tidal signal has been observed to propagate through the groundwater with little loss in magnitude on Big Pine Key (Hanson 1980) and Sugarloaf (Meadows et al. 2004). 


\section{ELECTRICAL RESISTIVITY}

\section{Background/Theory}

Rocks, minerals and fluids all have their own electrical properties, which can be measured with the use of geo-electrical methods including DC resistivity. To find the resistivity of a material, a current is applied and the resulting voltage is measured. With Ohm's law, the resistivity can be calculated: $R=\frac{V}{I}$ where $\mathrm{R}$ is the resistivity, $\mathrm{V}$ is the potential difference or voltage, and I is the current (Telford 1990).

For a geophysical survey, an array of electrodes is set in the ground with two current electrodes and two potential electrodes (Figure 4). Similar to a normal electrical circuit, the earth acts as the resistor and the calculation is as follows:

$$
\rho=\frac{2 \pi^{*} \Delta V}{I} * \frac{1}{\left\{\left(\frac{1}{r_{1}}-\frac{1}{r_{2}}\right)-\left(\frac{1}{r_{3}}-\frac{1}{r_{4}}\right)\right\}}
$$

The lengths $r_{1}, r_{2}, r_{3}$, and $r_{4}$ correspond to the distances between current and potential electrodes and $\rho$ is the apparent resistivity over a half space. The longer the distances are between the electrodes the larger the half-space is that it covers and the deeper the depth of resolution. For the purposes of this study, a Wenner array was used. For the Wenner array, all electrodes are located at equal spacing (the a-spacing), meaning that $r_{2}=r_{3}=a$ and $\mathrm{r}_{1}=\mathrm{r}_{4}=2 \mathrm{a}$. This is a common array used in many surveys with a simple calculation:

$$
\rho_{a}=\frac{2 \pi a \Delta V}{I}
$$


(Telford 1990). The apparent resistivity is the resistivity over the half space of the array. It depends on the electrode spacing and sensitivity and cannot be interpreted as the actual resistivity if the subsurface is not homogenous.

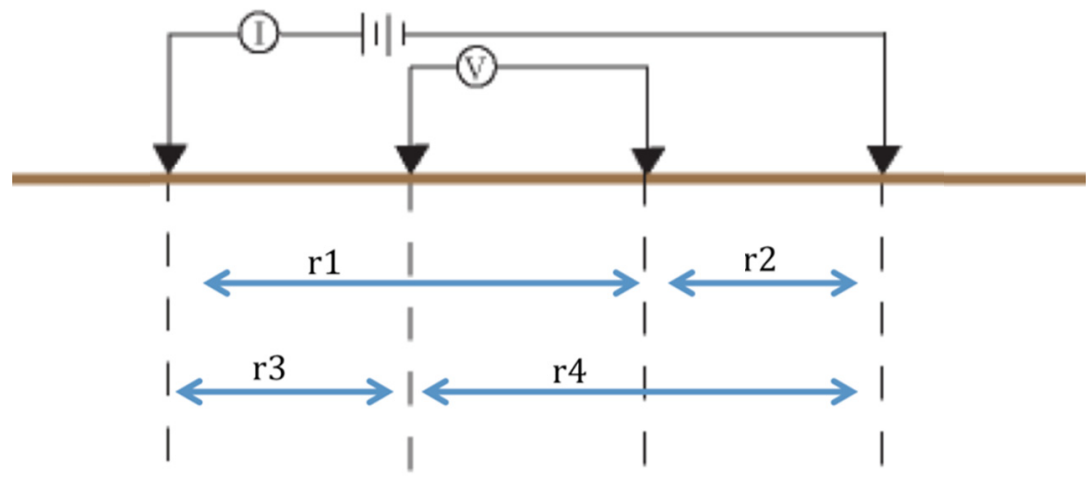

Figure 4 - Electrical resistivity array where r1, r2, r3, and r4 represent the lengths with respect to the current and potential electrodes.

\section{Electrical Resistivity Tomography (ERT)}

Electrical Resistivity Tomography is a geophysical technique that produces a subsurface image of the resistivity along a profile line. A number of electrodes are placed an equal distance apart from each other along a line and connected by a multi-electrode cable. The cable is connected to a switch box and resistivity meter. To collect the set of apparent resistivities to produce the image, the switch box changes the potential and current electrodes, using electrodes at different distances apart from each other and at different locations along the line. This set is then used to construct a model of the true subsurface resistivity.

\section{Inversion}

The apparent resistivity values obtained after measurement require inversion to produce a 2-D model of the resistivity structure beneath the profile. Inversion is the method by which a set of data is used to solve for a model with an approximation of the 
electrical properties of the subsurface. The inverse problem is non-unique, and with data errors, it requires constraints to be placed on the inversion, which can be done by solving it as a regularized optimization problem. For the purposes of this study, Occam's inversion for ERT developed by LaBreque et al. (1996) was utilized using the 2-D inversion program, R2 (Binley 2011). Occam's inversion (Constable et al. 1987) refers to the regularization process of the underdetermined problem that constrains changes in the model to be smooth. The objective function to be minimized is

$$
\Psi(\mathbf{m})=[\mathbf{D}-\mathbf{F}(\mathbf{m})]^{T} \mathbf{W}_{D}[\mathbf{D}-\mathbf{F}(\mathbf{m})]+\alpha \mathbf{m}^{T} \mathbf{R} \mathbf{m}
$$

where $\mathrm{m}$ is the parameter vector for the model, $\mathrm{D}$ is the known data values, $\mathrm{F}(\mathrm{m})$ is the forward operator, $\mathrm{W}_{\mathrm{D}}$ is the data weighting matrix, $\alpha$ is the stabilization parameter, and $\mathrm{R}$ is the roughness matrix. For each non-linear iteration, the parameter change is

$$
\Delta \mathbf{m}_{k}=\mathbf{m}_{k+1}-\mathbf{m}_{k}
$$

which can be found using

$$
\Delta \mathbf{m}_{k}=\left(\mathbf{G}_{k}^{T} \mathbf{W}_{D} \mathbf{G}_{k}+\alpha \cdot \mathbf{R}\right)^{-1}\left(\mathbf{G}_{k}^{T} \mathbf{W}_{D} \Delta \mathbf{D}_{k}-\alpha \cdot \mathbf{R} \cdot \mathbf{m}_{k}\right)
$$

where $\mathrm{G}_{\mathrm{k}}$ is the sensitivity matrix and $\Delta \mathbf{D}_{k}=\mathbf{D}_{k}-\mathbf{F}(\mathbf{m})$. The conjugate gradient method is used to estimate a solution to the parameter change.

Often, time-series resistivity profiles are inverted separately. Inversion itself can introduce artifacts, so with separate inversions small changes are often not detected (Hayley et al. 2011). To reduce systematic error introduced in an individual inversion, each measurement can be inverted with information from the previous time step taken into account. 
One such inversion scheme is the difference inversion developed by LaBrecque and Yang (2001). Difference inversion is modified from the Occam's inverse method and uses the inversion model from the previous time step as a starting model for the inversion of the following time-step. The inversion on the difference in data becomes

$$
\Delta \mathbf{D}=\left(\mathbf{d}_{o b s}-\mathbf{d}_{o b s}^{O}\right)-\left[\mathrm{g}(\mathbf{m})-\mathrm{g}\left(\mathbf{m}^{O}\right)\right]
$$

where $d_{o b s}$ is the observed data vector, $d_{o b s}{ }^{\circ}$ is the prior data vector, and $m^{\circ}$ is the model derived from the prior time step. The objective function to be minimized then becomes

$$
\Psi(\mathbf{m})=\Delta \mathbf{D}^{T} \mathbf{W}_{D} \Delta \mathbf{D}+\alpha \cdot\left(\mathbf{m}-\mathbf{m}^{O}\right)^{T} \mathbf{R}\left(\mathbf{m}-\mathbf{m}^{O}\right)
$$

and the parameter change vector to be solved with the conjugate gradient method becomes

$$
\Delta \mathbf{m}_{k}=\left(\mathbf{G}_{k}^{T} \mathbf{W}_{D} \mathbf{G}_{k}+\alpha \cdot \mathbf{R}\right)^{-1}\left(\mathbf{G}_{k}^{T} \mathbf{W}_{D} \Delta \mathbf{D}+\alpha \cdot \mathbf{R} \cdot\left(\mathbf{m}^{O}-\mathbf{m}_{k}\right)\right) .
$$

It produces a model for the given apparent resistivity and a model of the difference in the resistivity between the two time-steps. The difference and separate inversion methods were utilized through the 2-D inversion program, R2 (Binley 2011).

\section{Formation Factor}

In non-conductive rocks, the pore fluid, porosity, lithology, and temperature control electrical properties of the subsurface. Archie (1942) derived a few relationships based on porosity and pore fluid to interpret bulk resistivity values. The first relationship states that the formation resistivity factor, $F$, is

$$
F=\frac{\rho_{o}}{\rho_{w}}
$$


where $\rho_{\mathrm{o}}$ is the resistivity of the bulk saturated rock and $\rho_{\mathrm{w}}$ is the resistivity of the pore fluid of the rock. The second relationship, Archie's first law, is based on the electrical conductivity of a saturated rock and its porosity. Archie's law states

$$
F=\frac{1}{\phi^{m}}
$$

where $\phi$ is the porosity of the rock and $m$ is the cementation factor. The cementation factor depends on the pore structure, which affects the resistivity of the rock. This equation is the original and simplest form of Archie's law but there are a number of variations of Archie's Law. The most common form replaces 1 with $a$, making the $\mathrm{F}=a^{*} \phi^{-\mathrm{m}}$, sometimes referred to as the Humble formula (Tiab and Donaldson 2004). However, the general relationship that works well for most carbonates is

$$
F=\frac{1}{\phi^{2}} \text { (Tiab and Donaldson 2004). }
$$

\section{Data and Method of Analysis}

\section{Field Operations and Data}

The area of study is located in the northern half of Big Pine Key. There is some development on this part of the island but there are many more natural areas than can be found in the southern half of the island making it more suitable for study. The north part of the island is ideal because it lacks many residential wells, pavement, and utility lines that could affect the measurements. The lens reaches a maximum depth of about 7 meters in the middle of the island and the horizontal extent varies mostly as a consequence of proximity to canals (Hanson 1980; Wightman 1990). 
The fieldwork for this study was initiated by another study conducted by Ogurcak (2010). Part of the Ogurcak study, which focuses on plant community dynamics in the lower Florida Keys, is to map the seasonal extents of the freshwater lens on the island using DC resistivity measurements. On Big Pine Key and Sugarloaf, a nearby smaller island, five ERT profile lines (ranging from $220 \mathrm{~m}$ to $278 \mathrm{~m}$ in length) were established along transects where plant studies are being conducted. Short screened wells (1.5-2 meters) are located along these transects, with at least three wells falling along the ERT lines (Figure 5). The ERT measurements were taken using an Advanced Geosciences Inc. (AGI) SuperSting R1 IP meter and a 28-electrode cable. Using 2-meter spacing of the electrodes and the Wenner array, a roll-along survey was conducted at the end of the wet and dry seasons for each line, for a total of 10 surveys. The ERT survey dates are listed in Table 1.

To conduct a roll-along survey, the cable is disconnected in the middle after the first measurement and the first half of the cable is moved and attached at the end of the second cable. The next measurement is taken and the same procedure is repeated. This allows for continuous profiling regardless of the length of the cable. Coincident well measurements were taken along with the ERT for water level, temperature, and conductivity.

Measurements were conducted in May 2011, for the dry season, and in November and December 2011, for the wet season. Due to time constraints, Transect B2 was not measured at the very end of the wet season and was conducted in December. Part of the present study focuses on the inversion of the seasonal profiles and the use of the well 
conductivity and ERT to develop a formation factor, but the seasonal change in salinity will not be analyzed for these profiles.

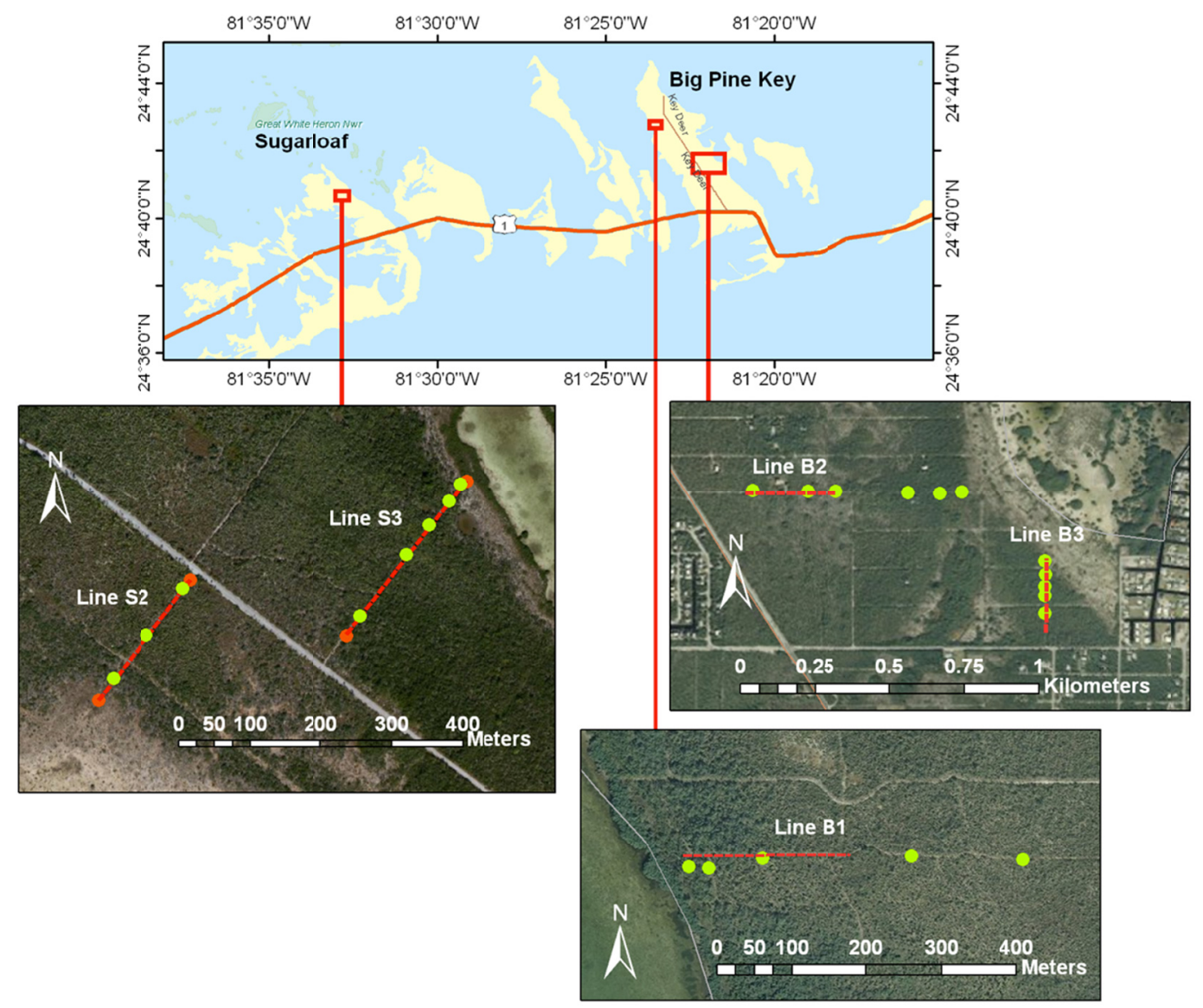

Figure 5 - The seasonal ERT profiles, red dashed lines, and shallow wells, green dots, for the Ogurcak study on Big Pine Key and Sugarloaf. The data collected along these lines will be used for formation factor determination.

\begin{tabular}{|l|l|l|}
\hline Date (Month/Day/Year) & Profiles & Seasonal/Tidal survey \\
\hline $\mathbf{5 / 2 0 / 2 0 1 1}$ & B $~$ & Seasonal \\
\hline $\mathbf{5 / 2 1 / 2 0 1 1}$ & B 3 & Seasonal \\
\hline $\mathbf{5 / 2 2 / 2 0 1 1}$ & S3 & Seasonal \\
\hline $\mathbf{5 / 2 3 / 2 0 1 1}$ & S2 & Seasonal \\
\hline $\mathbf{5 / 2 4 / 2 0 1 1}$ & B2 & Seasonal \\
\hline $\mathbf{7 / 2 8 / 2 0 1 1}$ & B1WE & Tidal \\
\hline
\end{tabular}




\begin{tabular}{|l|l|l|}
\hline $\mathbf{7 / 2 9 / 2 0 1 1}$ & B1NS & Tidal \\
\hline $\mathbf{1 1 / 1 1 / 2 0 1 1}$ & B3 & Seasonal \\
\hline $\mathbf{1 1 / 1 2 / 2 0 1 1}$ & S3 & Seasonal \\
\hline $\mathbf{1 1 / 1 3 / 2 0 1 1}$ & S2 and B1 & Seasonal \\
\hline $\mathbf{1 2 / 1 0 / 2 0 1 1}$ & B2 & Seasonal \\
\hline $\mathbf{5 / 7 / 2 0 1 2}$ & B1WE & Tidal \\
\hline $\mathbf{5 / 8 / 2 0 1 2}$ & B3 & Tidal \\
\hline
\end{tabular}

Table 1 - Dates of seasonal and tidal surveys. Seasonal surveys were conducted for Ogurcak's study. They were inverted and used for determination of formation factor. Change analysis was only conducted on the tidal surveys.

\section{Tidal Survey}

A total of 4 tidal surveys were conducted in the locations indicated in Figure 6. Two were conducted in late July 2011 and the other two were conducted in May 2012. They were conducted at these times to observe whether the seasons affected the tidal fluctuations. A Wenner array was used with 2-meter spacing of the electrodes. ERT measurements were taken hourly. Measurements of water level, temperature, and conductivity were taken with an OTT Morpheus Mini data logger every 15 minutes along with the ERT measurements at well B11 closest to the profile, approximately $16 \mathrm{~m}$ inland on the profile.

The 2011 surveys were taken on the $28^{\text {th }}$ and $29^{\text {th }}$ of July, during a lull in the wet season that normally occurs towards the end of July. Conducting ERT surveys when there is small likelihood of rainstorms is ideal since the rainwater percolation can create noise in the readings and, if there is any presence of lightning, the cable and electrodes must be removed and packed up. Two time-lapse surveys were taken over a period of 11 hours each. One of the surveys, B1WE, was conducted on the beginning of the seasonal line B1, extending inland from the coast. The second, B1NS, was conducted roughly parallel 
with the coast, intersecting the first line around $20 \mathrm{~m}$ inland from the coastal end. The surveys were conducted from just before the high tide to the low tide of each day.
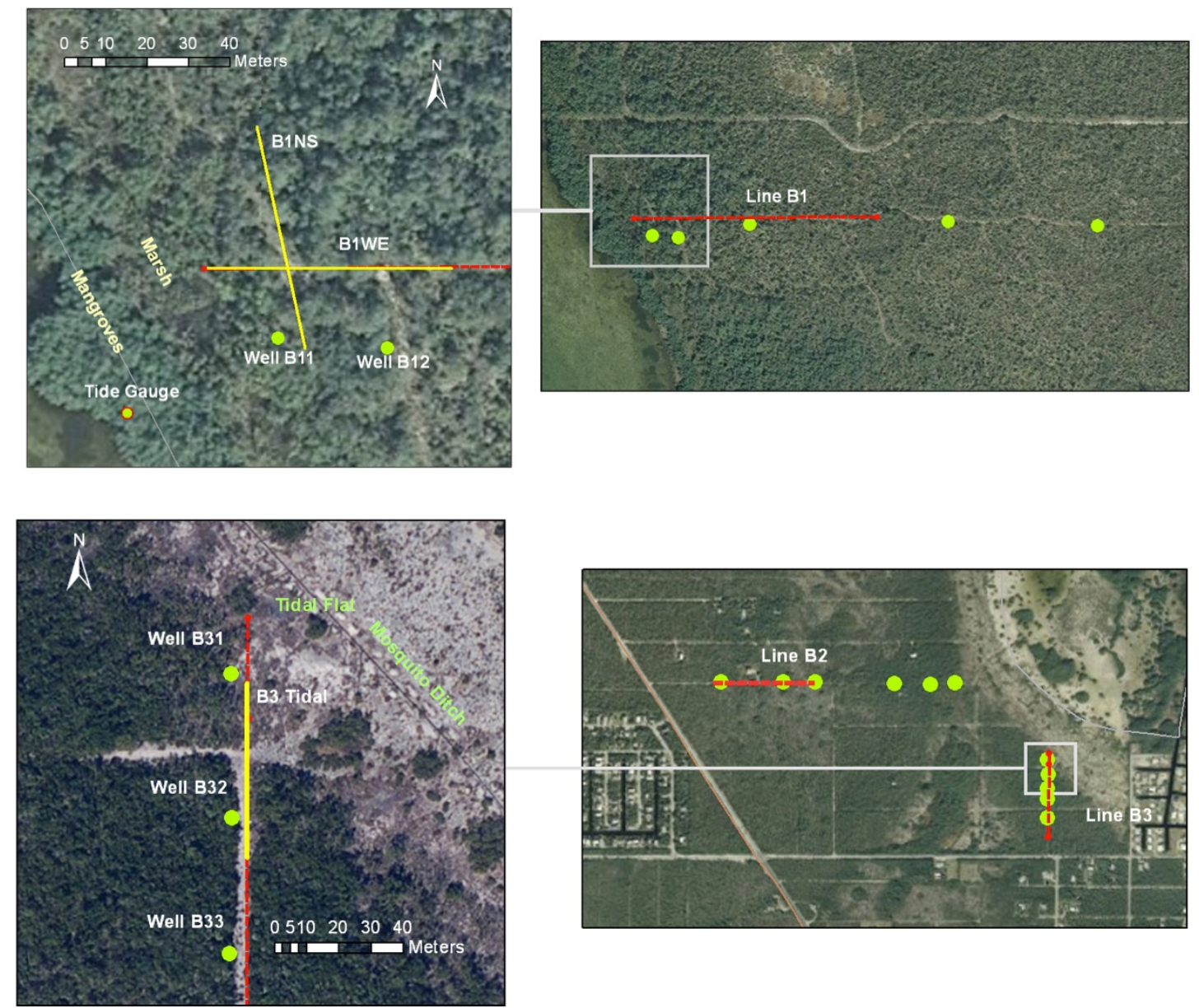

Figure 6 - Tidal profiles (yellow lines) referenced to their locations on the seasonal profiles (red lines) from Figure 6. Green dot represent wells. The B1 site has a coastal boundary of mangroves and a salt marsh. The B3 site is on the edge of a large tidal flat with a network of mosquito ditches in the area.

The 2012 surveys were conducted on the $7^{\text {th }}$ and $8^{\text {th }}$ of May, at the end of the dry season during the spring tide. The first one was a repeated measurement of the one conducted in July on line B1WE. The measurement was taken once an hour for 14 hours, from high tide until past the low tide as the tide was rising again. In addition to the well measurements at B11, a tidal station was set up near the line and hourly measurements of the ocean surface level were made. Water level measurements were also taken at well 
B12 at the inland end of the profile. The second survey was conducted along Line B3. This line is located next to a tidal flat rather than the actual coastline. The tidal profile was extended inland from the edge of the tidal flat. The survey was taken for 7 hours from the high tide to the low tide. The data logger was set in the well B31, measuring water level, temperature, and conductivity.

\section{Inversion Methods}

Inversions were conducted on both the tidal and seasonal ERT profiles. R2 v2.7, a forward/inverse 2D resistivity modeling program (Binley 2011; Binley and Kemna, 2005), was used. Both separate inversions and difference inversions were conducted on the B1WE time-lapse ERT data from May 2012 and the seasonal Big Pine Key lines to compare the two types of inversion based on artifacts and noise. Difference inversion was used on all remaining tidal data sets and separate inversion was used on the seasonal Sugarloaf data sets.

The quadrilateral mesh created for the inversion was set up differently for the seasonal and tidal ERT because of the size constraints of the R2 program. The size of the seasonal ERT data sets was too large to run a mesh with the same amount of nodes between each electrode as the tidal ERT. For the seasonal ERT profiles, a regularized quadrilateral mesh was created with 4 nodes between electrodes for a horizontal node spacing of $0.5 \mathrm{~m}$ and vertical node spacing of $0.2 \mathrm{~m}$ at the surface and increased by a factor of 1.1 to maximum depth of $9.3 \mathrm{~m}$. For the tidal ERT, the mesh was created with a horizontal node spacing of $0.25 \mathrm{~m}$ ( 8 nodes between electrodes) and a vertical node spacing of $0.1 \mathrm{~m}$ at the surface and increased by a factor of 1.1 to a maximum depth of 
$9.3 \mathrm{~m}$. Past the bounds of the measured region (the foreground), the mesh includes a background region to account for infinite boundary conditions. The mesh in this region extends before the beginning and after the end of the electrode array with exponentially increasing elements and extends vertically past the maximum depth, increasing in size with depth.

The R2 settings were the same for the seasonal and tidal ERT inversions with some exceptions for the difference inversion. The patch size, which lumps together adjacent nodes, was set to 2 blocks in the $\mathrm{x}$ direction to reduce the number of degrees of freedom. The inverse type was set to a regularized solution with linear fit. For the separate inversions, the error variance model parameters, $\operatorname{var}(\mathbf{R})=a_{\text {weight }}^{2}+b_{\text {weight }}^{2} * \mathbf{R}^{2}$, were set to $a_{\text {weight }}=.01 \mathrm{ohms}$ and $b_{\text {weight }}=.02 \mathrm{ohms}$. For the difference inversion used on the tidal plots, these weights were too large and immediately returned the solution of the previous time step. They were changed to .0001 for $a_{\text {weight }}$ and .0002 for $b_{\text {weight }}$. Since the seasonal plots were conducted so far apart and some electrodes may not have been placed in the exact same holes as the previous season, the weights for the difference inversion were kept the same as those in the separate inversions.

\section{Estimation of Formation Factor and Salinity}

The resistivity results from the seasonal surveys and the corresponding conductivity data collected from the wells (Figure 5) were used to obtain a formation factor for the island. The electrical conductivity measurements were converted to pore water resistivity in $\Omega-\mathrm{m}$ using $\rho=1 / \sigma$. Resistivity after inversion at the corresponding depth and location of the wells were used for the bulk rock resistivity. A scatterplot was 
produced of the bulk rock resistivity vs. the well water resistivity to see if they followed a linear trend. These scatterplots were then separated by island and by transect.

An orthogonal regression line through the origin was fit to the scatterplots with their uncertainties. Since the well conductivity measurements and the resistivity measurements are both variable, orthogonal regression was the best choice for the slope and uncertainty. Unlike linear least squares regression lines which compute the least square distance of the vertical offset, orthogonal regression computes the smallest distances of the perpendicular offset. Since both variables contain errors, the slope of these regression lines were calculated as $m=\Sigma \rho_{\mathrm{o}} / \Sigma \rho_{\mathrm{W}}$. The slope is the formation factor for that given data set. To determine the uncertainty, the residual of the data points had to be determined with respect to the perpendicular offset. The equation to determine the residual was as follows:

$$
\text { residual }=\sin \left(-\arctan (m)+\arctan \left(\rho_{O} / \rho_{W}\right)\right) * \sqrt{\rho_{W}^{2}+\rho_{O}^{2}}
$$

Then the standard deviation of the residuals determined the uncertainty.

Salinity profiles were created utilizing the bulk formation factor. First the bulk resistivity was converted to the pore water resistivity given the determined formation factor. The pore water resistivity results were then converted to conductivity and corrected to $25^{\circ} \mathrm{C}$ using the temperature in well $\mathrm{B} 11$ at the time of the measurement with the equation

$$
C_{25}=\frac{\frac{10}{\rho_{w}}}{1+0.02(T-25)}
$$


where $C_{25}$ is the temperature corrected conductivity in $\mathrm{mS} / \mathrm{cm}$ and $T$ is the temperature in Celsius (Radtke et al. 2005). The conductivity was converted to salinity with the equation

$$
S=0.0120+\left(-0.217 * R^{1 / 2}\right)+(25.33 * R)+\left(13.77 * R^{3 / 2}\right)+\left(-6.479 * R^{2}\right)+\left(2.584 * R^{5 / 2}\right)
$$

(Wagner et al. 2006) where $R$ is the ratio of the $C_{25}$ to the conductivity of standard seawater $(35 \mathrm{ppt})$ at $25^{\circ} \mathrm{C}$.

\section{Results}

\section{Resistivity}

The inversions results for all of the ERT measurements are shown in Appendix A. The difference plots between the time steps of the difference inversion results display the percentage change in the resistivity from the previous time step. Since some error can be expected between each time step, values less than $2 \%$ change in resistivity were deemed insignificant and not plotted.

Figure 7 is an example of one of the ERT measurements. The first $14 \mathrm{~m}$ along the line flooded during the high tide, which is reflected by the low resistivity zone near the surface. The further inland on the profile the higher the resistivity becomes, indicating a decreased salinity. 


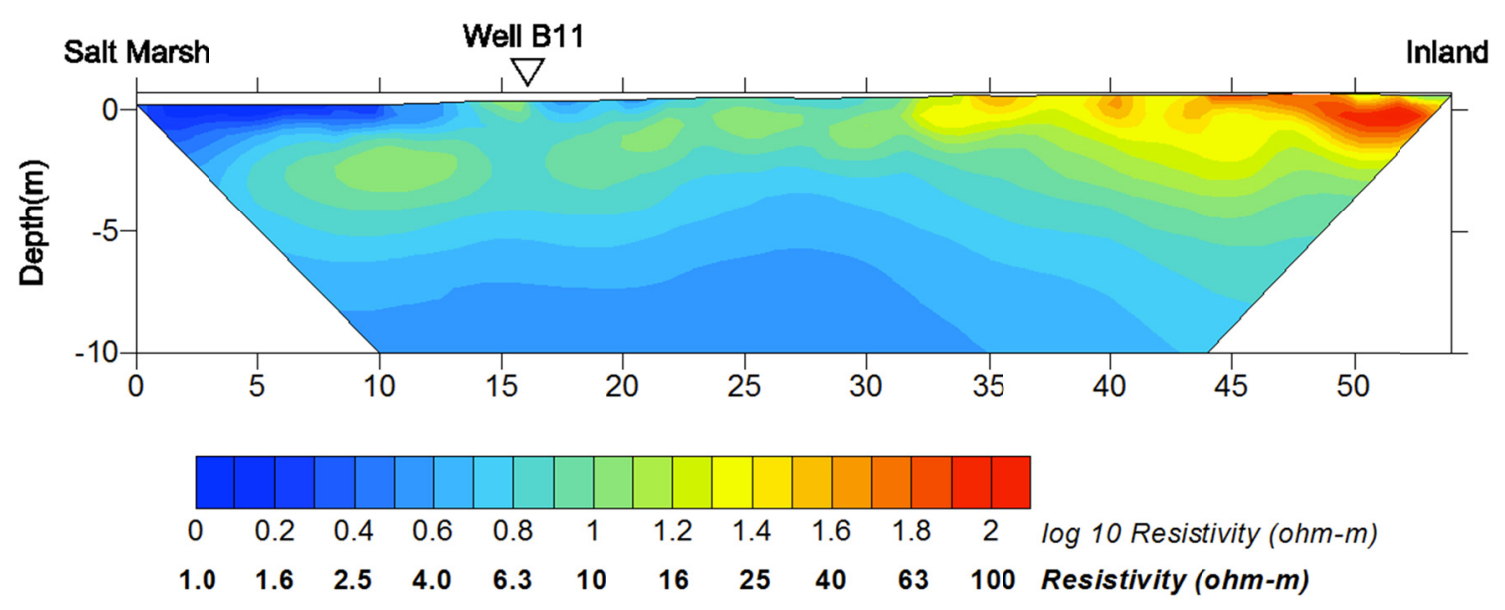

Figure 7 - High tide ERT results for B1WE at 15:20 on 5/7/12. The color scale is in log 10 with the real resistivity labeled below.

\section{Seasonal ERT}

Since the seasonal transects were only used for the formation factor analysis, they were not converted to salinity. Separate inversions were run on all of the seasonal profiles. The November measurements for each are expected to have a higher resistivity overall than the May 2011 measurements, with the exception of the very near surface. The unsaturated zone at the near surface would become thinner and result in lower resistivity. The end of the dry season and beginning of the wet season normally takes place in the month of May while the wet season normally ends in early November. Therefore, the November measurement takes place when the fresh groundwater is at its peak due the increased recharge. 


\section{Individual Inversion B1}

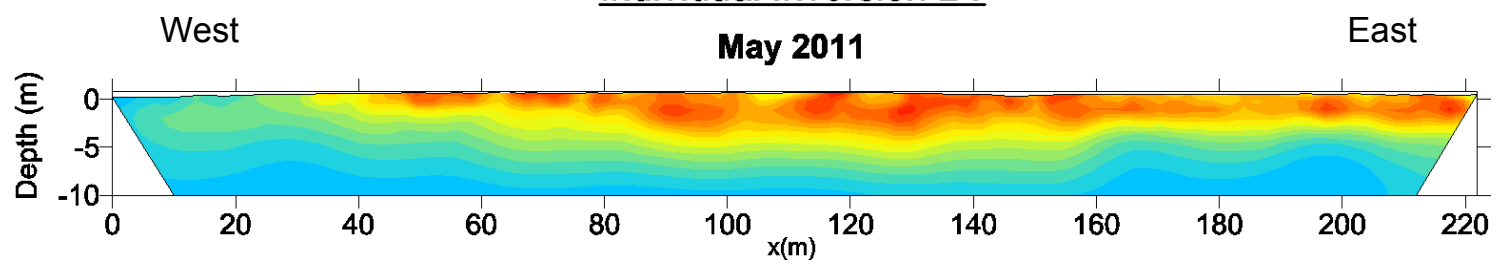

November 2011
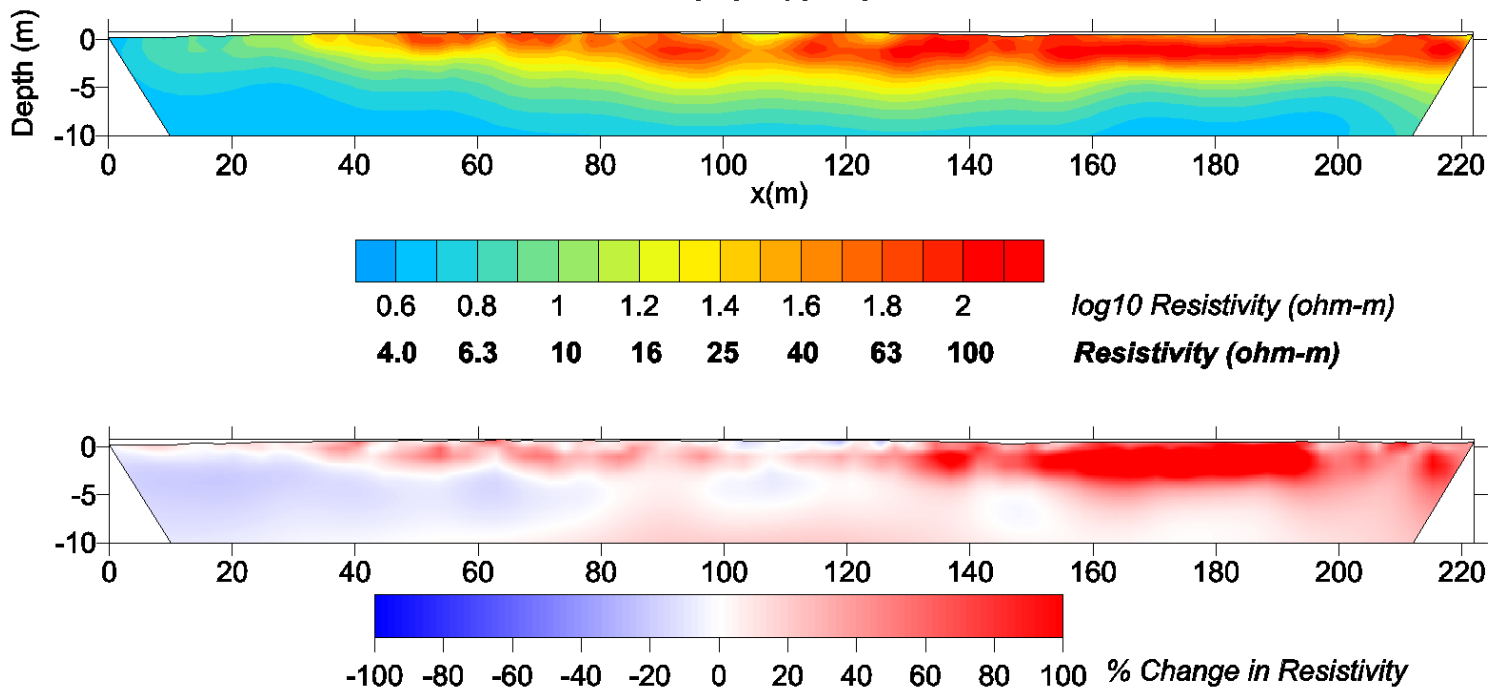

Difference Inversion on Line B1

November 2011
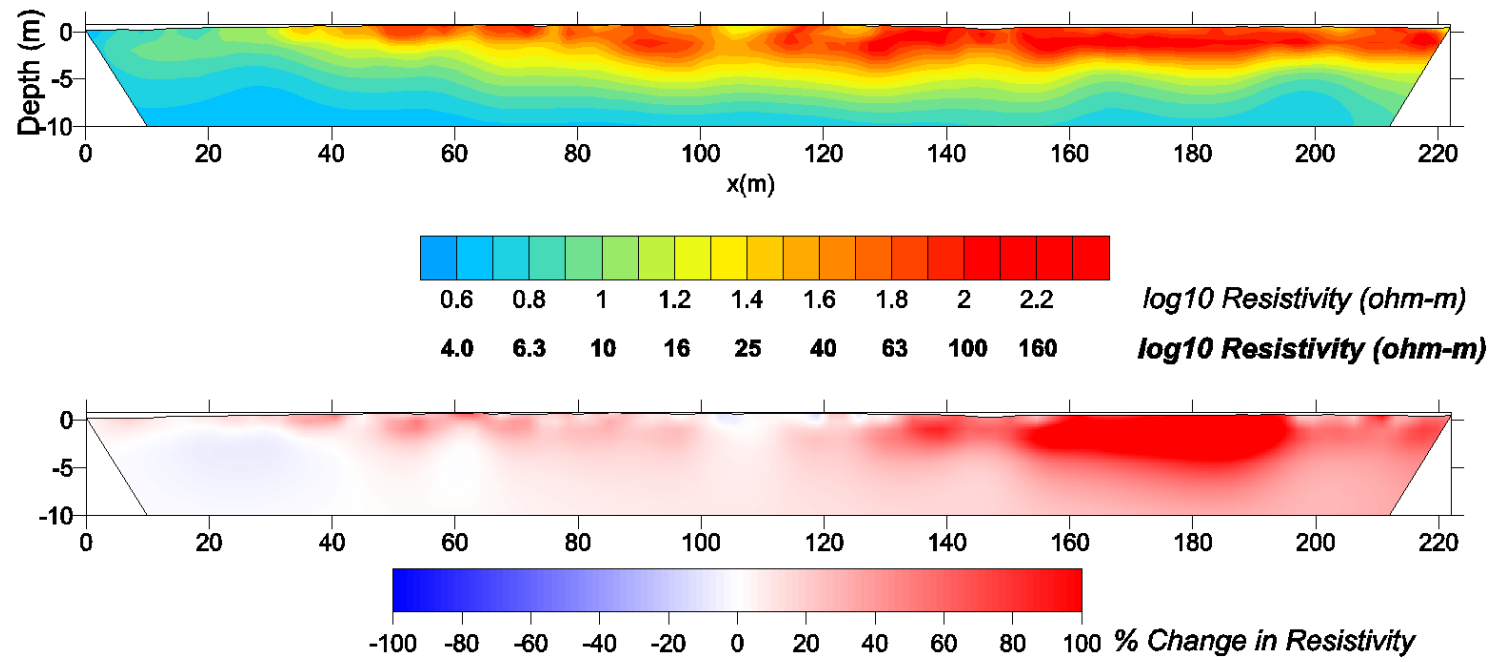

Figure 8 - ERT results for the seasonal line B1. Both inversion methods produce similar percent differences in resistivity over the season. There is a clear increase in resistivity caused by the increase in freshwater to the lens over the wet season. 


\section{Individual Inversion B2}
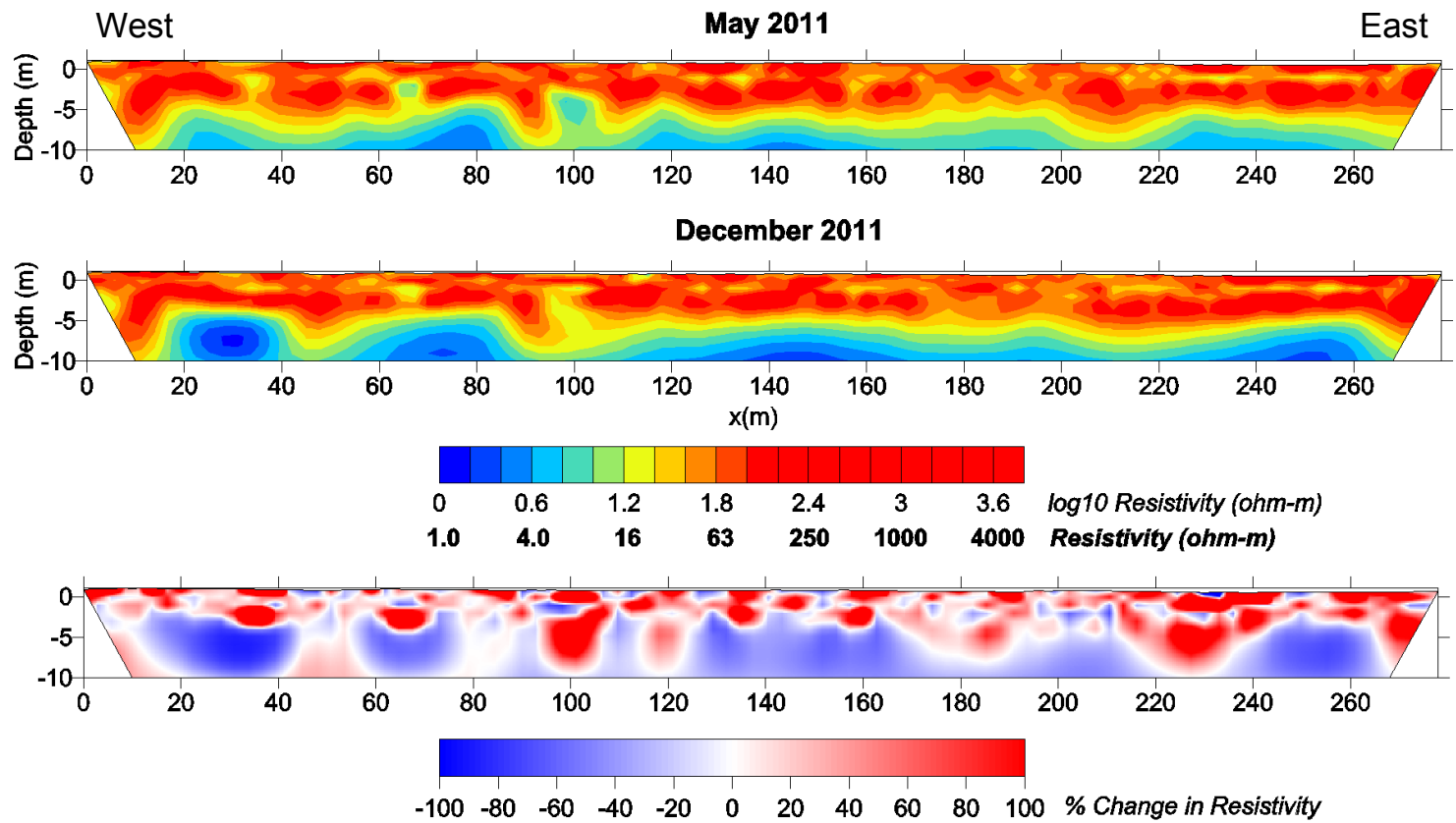

\section{Difference Inversion Line B2}
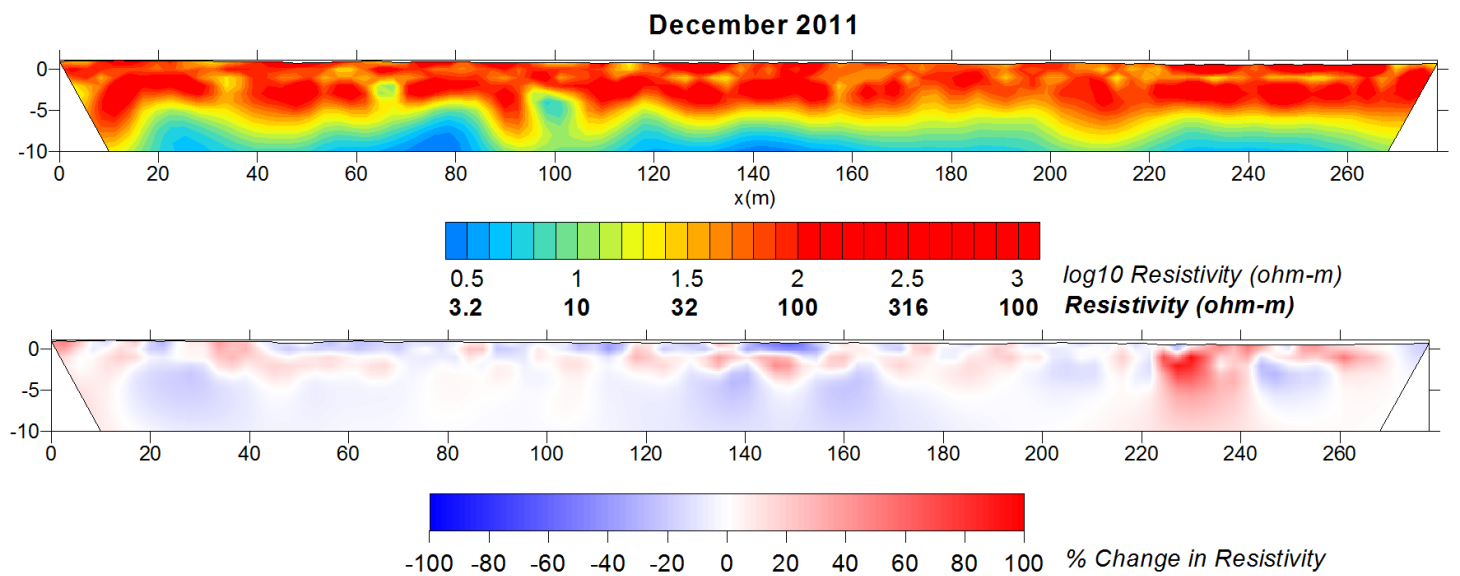

Figure 9 - ERT results for the seasonal line B2. Large changes observed in the percent change of the seperate inversion are caused by a variation on the modeled resistivity for the December results. The water table at this site is deeper than the others due to the higher elevation. The top meter is the vadose zone, which explains the presence of the high resistivity $(>1000 \mathrm{ohm}-\mathrm{m})$. 


\section{Individual Inversion B3}

North

May 2011

South

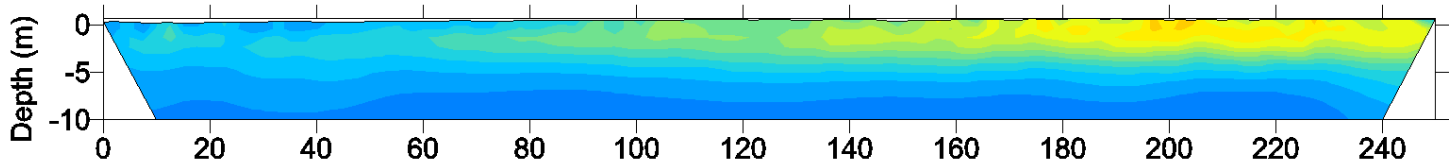

November 2011
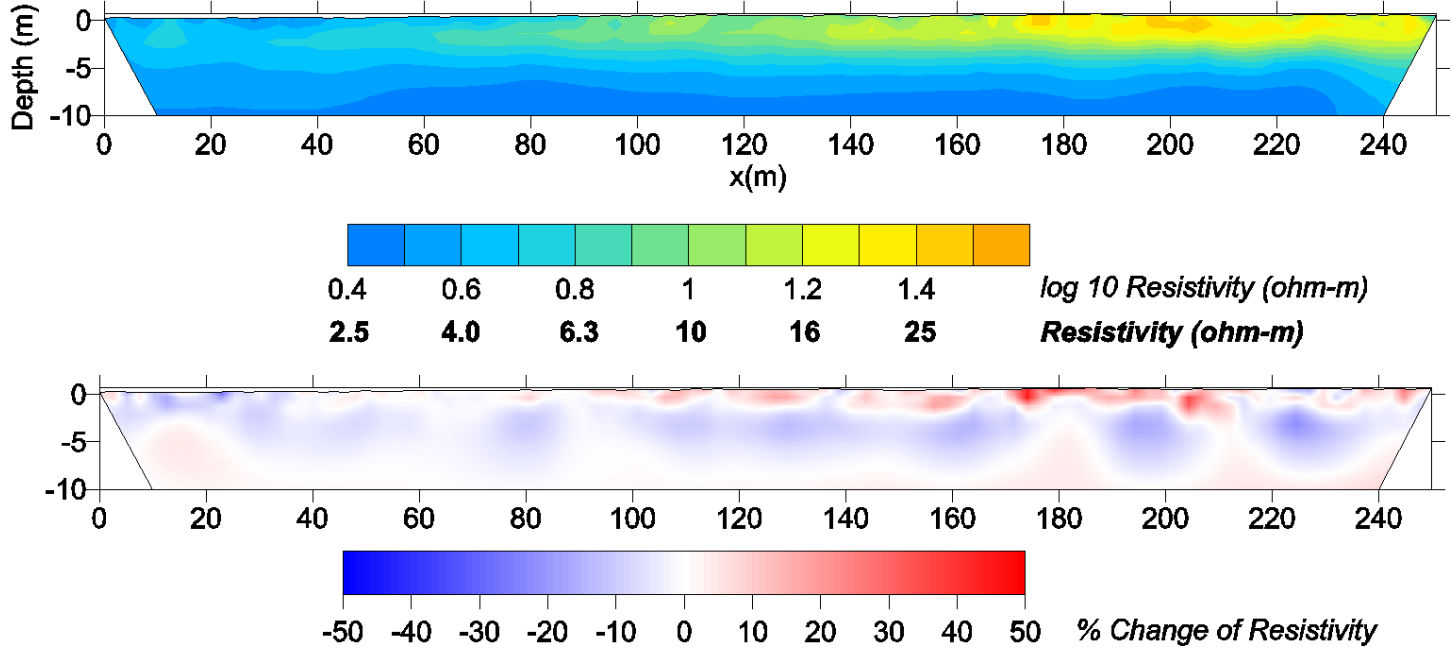

Difference Inversion Line B3
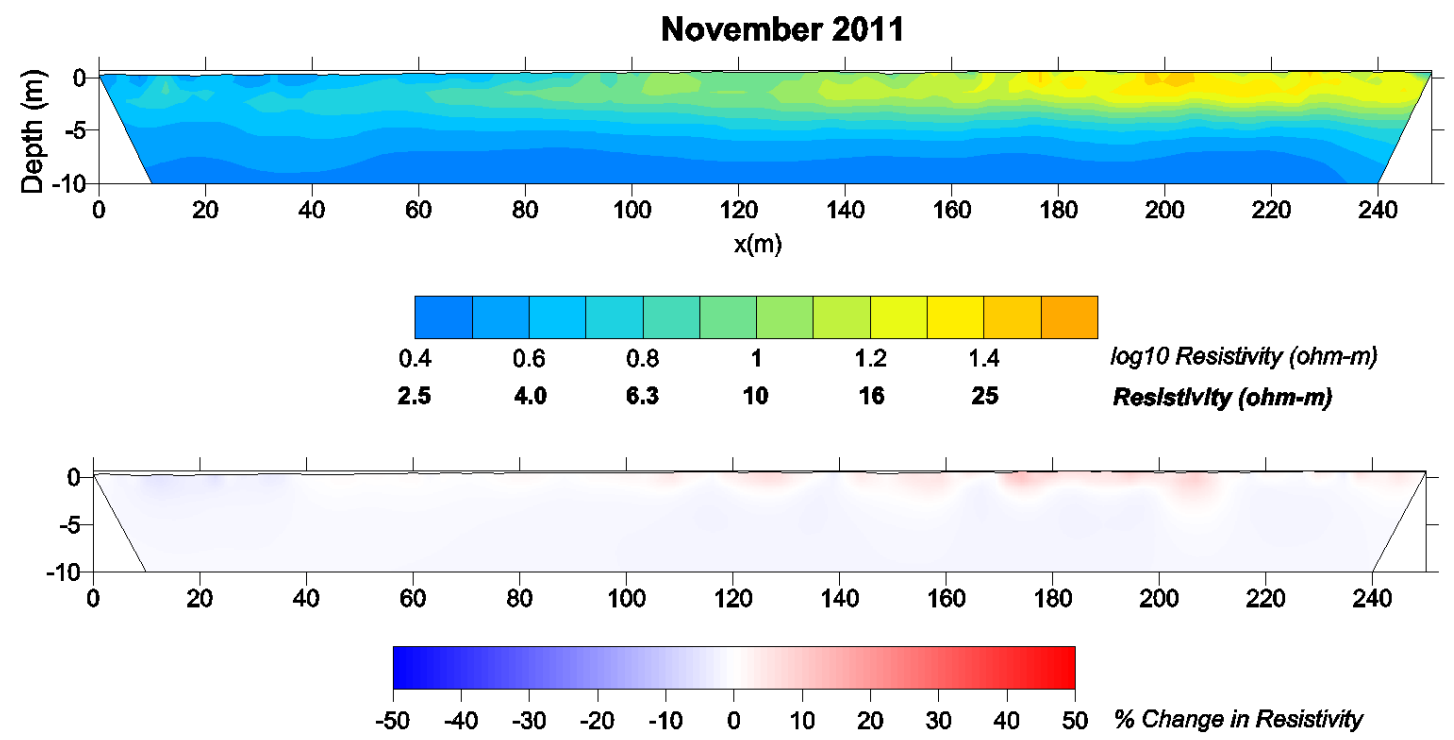

Figure 10 - ERT results for the seasonal B3 line. The color scale of the percent change plot had to be lowered compared to the other seasonal plots. The seasonal change in precipitation and recharge appears to have little effect on the groundwater. 


\section{Individual S2}

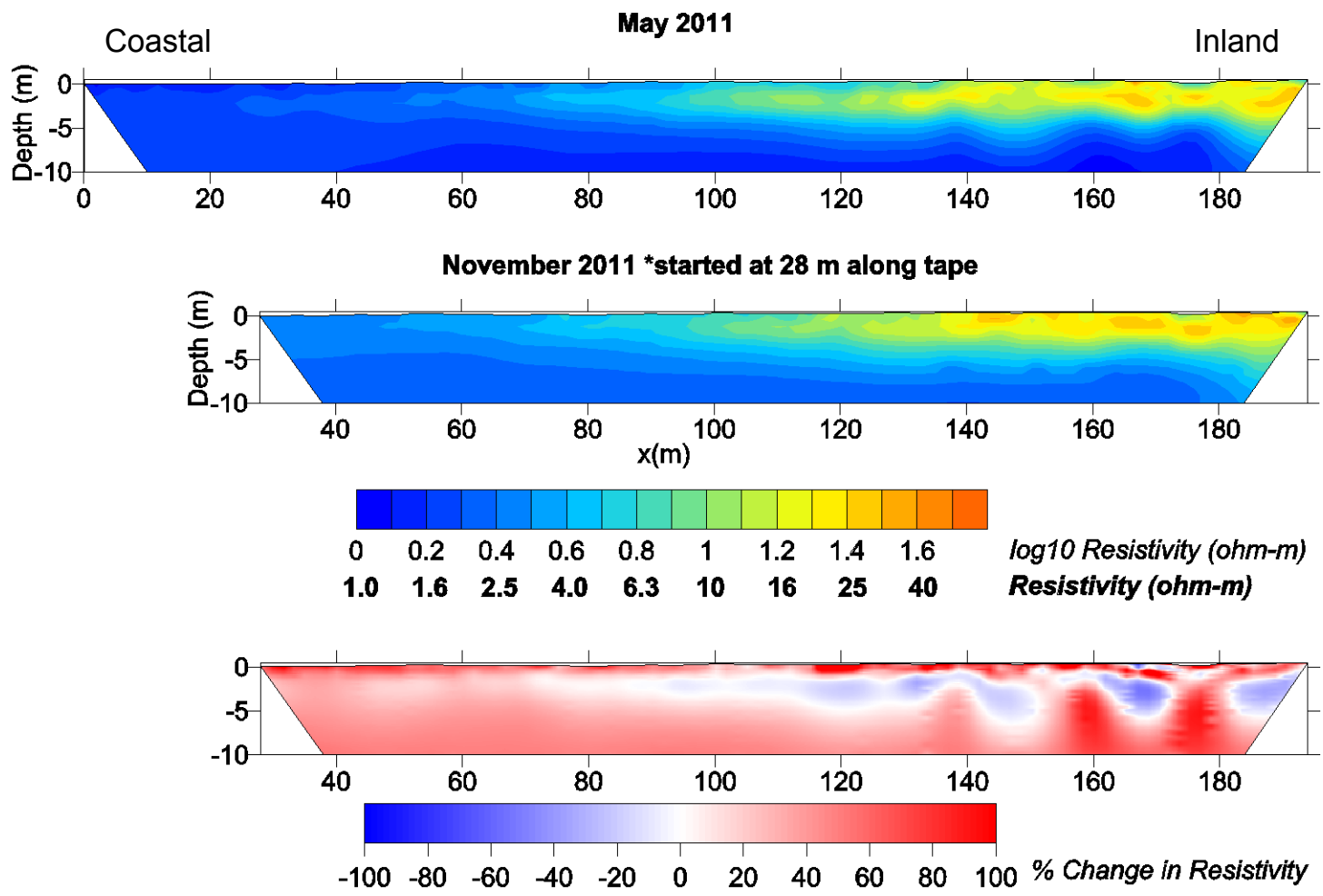

Figure 11 - ERT results for seasonal line S2. Due to high tide flooding, the beginning of the November 2011 measurement had to be shifted up. Changes are not very large over the season but the overall increase in resistivity suggests an increase in freshwater recharge.

All profiles show that the resistivity increased from the dry to the wet season with the exception of B3. The B1 transect (Figure 8) displays a large increase in the upper $5 \mathrm{~m}$ between 150 and $200 \mathrm{~m}$ on the line. The B2 (Figure 9) displays very patchy changes. Primarily the difference plot indicates an increase in resistivity. B3 (Figure 10) only shows signs of increase $(\sim 25 \%)$ in the upper $2 \mathrm{~m}$ with very little change in the first $100 \mathrm{~m}$ of the transect. The B3 line has the lowest resistivity of all of the Big Pine Key lines suggesting it is the most affected by saltwater intrusion. S2 (Figure 11) is low in resistivity similar to $\mathrm{B} 3$ but the transition is a little sharper considering the length of the line. The May 2011 S3 (Figure 12) inversion results has a number of artifacts but overall 
the difference plot indicates an increase in fresh groundwater over the wet season on the S3 profile.

Individual S3

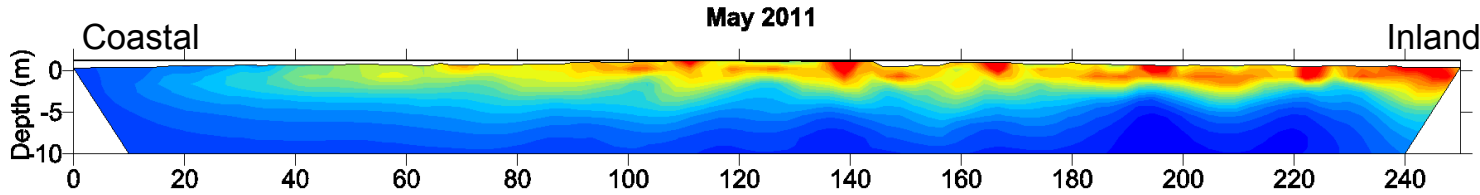

November 2011
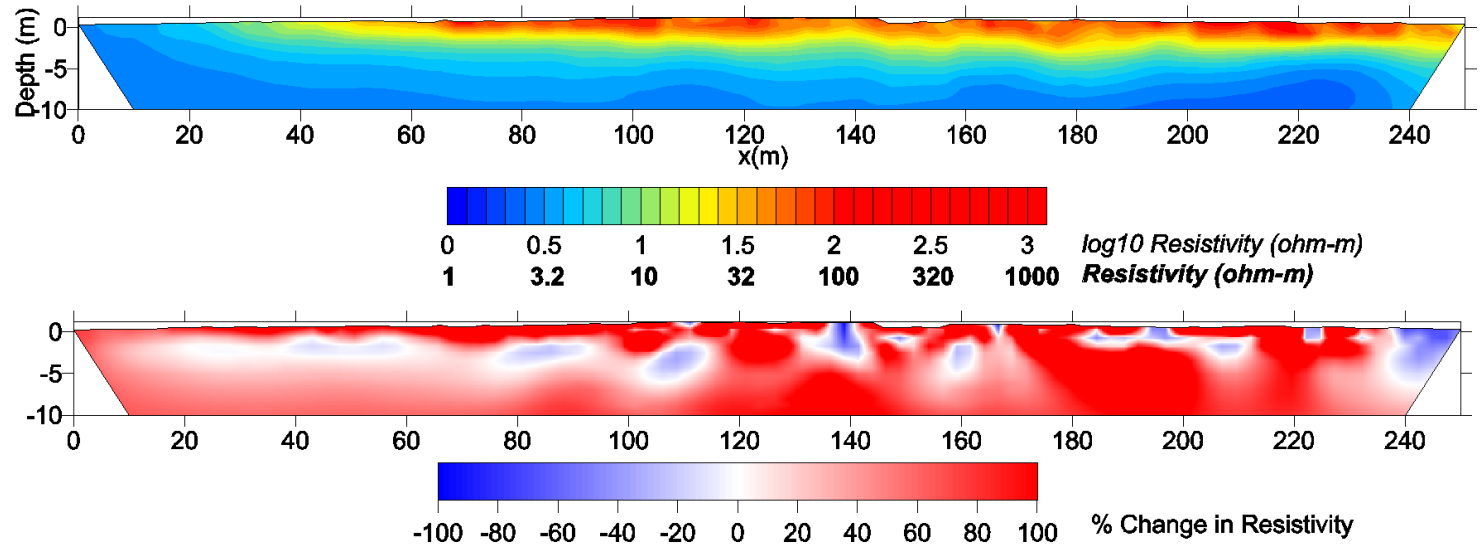

Figure 12 - ERT results for seasonal line S3. The May 2011 measurement has a number of artifacts causing the percent change plot to be difficult to interpret. Overall, there appears to be an increase in resistivity.

\section{Estimation of Formation Factors}

Utilizing the seasonal ERT results and the groundwater measurement taken coincident with the field measurements, a formation factor was determined for each survey line, for each island, and for the entire combined study area. The water level, temperature, conductivity, and bulk rock resistivity measurements collected for the Ogurcak (2010) study and used here are in Appendix B. Figure 13 is the scatter plot of the individual points. Pearson's R-value of .902 indicates a strong correlation between the bulk rock resistivity and the pore water resistivity. With a p-value less than 0.05 , this correlation can be considered significant and agrees with Archie's law that there is a positive correlation between bulk rock resistivity and pore water resistivity. 


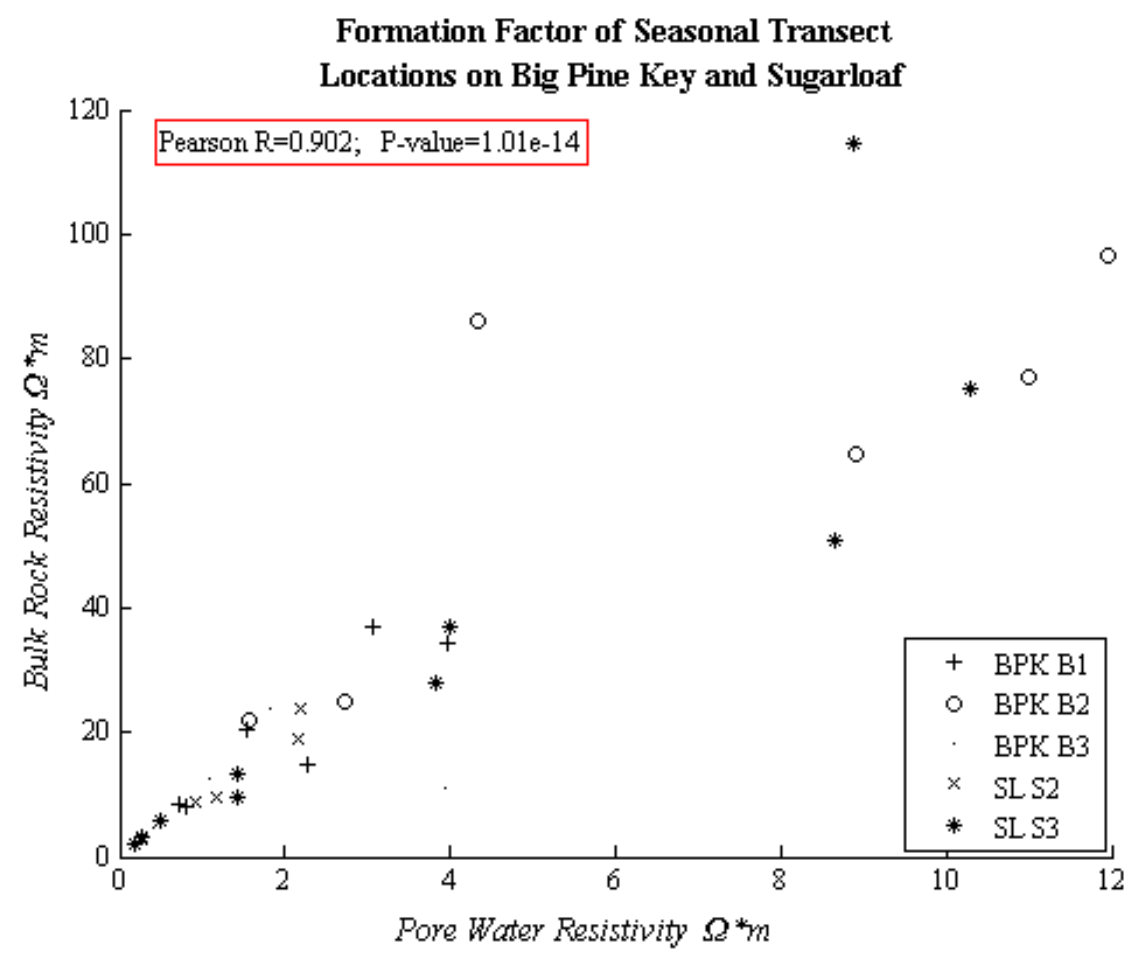

Figure 13 - Scatter plot of bulk rock resistivity vs. pore water resistivity of all measured wells on seasonal profile lines.

The slope of the best-fit line gives the formation factor. Figure 14 shows the formation factor for each seasonal transect. The formation factors range from 9.89 to 7.51. The individual lines by themselves are not based on a large number of data points and the data is relatively scattered as can be seen from the residuals. Therefore, the individual lines themselves were not used to convert resistivity values to salinity.

The mean formation factor by island (Figure 15) is 9.27 with a standard deviation of 1.52 for Big Pine Key and 8.74 with a standard deviation of 1.40 for Sugarloaf. The pattern of higher error with higher resistivity is evident by the residuals for each island. The geology of the two islands, Sugarloaf and Big Pine Key, are very similar, with the same outcropping formation, Miami Oolite. Since the formation factor determined here 
can only apply to the Miami Oolite, it is reasonable to assume that the formation factor for both islands should be similar.
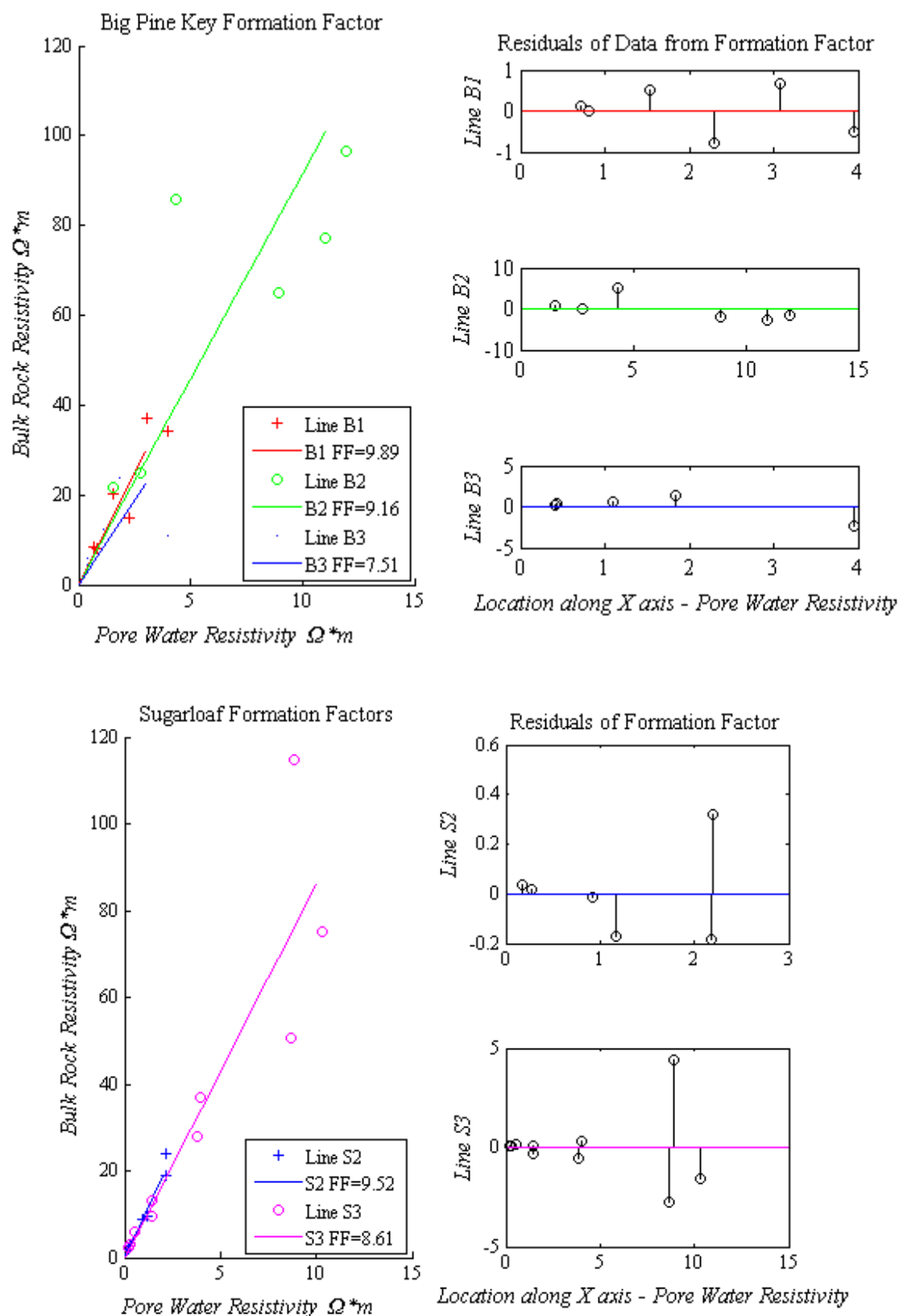

Location along $X$ axis - Pore Water Resistivity

Figure 14 - Formation Factor for each line determined by the data points obtained on each, separated by island.

The combined formation factor of the islands ( 
Figure 16) is 9.05 with a standard deviation of 1.44 . This formation factor is a reasonable middle ground between the two islands. The standard deviation is reduced from the Big Pine Key formation factor and is a small increase from the standard deviation of Sugarloaf. This value was used to convert the ERT results to salinity distributions.
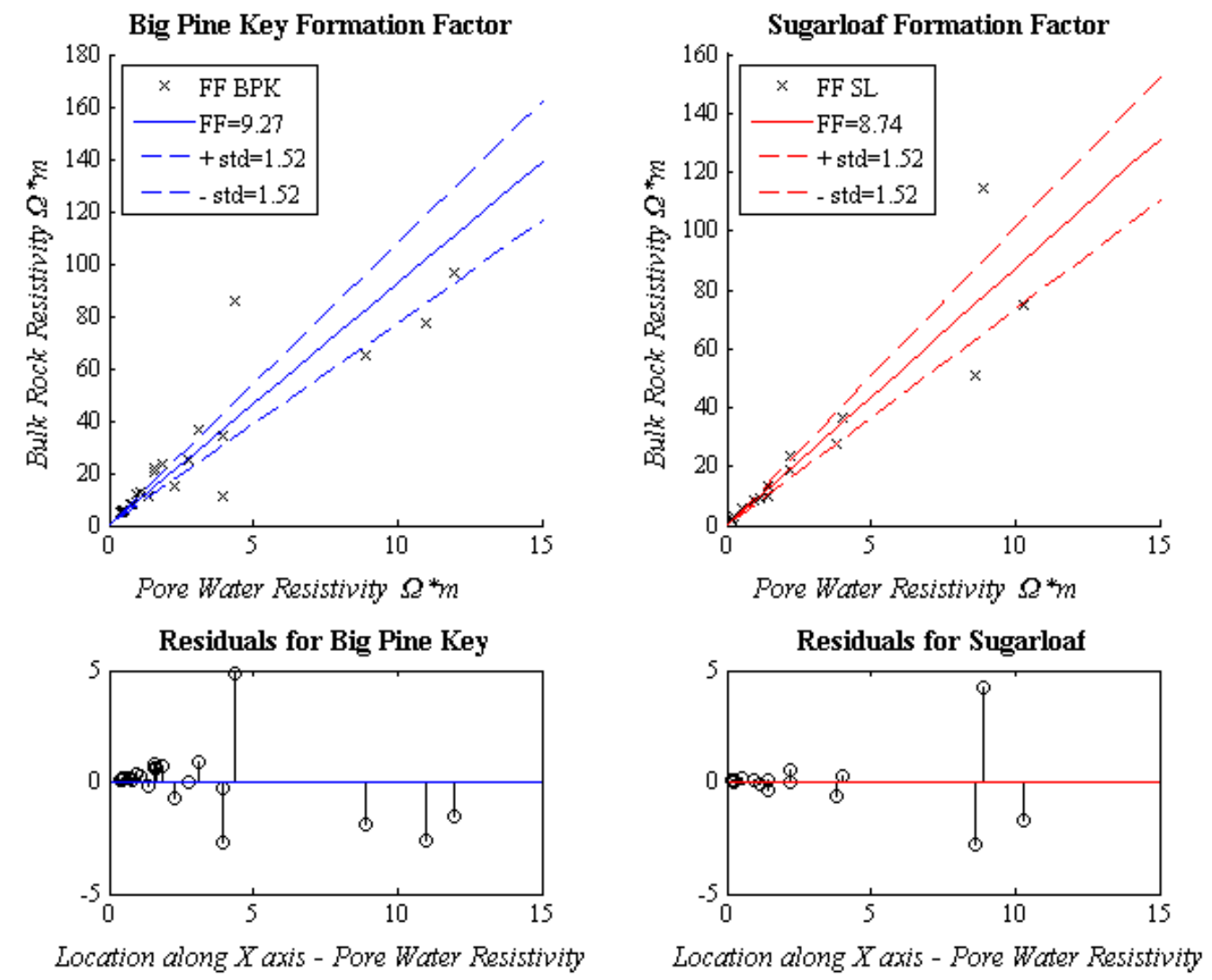

Figure 15 - Formation Factor of each island determined by the combined data points of each. Both formation factors determined are within each other's uncertainties. The error increases with higher resistivity. 


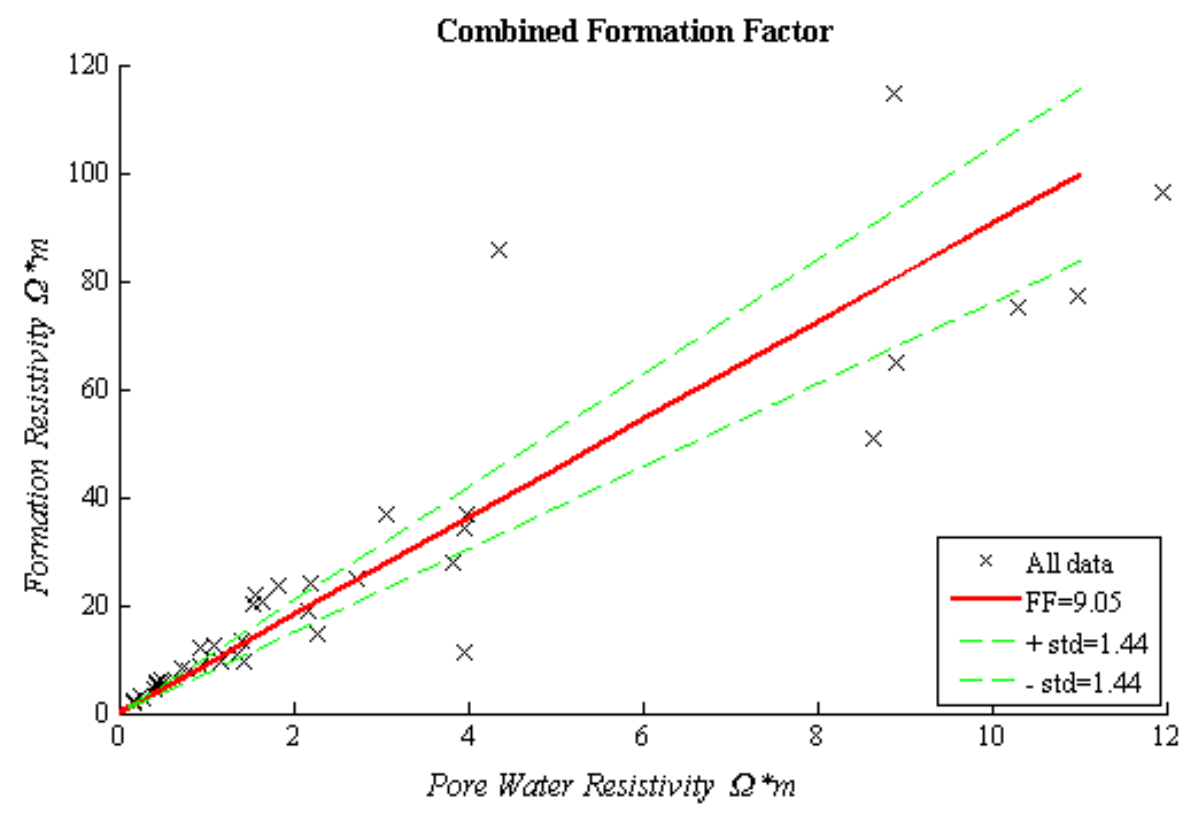

Figure 16 - Formation Factor of Big Pine Key and Sugarloaf.

\section{Salinity Profiles}

The salinity distributions for each tidal series can be found in Appendix C. Figure 17 demonstrates the effect of the uncertainty of in the formation factor on the salinity calculations. The seawater from the high tide flooding is clearly visible at the surface toward the beginning of the line. The larger formation factor shows increased salinity and the lower shows a decreased salinity. Neither contributes a significant change to the interpretation. 


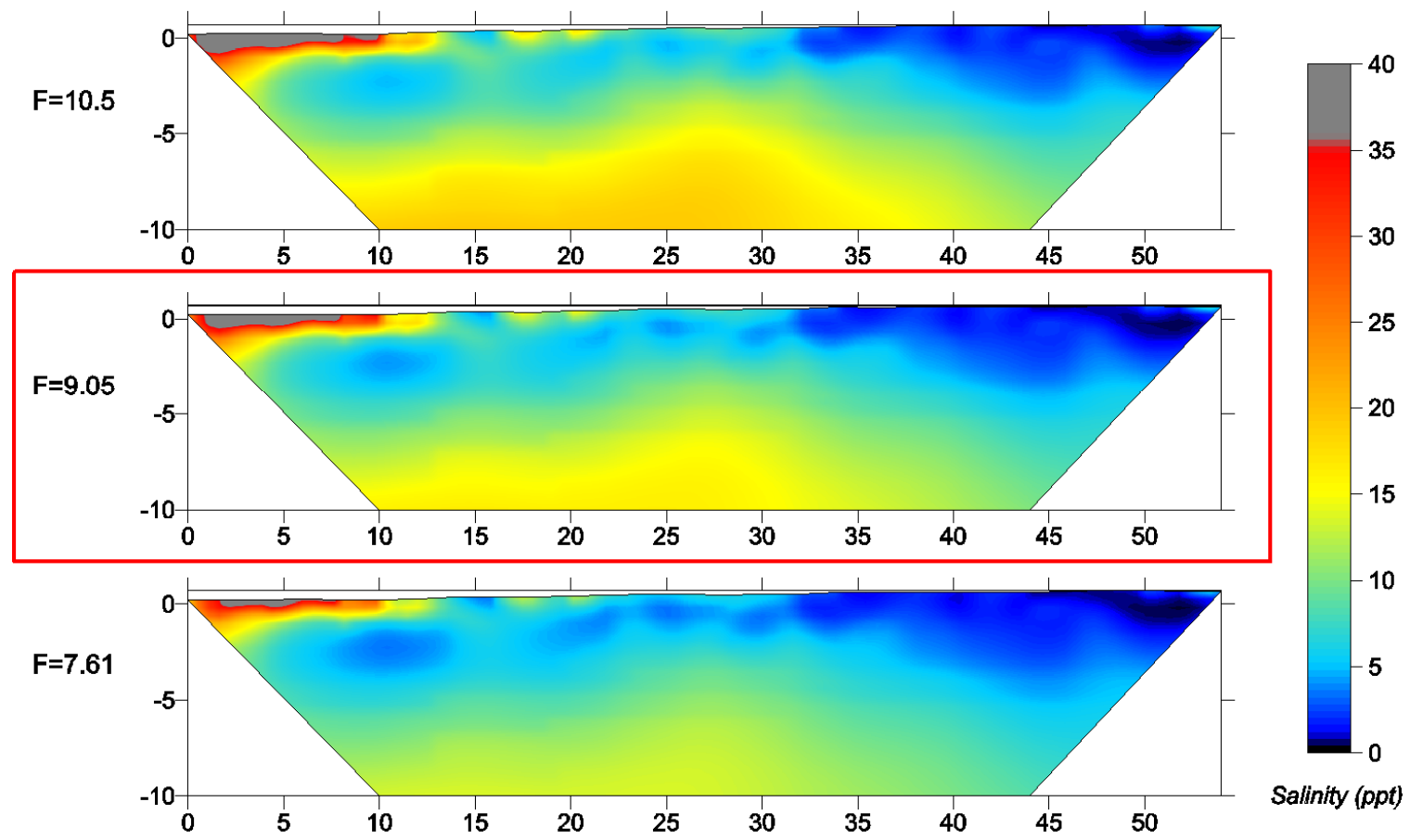

Figure 17 - B1WE high tide ERT converted to salinity using the formation factor. Middle profile shows the formation factor used for all conversions. Top and bottom profiles illustrate difference between upper and lower bounds of the uncertainty.

The profile B1WE captures the edge of the transition zone (Figure 17). The range in salinity is from 0.3 to a maximum of 63 ppt. A low salinity zone is at the end of the profile at the near surface. The high salinity above $35 \mathrm{ppt}$ is at the surface at the beginning of the line, corresponding with the area of grassy marsh and where the line became saturated during high tide. The salinity values remain low for the majority of the profile between the surface and 5 meters of depth, with the exception of a few pockets at the surface. 

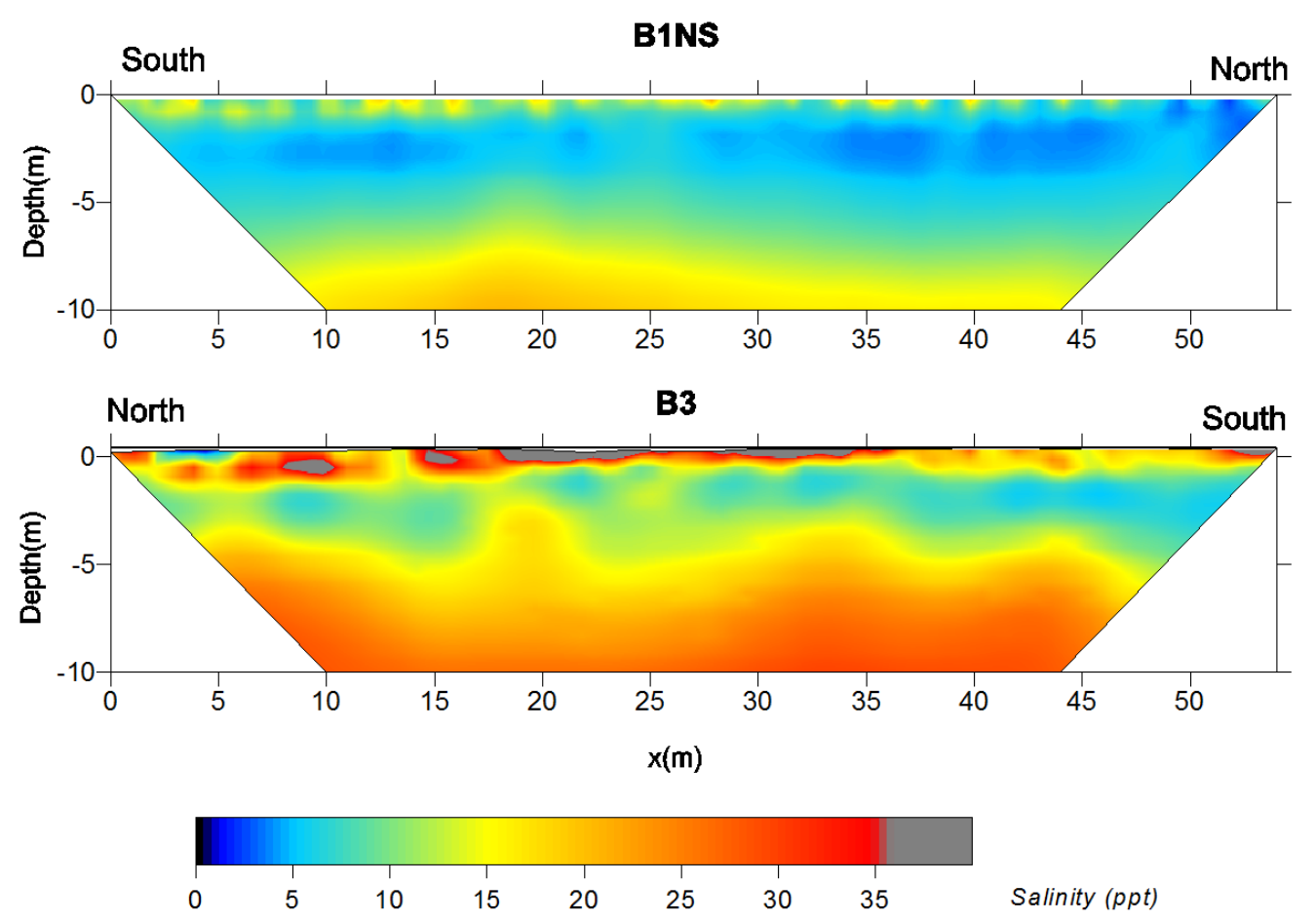

Figure 18 - Salinity profiles for B1NS from 7/29/11 and B3 from 5/8/12.

The B1NS profile (Figure 18, top) views a section of the transition zone roughly parallel with the coast and falling around $20 \mathrm{~m}$ inland on B1WE. The salinity range for B1NS in July 2011 was from 2 to 25 ppt. Lightly brackish water was only found at the near surface at the end of the transect and between 2 and 4 meters of depth. The majority of the profile is moderately brackish, at the surface and below 4 meters of depth. Only below 8 to 9 meters of depth does the salinity become very brackish. From this profile and the B1WE profile, it can be seen that the very top of the transition zone is higher in salinity while a several meter thick zone of lower salinity water lies underneath.

The tidal B3 profile (Figure 18, bottom) contrasts with the B1 profiles. The salinity range for the $\mathrm{B} 3$ tidal measurement was between 4.8 and 146 ppt. A salinity of $146 \mathrm{ppt}$ is unreasonably high but the areas are small and found primarily close to the surface. The only area of what appears to be light brackish water is in a thin zone at the 
surface between 2 and $5 \mathrm{~m}$ along the transect. The majority of the profile is moderately to very brackish. A zone of moderately brackish water appears between 1 and $4 \mathrm{~m}$ of depth, thinning out as it approaches the coast. This area has much more brackish groundwater than the B1 site.

At the beginning of the B1WE profile (first $4 \mathrm{~m}$ ) and along the majority of the surface of the B3 tidal profile, salinities above $35 \mathrm{ppt}$ were observed. The beginning of the B1WE profile and the tidal B3 profile share a common feature, which may be the source of these values. The B1WE profile starts the first few meters in a grassy salt marsh. The first $24 \mathrm{~m}$ of the B3 tidal profile is in a muddy tidal flat and the remainder of the line is on a gravel road with the some finer sediment mixed in. The mud varies in depth to limestone. For the most part, it was only a few centimeters deep but solution holes were also filled in with the mud. The gravel on the road was a thin layer, varying around a centimeter or two of depth to the limestone. The mud found on B1WE and B3 are both classified as marl by soil survey maps from the Natural Resource Conservation Service (Hurt 1995). Marl, a calcerous mud, would have a lower resistivity and a different formation factor than the surrounding limestone. The marl may contain some clay which is itself conductive.

\section{Change Analysis}

Tidal Change

The tidal survey that displayed the most change was the May 2012 measurement on B1WE. The high and low tide measurement along with the percent change is displayed in Figure 19. The largest change takes place near the surface at the beginning 
of the profile. At high tide, seawater flooded the first 14 meters of the profile and is visible in the high tide salinity profile. As can be discerned in the series of salinity profiles (Appendix C), a salt-water wedge moved in from the coast after the first time step and reached its maximum encroachment at 15:20. The source is primarily from overland flow although at 15:20 the wedge appears to extend over 2 meters down on the coastal edge. A small decrease in salinity is observed below the wedge and to the east of the wedge on the surface at high tide but later increases in salinity with the low tide while the saltwater wedge recedes. 


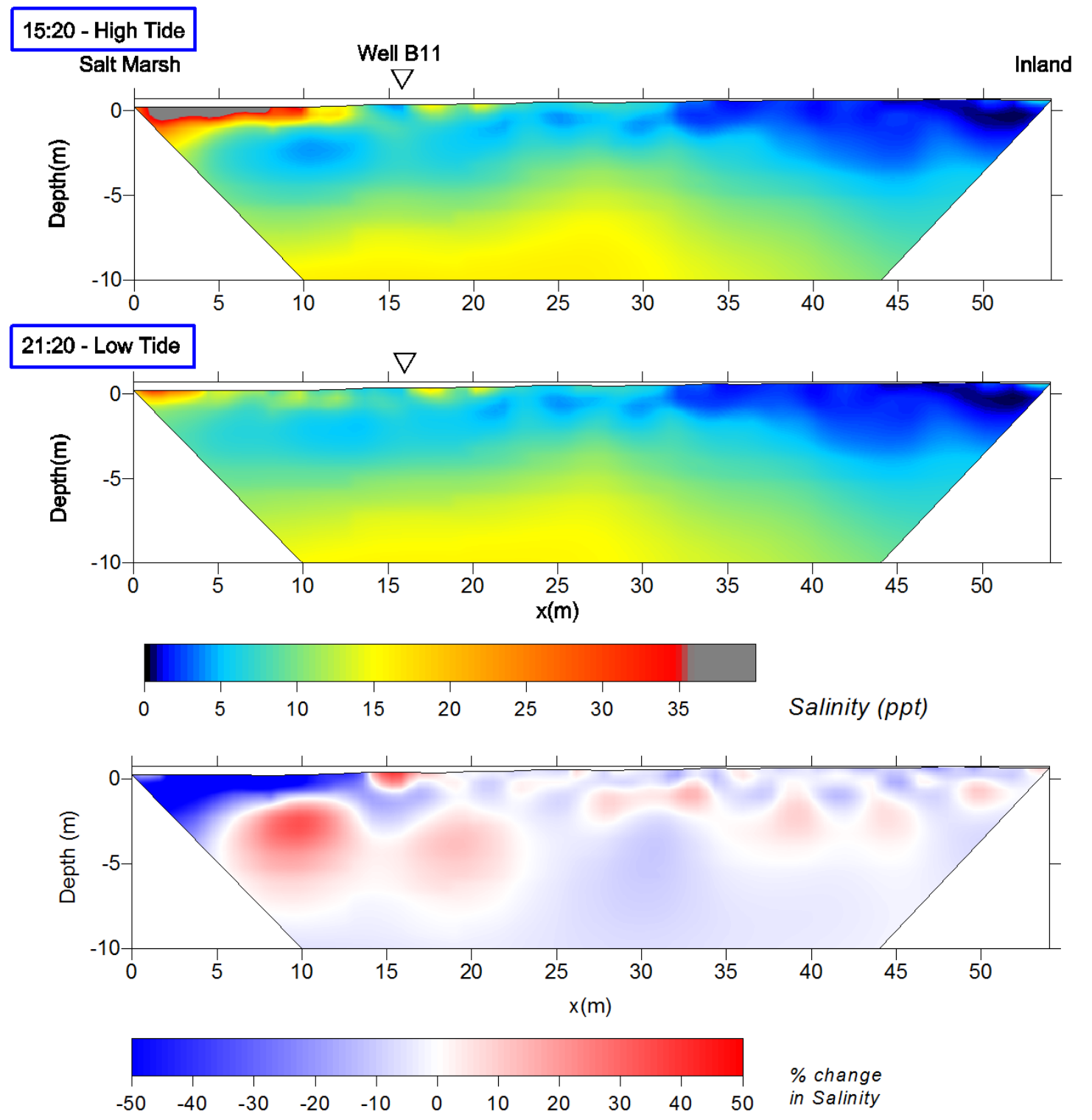

Figure 19 - B1WE high and low tide salinity results from 5/7/12. The bottom plot is the percent change in salinity over this time period. The overland flow of the saltwater during high tide is noted by the surficial high salinity and the percent change plot. An increase in salinity occurs in the groundwater closest to the region flooded by low tide. The eastern half shows a small decrease in overall salinity.

The well water levels and tide results do not follow the expected pattern. Reviewing well and tide results (Figure 20), the stage of the furthest inland well, B12, reaches the highest level by the first measurement at 14:29 and starts to decline by the second measurement an hour later. Well B11 also reaches the highest level by 15:00 and 
begins to decline by 15:30. The local tide measured close to Well B11 recorded the high tide at 15:45 and started to decline by the next measurement at 16:00. Under normal coastal conditions, the opposite would be expected. Groundwater should have a delayed response to the tidal variations. It should not precede the tide unless another force is acting on it from another direction.
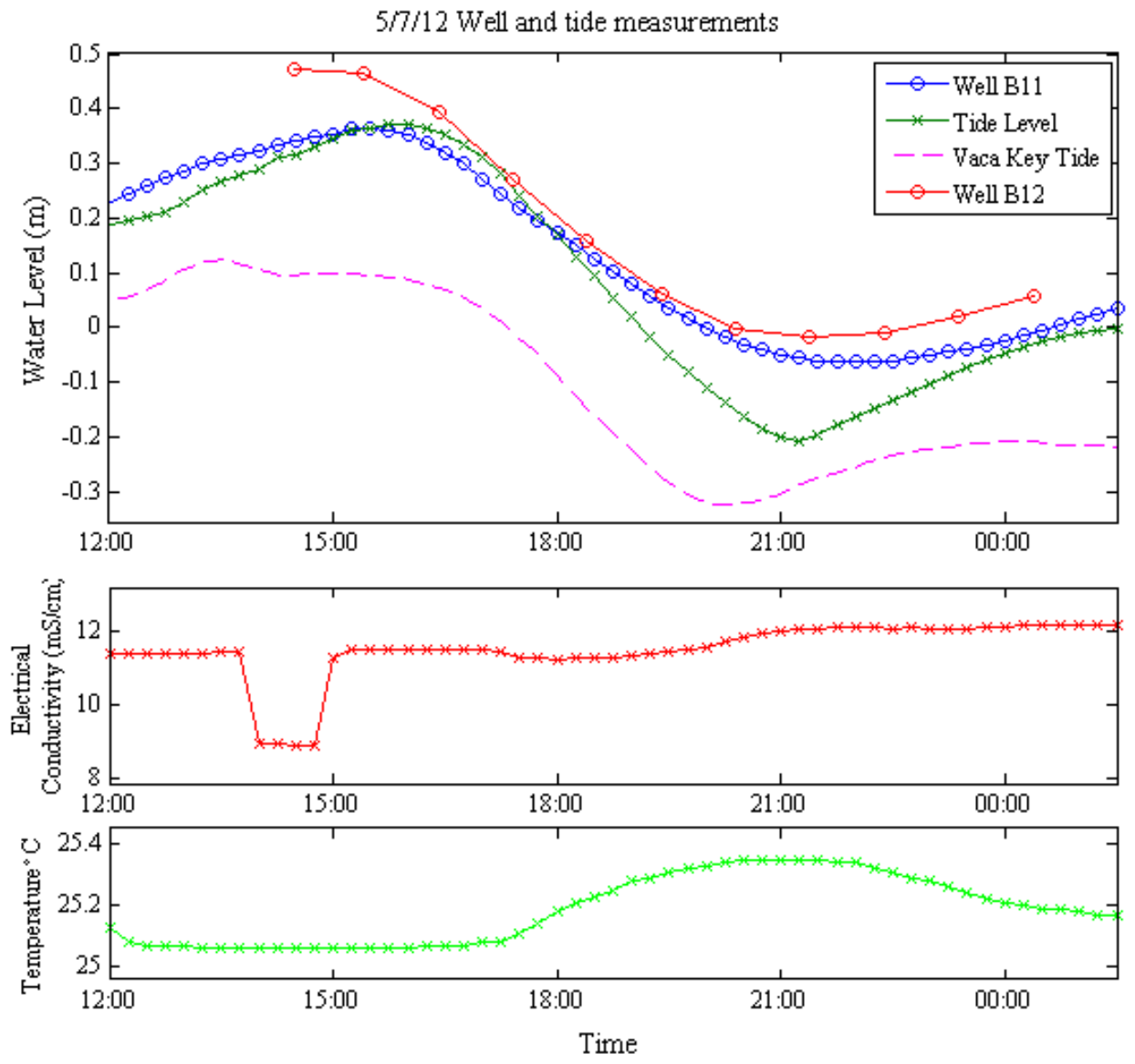

Figure 20 - Well and tide gauge measurements collected during B1WE tidal survey on 5/7/12. The temperature and electrical conductivity measurements are from Well B11. Well B12 water level measurements were conducted manually once an hour. The tide measurements are from the temporary gauge set up near the site and the Vaca Key measurements are from NOAA/NOS chart \#11453. 


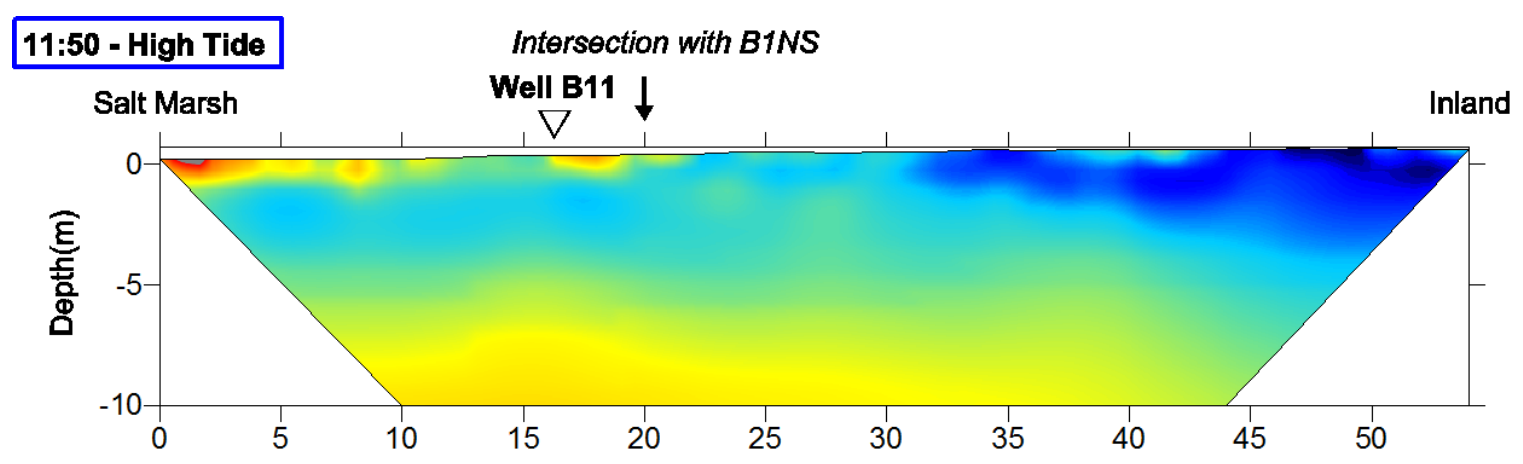

18:50 - Low Tide
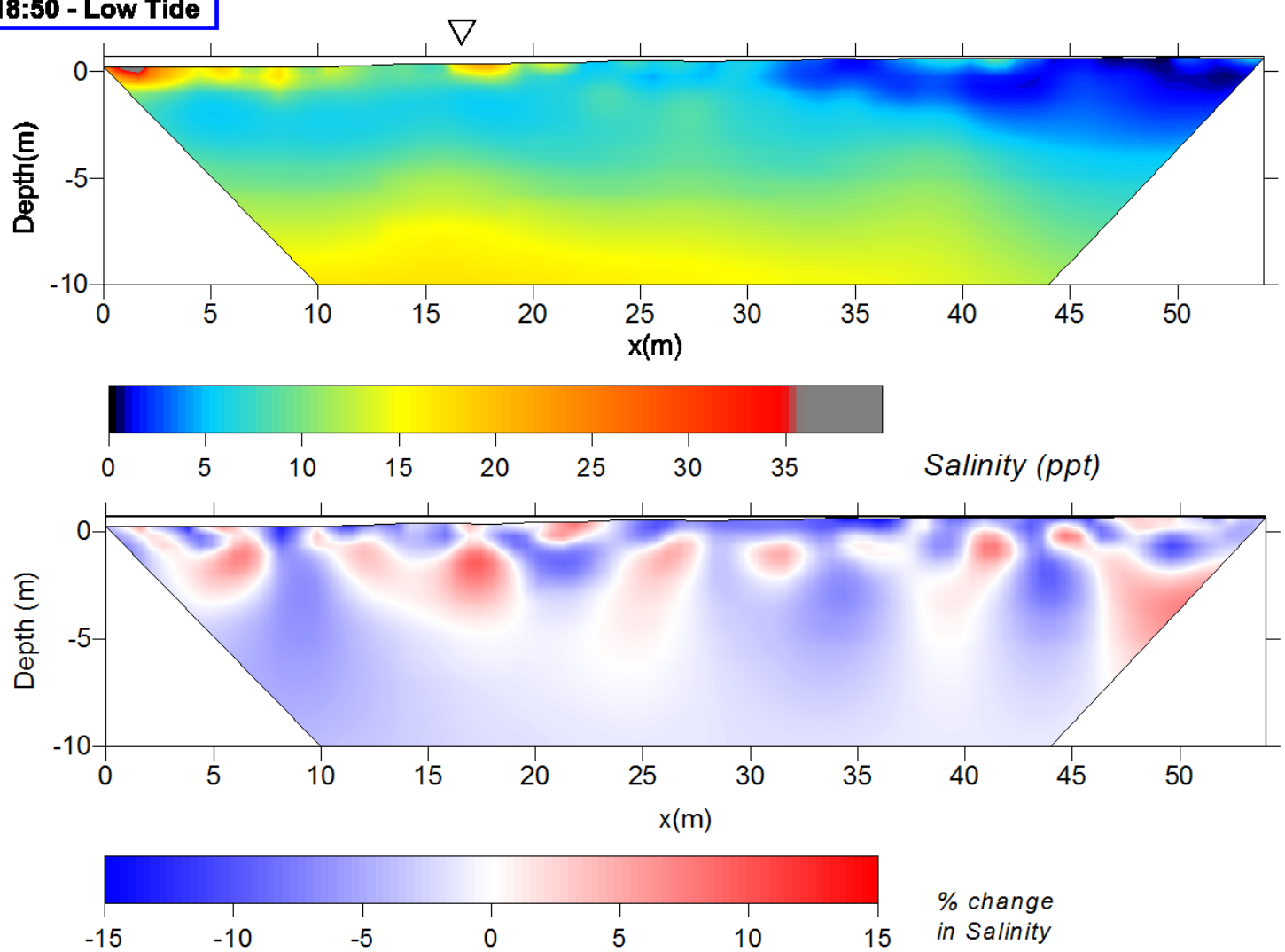

Figure 21 - High and low tide results from B1WE tidal survey on 7/28/11. The percent difference scale is smaller than the $5 / 7 / 12$ plot. Tidal changes were much smaller over this survey.

The July 2011 B1WE tidal survey showed very little change when compared to the May 2012 survey (Figure 21). The total change in salinity was small, 15\% at most, over the shift from low to high tide. A decrease in salinity corresponds with the receding tide primarily at the surface. The decreases at the surface may be the result of the desaturation of the rock or sediment at the surface as the tide went out and the water table 
levels lowered. Desaturation would have created an increase in resistivity resulting in an apparent decrease in salinity. The remaining increases and decreases in salinity are smaller and have no clear pattern that can be explained by the receding of the tide. The electrical conductivity of the well water in B11 follows the change in water level, corresponding with the tide, until around 15:00 at the mid-tide (Figure 22). The increase in conductivity as the tide recedes may be a result of saltwater left over from the high tide sinking and mixing with the groundwater. Overall, these changes are very small and suggest that the tide had little effect on the groundwater.

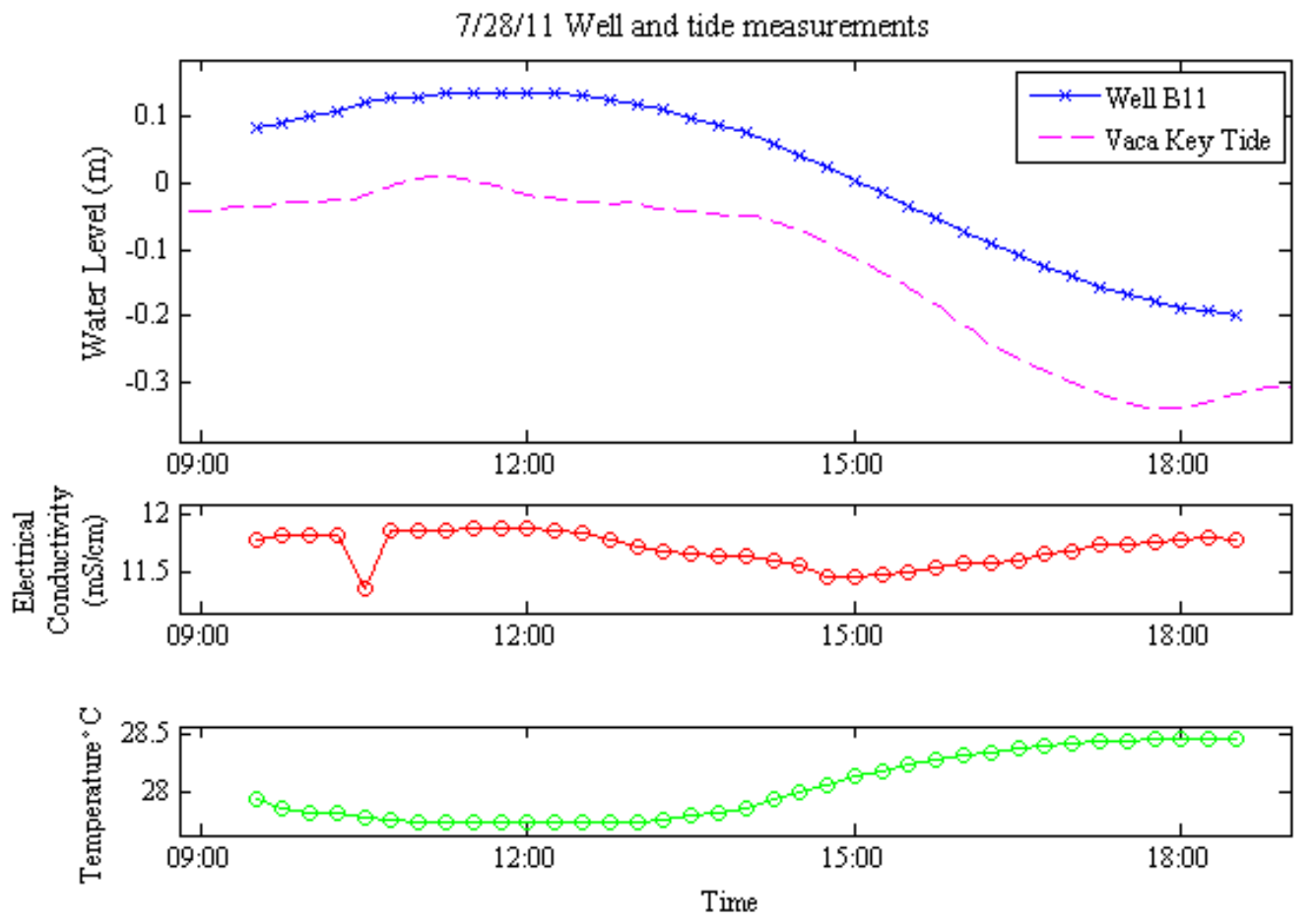

Figure 22 - B11 well measurements and Vaca Key tide level collected during the 7/28/11 survey. The conductivity follows the trend of the water level until mid-tide where it begins to increase again while the water level drops. The temperature increases as the water level recedes, inversely following the trend of the water level.

The B1NS profile shows a small decrease in salinity over the change in tide only visible in the percent change between high and low tide (Figure 23). The largest 
decreases appear mostly at the surface. The B11 well water displays the same changes in temperature and conductivity as the day before (Figure 24). The overall decrease in salinity agrees well with the B1WE measurement from the day before. This change is likely due to the drop in the water table with the receding of the tide and the receding of saltier water towards the coast.

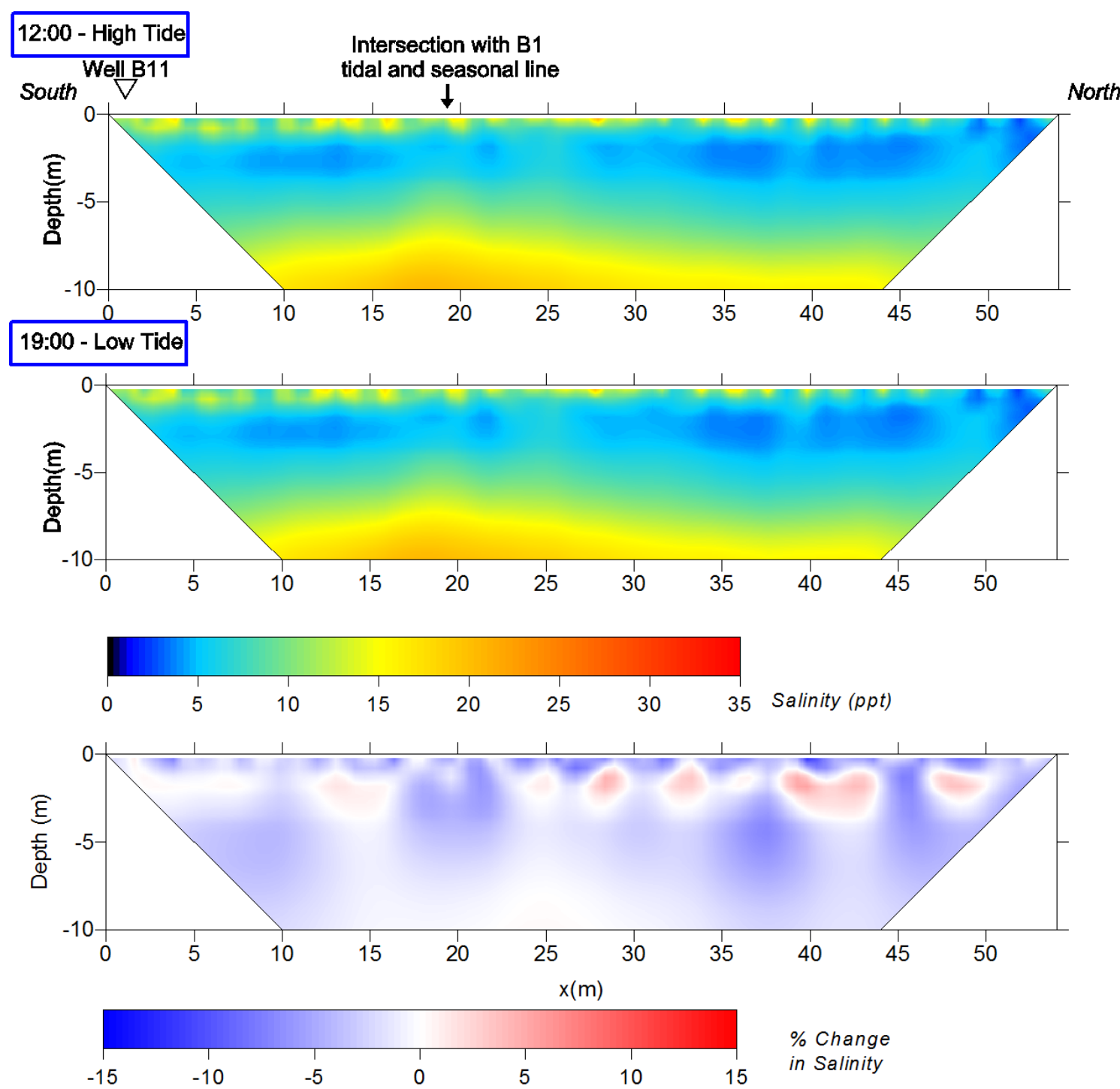

Figure 23 - B1NS high and low tide results from 7/29/11. The percent change between high and low tide shows a very small decrease in salinity for the majority of the profile. 


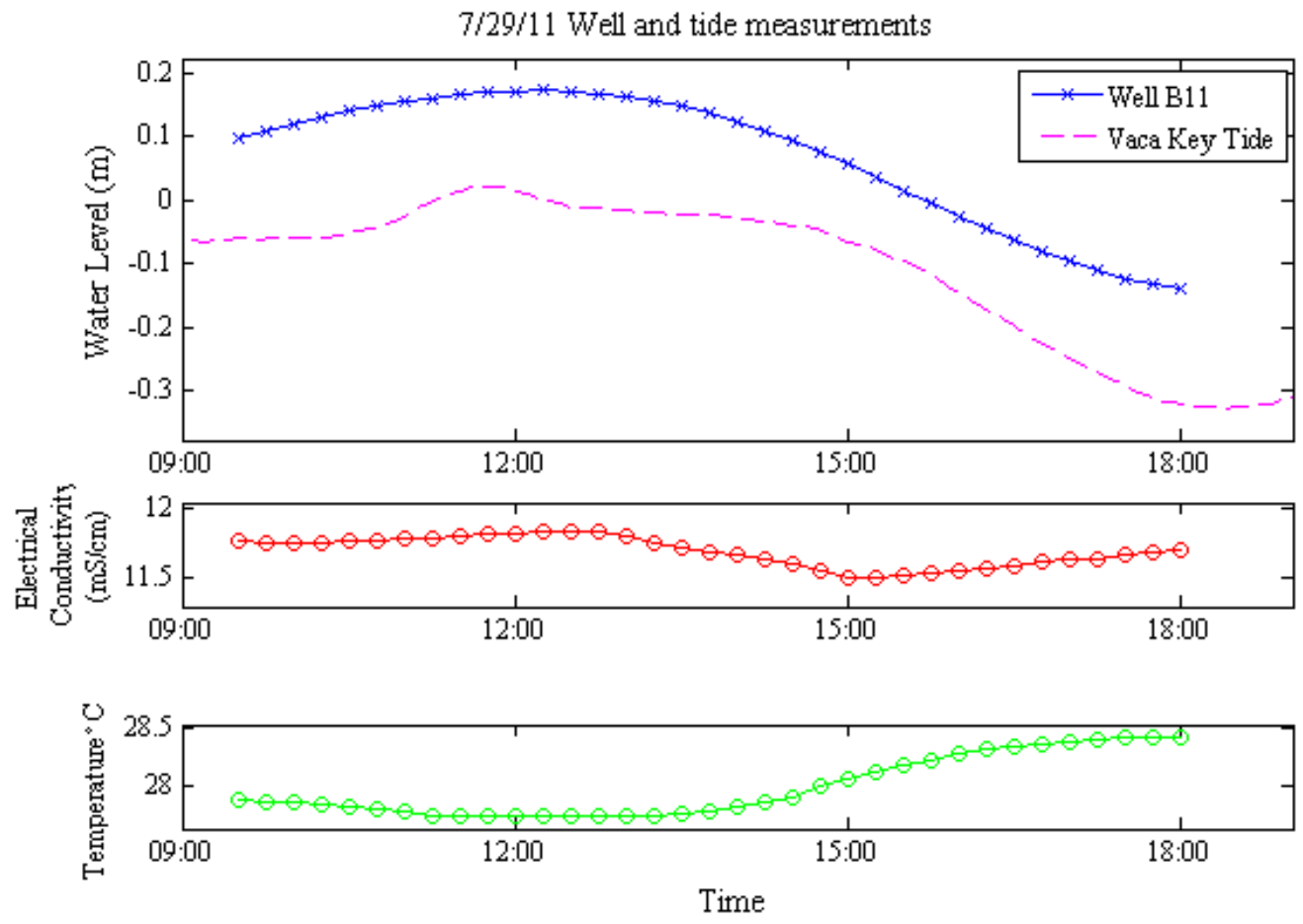

Figure 24 - Well B11 and Vaca Key tidal results during the B1NS survey on 7/29/11. The electrical conductivity and temperature follow the same pattern as measurements from 7/28/11.

The B3 tidal survey is a little more anomalous in the change of salinity from high to low tide but overall does not show much change in salinity with the tide (Figure 25). The salinity increases the most at the surface. The surface at this site consisted primarily of marl and the tidal flat conditions causes some water to flow in but it collects in low areas where it will not flow back out with the low tide. The saltwater that did not recede may have led to some saltwater percolating down instead of out with the tide. The limestone below the sediment decreases in salinity during low tide with the exception of the area between 0 and $15 \mathrm{~m}$. The solution holes and porous spaces may be better connected in this area and could have led to further infiltration of the saltwater into deeper into the rock. The measurements from the well (Figure 26) show that unlike any 
of the B11 measurements, the electrical conductivity does not change much or in any pattern. The lack of change in the well would suggest that there is no tidal influence on the salinity on this profile.

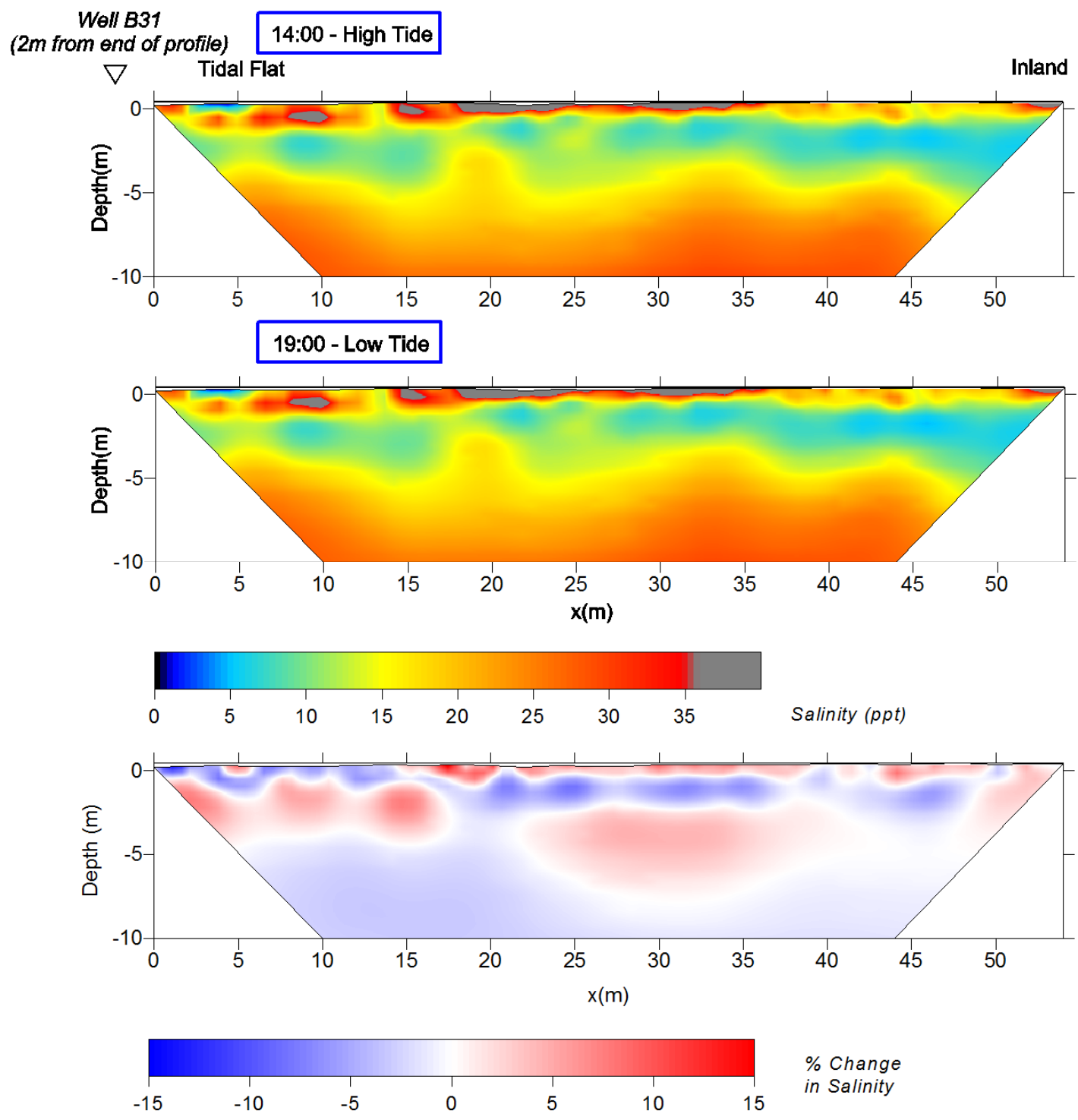

Figure 25 - High and low tide salinity results from B3 tidal survey on 5/8/12. Areas of high salinity near the surface are likely casued by marl, which has a lower resistivity than the limestone. Similar to the B1WE and B1NS surveys in 2011, tidal changes were very small. 


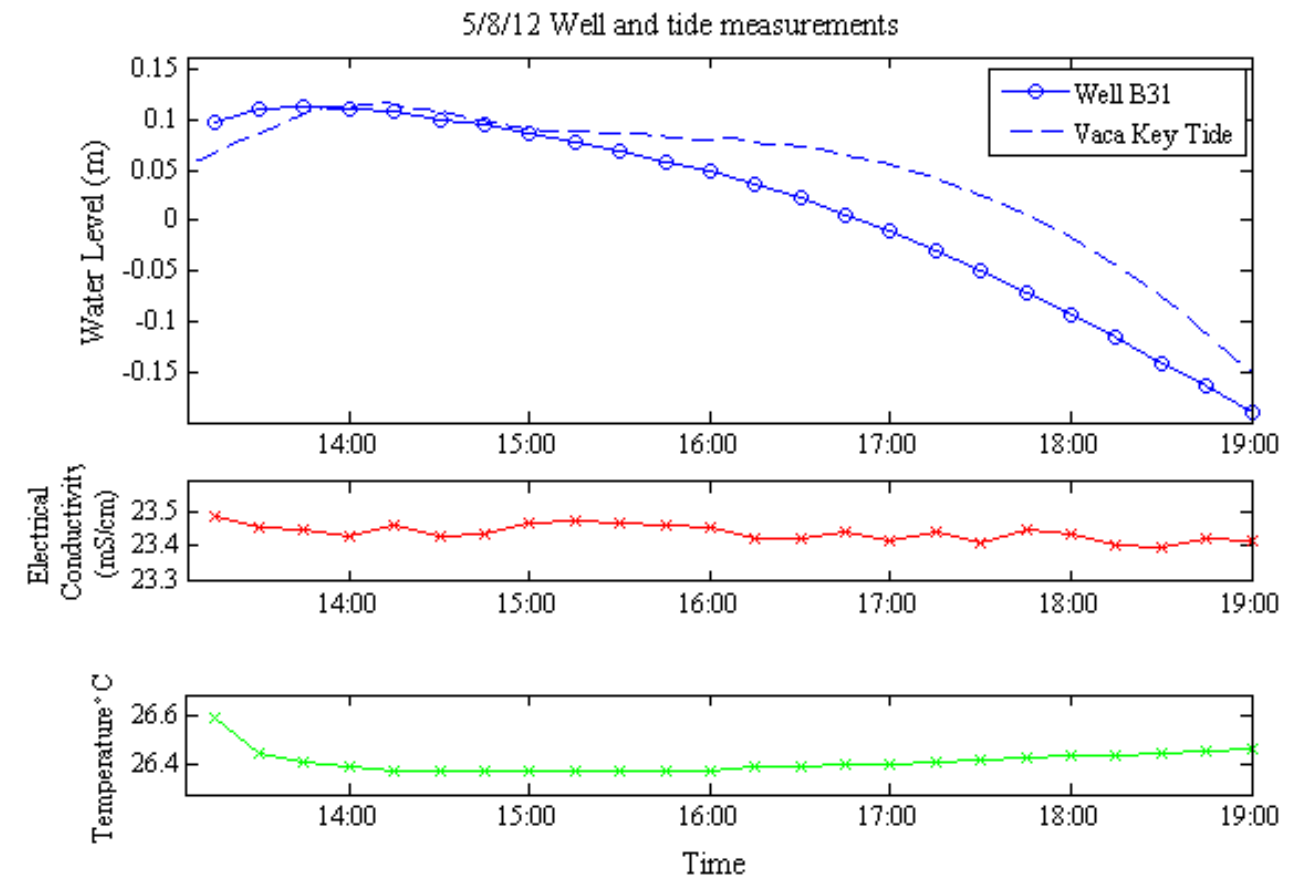

Figure 26 - Well and tide measurements during the $B 3$ tidal survey. While temperature follows the same pattern as the measurements at the B11 well, the conductivity shows no pattern and changes little over the survey. 


\section{GROUNDWATER MODELING}

\section{Background}

\section{Freshwater Lens}

The fresh groundwater on an oceanic island acts as a lens "floating" on the top of seawater. Freshwater with a density of $1.00 \mathrm{~g} / \mathrm{cm}^{3}$ is more buoyant than seawater, with a density of $1.025 \mathrm{~g} / \mathrm{cm}^{3}$. Ghyben-Herzberg Principle is the theoretical relationship of freshwater and seawater in coastal/island groundwater. The depth to the interface $(z)$ is

$$
z=\frac{d_{f}}{d_{s}-d_{f}} * h
$$

where $d_{f}$ is the density of the freshwater, $d_{s}$ is the density of the saltwater, and $h$ is the freshwater head. Insert the densities and the simplified relationship becomes

$$
z=40 * h
$$

The depth to the seawater is 40 times the freshwater head above sea level. The size and shape of the lens depends on the area and elevation of the land surface, the amount of recharge on the island and the permeability of the rock formations.

The Ghyben-Herzberg principle assumes a sharp freshwater/seawater interface with no mixing, which is unrealistic. The interface is composed of a brackish transition zone because of dispersion and diffusion of the two fluids. The dispersion can be from the flow of the freshwater into the seawater, changes in recharge rates, or tidal changes in the sea level. With this transition zone, the depth to the interface given by the GhybenHerzberg principle will correspond with some position within the transition zone. 


\section{Variable-Density Groundwater Modeling}

Mathematical modeling is used to simulate a lens with a transition zone, since analytical solutions can only provide a 1-D solution. Mathematical modeling relies on the principle of mass conservation of the fluid and solute. The general form of the partial differential equation for variable density groundwater flow in a porous media expressed in terms of fluid density and pressure is

$$
-\nabla \cdot(\vec{q} d)+q_{s} \bar{d}=d S_{p} \frac{\partial P}{\partial t}+\theta \frac{\partial d}{\partial C} \frac{\partial C}{\partial t}
$$

where:

$$
\begin{aligned}
& \nabla: \text { gradient operator } \frac{\partial}{\partial x}+\frac{\partial}{\partial y}+\frac{\partial}{\partial z} \\
& d: \text { fluid density }\left[\mathrm{M} / \mathrm{L}^{3}\right] \\
& \vec{q}: \text { specific discharge vector }[\mathrm{L} / \mathrm{T}] \\
& \bar{d}: \text { density of water from source or sink }\left[\mathrm{M}^{3} \mathrm{~L}^{3}\right] \\
& q_{s}: \text { volumetric flow rate per unit volume of aquifer representing sources and } \\
& \quad \text { sinks[1/T] } \\
& S_{p}: \text { specific storage }\left[\mathrm{LT}^{2} / \mathrm{M}\right] \\
& P \text { : fluid pore pressure }\left[\mathrm{M} /\left(\mathrm{LT}^{2}\right)\right] \\
& \theta: \text { porosity } \\
& C: \text { salt concentration }\left[\mathrm{M} / \mathrm{L}^{3}\right]
\end{aligned}
$$

The left hand side of the equation represents change in mass with the gradient accounting for mass flux across the faces of a volume and the mass flux from sources and sinks. The right hand side represents the rate of change in 
mass over time, with the first term representing changes that result from pore fluid pressure changes and the second because of changes in solute concentrations. For the purposes of this study, the freshwater lens was modeled with SEAWAT-2000 (Guo and Langevin 2002), a variable density, transient groundwater flow program. The flow equation for the program was developed in terms of equivalent freshwater head and fluid density. The governing equation for typical seawater is

$$
\begin{aligned}
& \frac{\partial}{\partial \alpha}\left(K_{f \alpha} \cdot d \cdot\left[\frac{\partial h_{f}}{\partial \alpha}+\frac{d-d_{f}}{d_{f}} \frac{\partial Z}{\partial \alpha}\right]\right)+\frac{\partial}{\partial \beta}\left(K_{f \beta} \cdot d \cdot\left[\frac{\partial h_{f}}{\partial \beta}+\frac{d-d_{f}}{d_{f}} \frac{\partial Z}{\partial \beta}\right]\right) \\
& +\frac{\partial}{\partial \gamma}\left(K_{f \gamma} \cdot d \cdot\left[\frac{\partial h_{f}}{\partial \gamma}+\frac{d-d_{f}}{d_{f}} \frac{\partial Z}{\partial \gamma}\right]\right)=d \cdot S_{f} \cdot \frac{\partial h_{f}}{\partial t}+\theta \cdot E \cdot \frac{\partial C}{\partial t}-\bar{d} \cdot q_{s} .
\end{aligned}
$$

where:

$$
\begin{aligned}
\alpha, \beta, \gamma: & \text { Principal permeability directions }[\mathrm{L}] \\
\mathrm{K}_{\mathrm{f}}: & \text { Freshwater hydraulic conductivity }[\mathrm{L} / \mathrm{T}] \\
\mathrm{h}_{\mathrm{f}}: & \text { Freshwater head }[\mathrm{L}] \\
\mathrm{Z}: & \text { Elevation above datum }[\mathrm{L}] \\
\mathrm{E}: & \text { Dimensionless constant }(0.7143) \text { for salinity ranging from } \\
& \text { freshwater to seawater }
\end{aligned}
$$

For variable density groundwater flow, the model must couple the solutions of the flow and solute transport equations using modified versions of MODFLOW and MT3DMS which are combined into one. Using a finite-difference approximation, the equations are discretized into time steps and solved starting with the flow equation and then the transport equation. 


\section{Methodology}

A transient groundwater model was created to simulate the tidal influence on the saltwater/freshwater interface observed with the time-lapse ERT on profile B1WE. The USGS program, SEAWAT-2000 (Guo and Langevin 2002), was used to simulate the variable density and transient groundwater flow. Groundwater Vistas 6 was used for preand post-processing of the SEAWAT files. First, a model had to be run to reach steadystate conditions under constant recharge and a steady ocean boundary. Then the tidal conditions of each of the B1WE tide investigations were run to simulate the same conditions.

The grid was set-up as a 2-D cross-section of the lens since the ERT is only a 2-D profile and this cut down on the run-time of the model. Since the study is concerned with effects close to the coast and a simulation of a whole lens would only mirror itself, only half of the lens was simulated. Average width of the island is $2 \mathrm{~km}$, therefore to simulate half the lens 1000 columns were used with $1 \mathrm{~m}$ spacing to total $1 \mathrm{~km}$. The grid depth was $50 \mathrm{~m}$ with 50 layers at $1 \mathrm{~m}$ spacing.

The top five layers were assigned the properties of the Miami Oolite and the remaining layers were assigned the properties of the Key Largo Limestone. A high hydraulic conductivity zone based on Mulligan et al. (2011), was set on the top western boundary of the model to simulate the shallow ocean conditions next to the island. Figure 27 shows the set up of the two layers and the high-K zone for the ocean boundary. All of the boundaries aside from the ocean boundary are no-flow. Since SEAWAT is a transient model, the groundwater simulation had to be run until the observation wells displayed no change. 


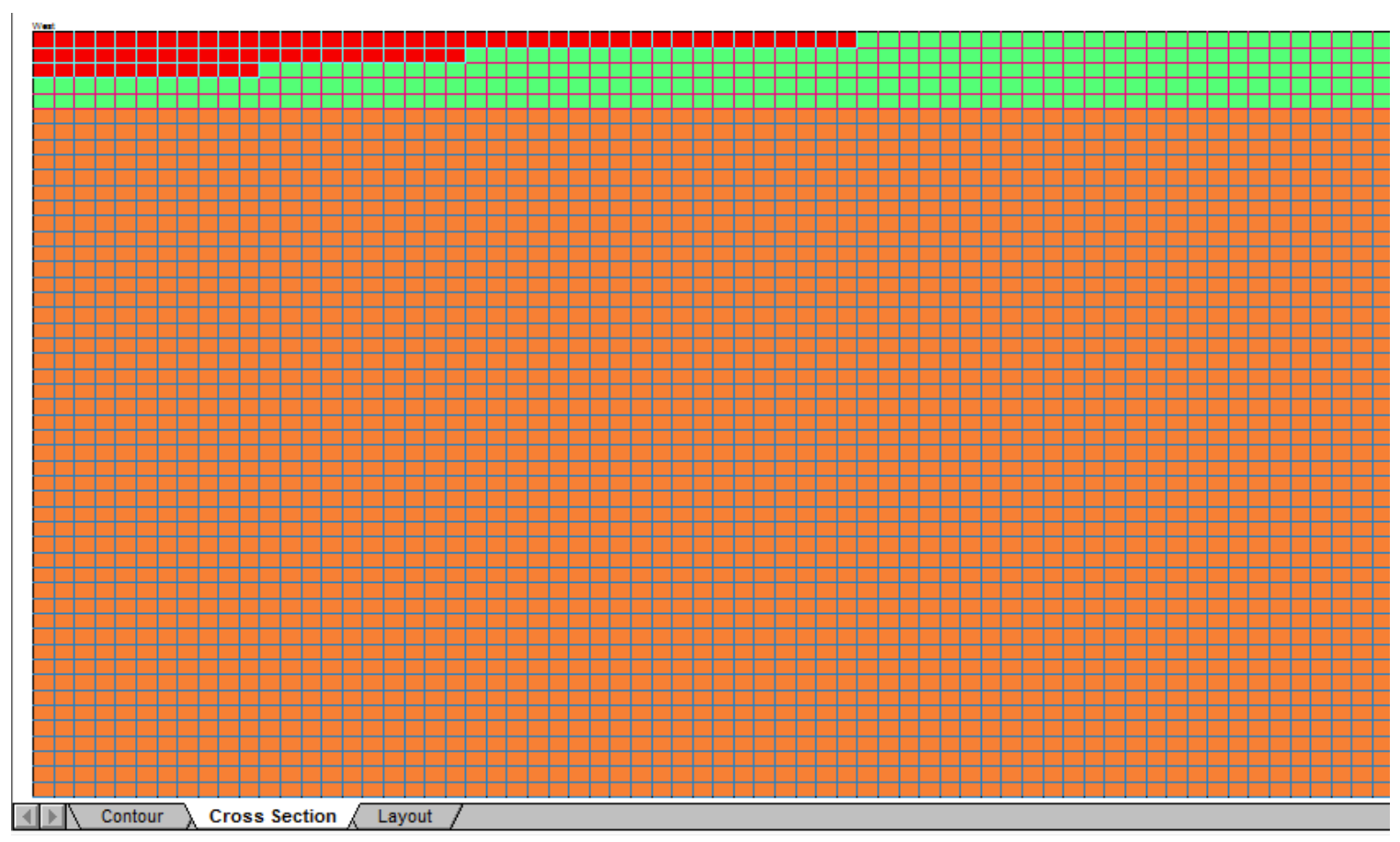

Figure 27 - Groundwater model boundary conditions created in Groundwater Vistas 6, showing. Red cells represent high hydraulic conductivity ocean boundary. Green cells represent Miami Oolite and orange cells are Key Largo Limestone.

The property values for the Miami Oolite and Key Largo Limestone layers were based in part on the previous studies conducted on the island. The hydraulic conductivity and recharge values were based on the Dupuit-Ghyben-Herzberg modeling by Wightman (1990). The layers for the Miami Oolite were assigned a conductivity of $120 \mathrm{~m} /$ day and the Key Largo Limestone layers were assigned $1400 \mathrm{~m} /$ day. The recharge was initially assigned $0.3 \mathrm{~m} / \mathrm{yr}$ based on the value determined by Wightman. Recharge was set to be uniform to time with no seasonal fluctuation. Using a method developed by Vacher and Ayers (1980), Wightman found the chloride concentration of the rainfall $\left(\mathrm{Cl}_{\mathrm{R}}{ }^{-}\right)$and the freshest groundwater obtained on the island $\left(\mathrm{Cl}_{\mathrm{r}}^{-}\right)$to calculate the ratio $\mathrm{Cl}_{\mathrm{R}}{ }^{-} / \mathrm{Cl}_{\mathrm{r}}{ }^{-}$, which measures the ratio of recharge to rainfall. He determined that $20 \%$ of the rainfall recharged the groundwater. 
Other properties were estimated on the basis of a priori knowledge. The effective porosity was set to 0.1 for the Miami Oolite and 0.2 for the Key Largo Limestone. Since the Key Largo Limestone is more permeable than the Miami Oolite, a larger effective porosity seemed reasonable. Longitudinal dispersivity was set to $0.05 \mathrm{~m}$ and transverse and vertical dispersivity was set to $0.01 \mathrm{~m}$ for both formations. These parameters were initially estimated and then changed to fit the concentrations within the ranges collected from wells along the seasonal profile B1 (Appendix B) and to reach a maximum head at the inland end no larger than $0.35 \mathrm{~m}$, determined from groundwater level results found in Hanson (1980).

The ocean boundary cells were assigned values to best simulate the open surface derived in part from parameters used in Mulligan et al. (2011). The salinity for all cells was set to a constant 35 ppt. Hydraulic conductivity was set to $10,000 \mathrm{~m} /$ day. Porosity was set to 1 while the storage coefficient was set to 0.3 . Longitudinal dispersivity had to be set low since the ocean cells were set to pure seawater concentration with no way to account for fresher water outflow from the lens. Longitudinal dispersivity was set to $0.0001 \mathrm{~m}$ and transverse and vertical dispersivity were set to $0.05 \mathrm{~m}$.

The storage coefficient, S, was determined using the tidal lag observed between the head in the well the tidal level collected at the temporary tide station. The tidal lag was simulated using the finite-difference form of the transient flow equation:

$$
h_{x, y, t}=h_{x, y, t-\Delta t}+\frac{T \Delta t}{S}\left[\frac{\left.h\right|_{x+\Delta x, y, t-\Delta t}-\left.4 h\right|_{x, y, t-\Delta t}+\left.h\right|_{x-\Delta x, y, t-\Delta t}+\left.h\right|_{x, y+\Delta y, t-\Delta t}+\left.h\right|_{x, y-\Delta y, t-\Delta t}}{(\Delta x)^{2}}\right]
$$

Transmissivity, $\mathrm{T}$, is equal to the aquifer hydraulic conductivity, $\mathrm{K}$, multiplied by the thickness of the aquifer, b. The transmissivity of both the Miami Oolite and Key Largo 
Limestone and the transmissivity of just the Miami Oolite were tested to see which best simulated the tidal signal. The tidal lag time came from the measurement on B1WE in May $7^{\text {th }}, 2012$ since a local tidal station was set up close to well B11. The tidal lag time from the low tide of the temporary station to the lowest level in the well was 30 minutes. The simulated signal using the finite-difference equation had to mimic the same time lag and amplitude difference measured in the field. The resulting storage coefficients determined were 0.07 using both formations and 0.006 using only the Miami Oolite. To test which worked best, they were both used in the tidal simulation of the May tidal signal to see which produced a similar result to the water level changes in Well B11. The storage coefficient determined for the Miami Oolite alone worked best but it still had to be corrected until it could match the amplitude in the well. The best storage coefficient determined was 0.004 .

To conduct the tidal simulations, most of the same parameters were kept the same with a few exceptions. The time unit was set to minutes so all of the parameters in units of time had to be changed accordingly. The hydraulic conductivity for the ocean boundary was increased to $100 \mathrm{~m} / \mathrm{min}(144,000 \mathrm{~m} /$ day $)$ so it could better simulate surface water. The ocean boundary was made transient with the head set to the tides of each of the B1WE measurements (Appendix D). Stress periods were set to 15 minutes each since tide measurements in the field and from the NOAA tide gauge are taken every 15 minutes. For the July tide, the Vaca Key tide was used. For the May tide, the temporary tide gauge measurements were used. The mean tide level was set to equal the ocean water level since the tide gauge datum level was in NAVD 88. 


\section{Results}

The recharge rate contributed as the largest problem in obtaining reasonable groundwater salinities. The value used by Wightman (1990) caused the seawater in the model to intrude too far inland. Therefore the recharge was eventually increased to $60 \%$ of the precipitation for the island. This new recharge made the salinities better resemble the measured ranges in the wells along line B1 while avoiding overshooting the maximum head, around $0.35 \mathrm{~m}$, in the middle of the island.

The resulting model for the steady-state simulation is shown in Figure 28. The freshwater (up to $1 \mathrm{ppt}$ ) is relatively thin, with a maximum of $3 \mathrm{~m}$. The transition zone thickness is around $20 \mathrm{~m}$. A Ghyben-Herzberg line was created based on the heads of the steady-state model. It corresponds with about 17 to $19 \mathrm{ppt}$, which is close to the middle of the transition from seawater to freshwater. Based on the line, it should be noted that the lens does not increase as quickly in depth after $5 \mathrm{~m}$, where the Key Largo Limestone conditions begin. The hydraulic gradient of the steady state model was compared to the hydraulic gradient of the mean of the observed well measurements at Well B12 and the local tide measurements from the May 2012 BIWE tidal survey. The area this corresponds to on the model is between 40 and $88 \mathrm{~m}$. The hydraulic gradient of the model was $3.40 \times 10^{-3}$ and the hydraulic gradient of the field measurements was $3.05 \times 10^{-3}$. The heads and salinity concentrations from this model were used for the starting model in the tidal simulations. 


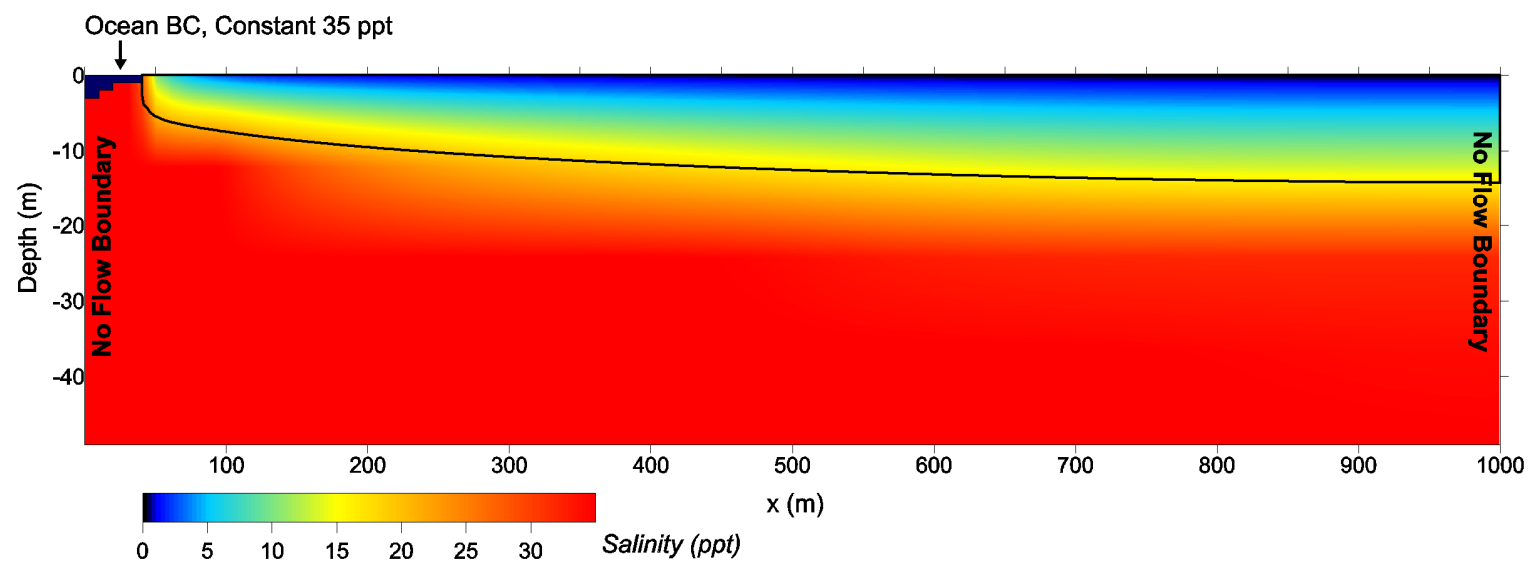

Figure 28 - Starting model for the tidal simulation with boundary conditions. Solid black line is Ghyben-Herzberg line based on head of the starting model. Salinity scale is set to the same bounds as the salinity distribution from ERT data. Vertical exaggeration is 5.3.

The tide simulation model outputs for July 2011 and May 2012 are displayed in Figure 29 and Figure 30. The tidal results are plotted to show the approximate area covered by the ERT results. The edge of the ocean boundary is set at $40 \mathrm{~m}$ and the ERT profile is $54 \mathrm{~m}$ long, so the bounds were set horizontally at 40 to $100 \mathrm{~m}$. The edge at $40 \mathrm{~m}$ is an approximation of the edge of the ERT profile since the actual mid-tide point in the field is hard to determine. Only the top 10 layers are displayed since the ERT 2-m spacing used cannot accurately resolve below that depth. 

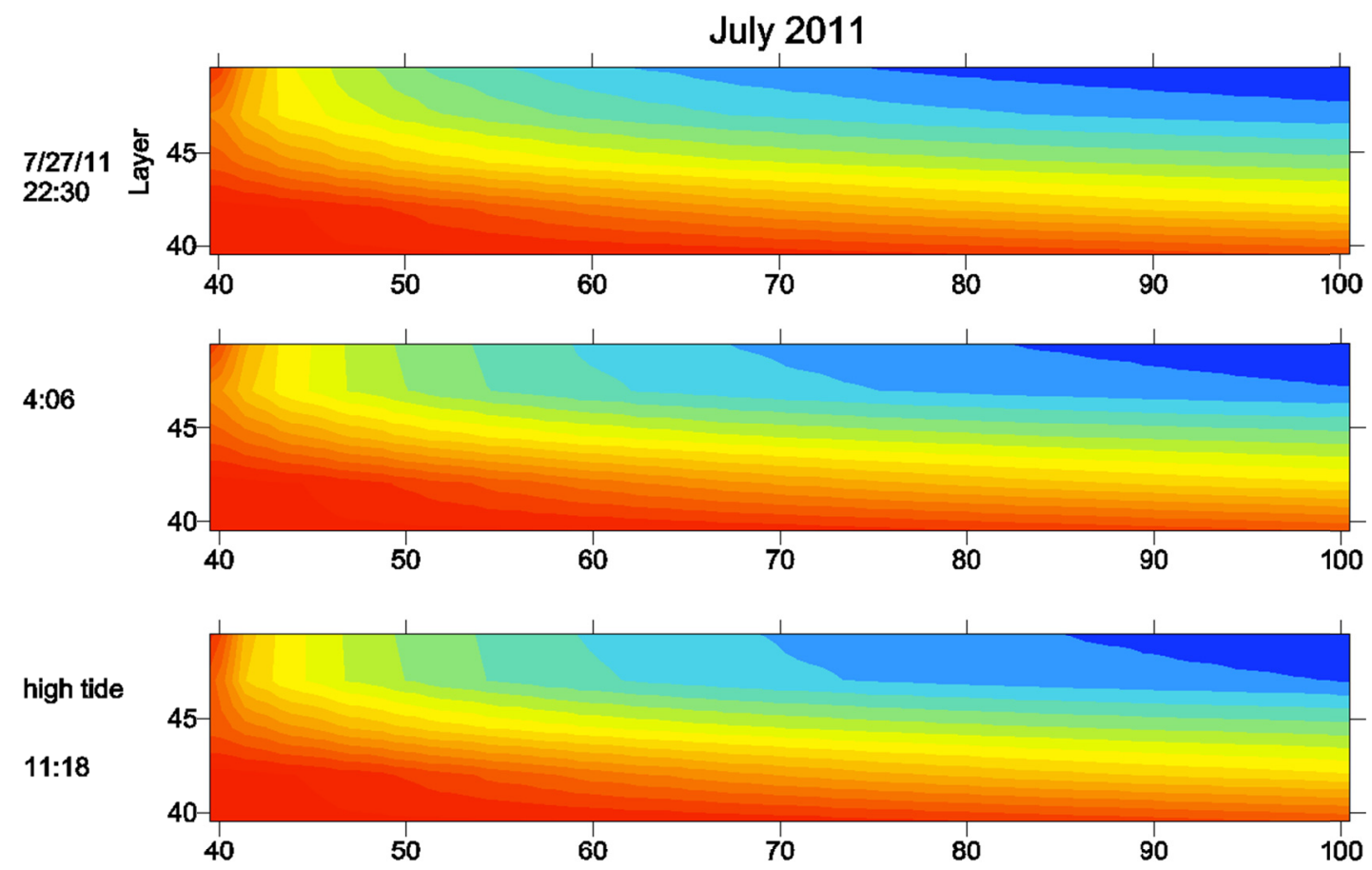

15:30
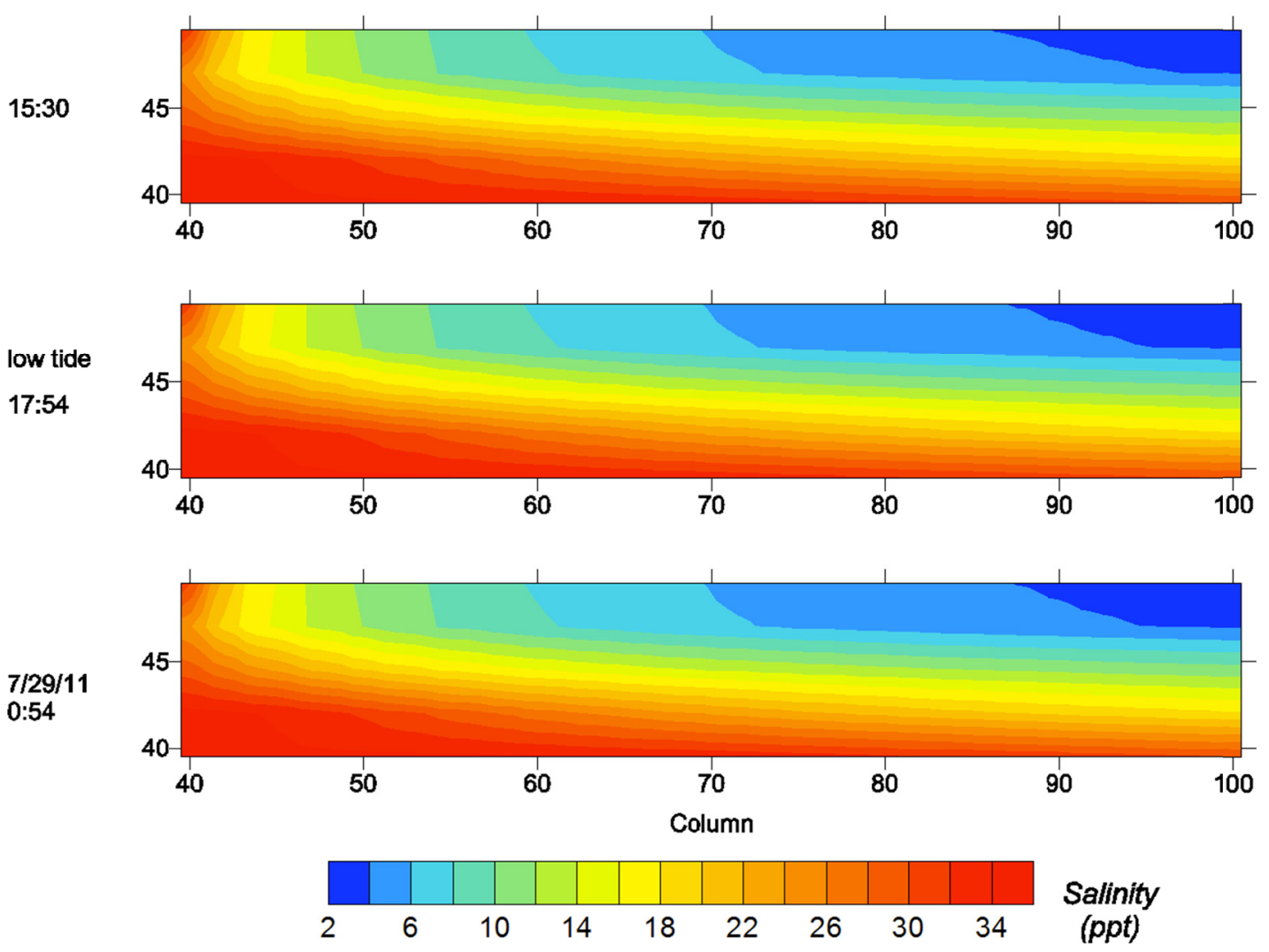

Figure 29 - Groundwater model results using the tide data from July 28th, 2011 corresponding to ERT measurement at B1WE. Tide level input came form the Vaca Key tide station. The coordinates are in layers $(\mathrm{m})$ and columns $(\mathrm{m})$ of the SEAWAT model. 

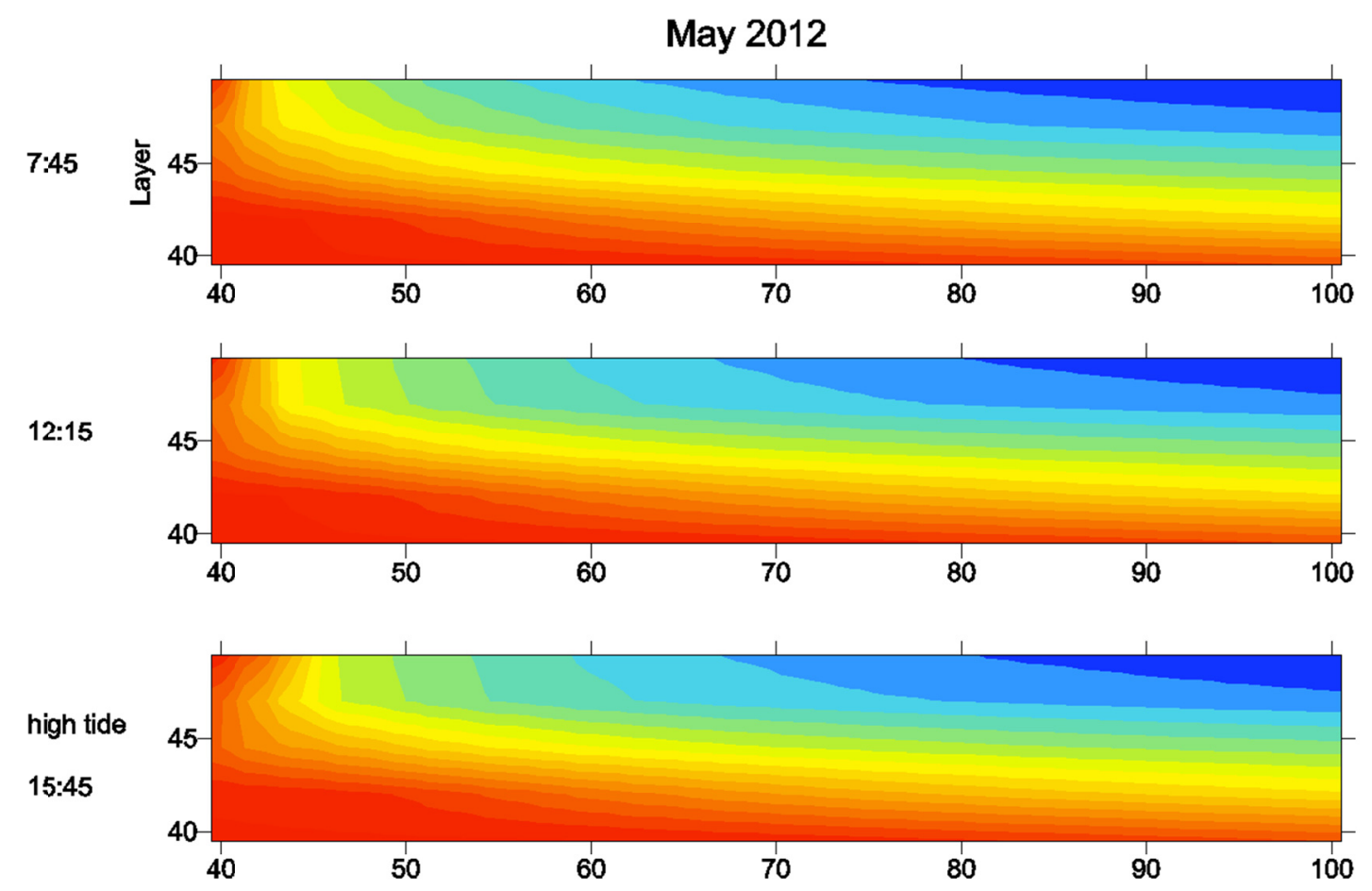

18:30
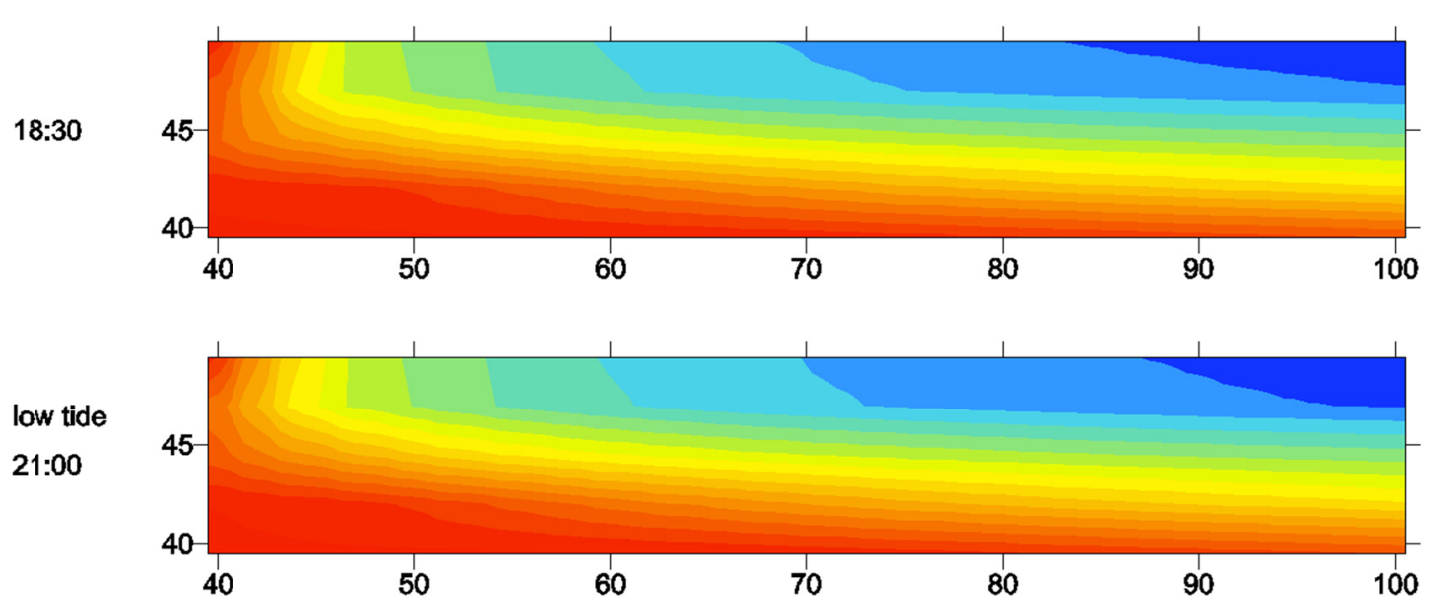

$5 / 8 / 12$

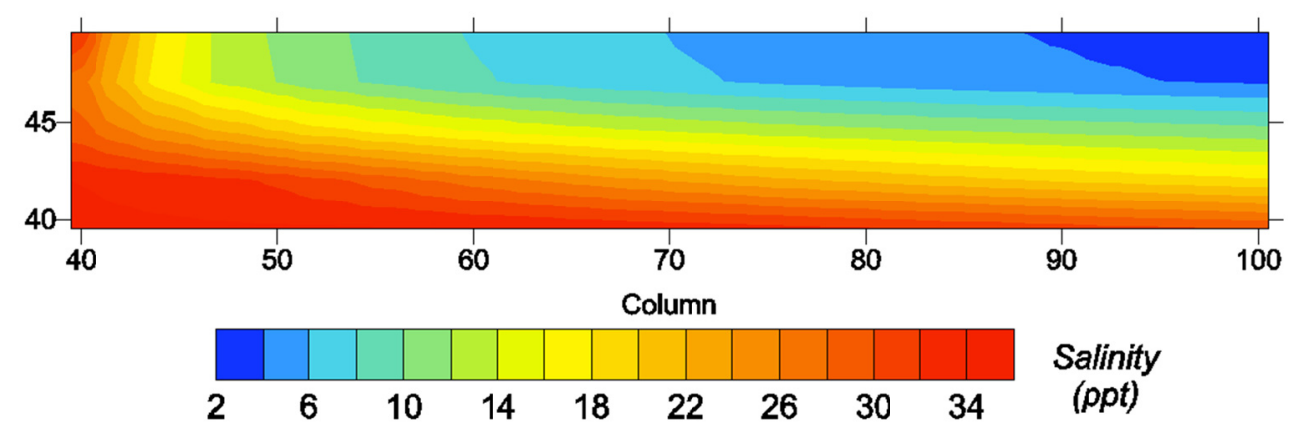

Figure 30 - Groundwater model results with the tide data from May 7th, 2012 corresponding to the tidal measurement at B1WE. Tide level input came from temporary tidal station set up at the site. 
The tide simulations share some similarities and differences. Both show that the transition zone becomes much thicker with the mixing induced by the tide. The fresher water at the inland edge changes in shape, becoming slightly thicker with depth but receding from the coastal side. They both share a similar shape at the low tide. The primary difference is the response to the high tide. The 2012 measurement with the larger tidal range causes the top edge to become more inundated with saltwater while forcing the fresher water inland to recede without changing in thickness until the tide recedes.

There are a few limitations to the groundwater model. The groundwater model does not simulate overland flow. Any mixing caused by this could not be modeled. The grid size is coarser with respect to depth than the ERT results. The starting vertical grid thickness of the ERT inversion was $0.1 \mathrm{~m}$ yet the grid for the groundwater model is 1 by $1 \mathrm{~m}$. The coastal boundary of the groundwater model in relation to the field site is uncertain. The intertidal zone at the B1 site is tens of meters wide and the location of the mean tide level is uncertain with the low gradient slope and vegetation. This uncertainty means that relating the tidal groundwater model to the measured field results corresponding locations could be off by several meters. 


\section{DISCUSSION}

Tidal changes in salinity were small and constrained to within the first $20 \mathrm{~m}$ closest to the coast. The most significant changes observed over the tide occurred on the May 2012 measurement along B1WE. The contrast of these results with the results at the same site in July 2011 is due to an increase in the tidal range. The conversion of the resistivity results to salinity using the formation factor makes the interpretation of the data simpler than just comparing the resistivity profiles. Difference inversion method proves to resolve these small changes from the tide better than separate inversions of each time step. The groundwater model results provided some insight on the tidal changes, but the accuracy in simulating the field measurements is poor.

\section{Formation Factor}

The formation factor agrees well with the porosity estimates given in other studies. The porosity can be estimated using the final combined formation factor. The general relationship of porosity and formation factor for most carbonates is

$$
F F=\frac{1.0}{\phi^{2}}(\text { Tiab and Donaldson 2004) }
$$

The result, using the formation factor of 9.05 , is a porosity of .332 or $33.2 \%$. This value is consistent with porosity estimates in the Miami Oolite near Miami, which range from $20-40 \%$ with a majority over $30 \%$ (Robinson 1967). It also falls within the total porosity range determined by Coniglio and Harrison (1983), which was for both formations on Big Pine Key.

The salinity results within the Key Largo Limestone formation are subject to interpretation since the formation factor was only determined for the Miami Oolite. The 
two formations have similar porosities $(\sim 30 \%)$ but the pore structure is different. Coniglio and Harrison observed that the older units of Key Largo Limestone had a higher degree of cementation and much better developed secondary porosity than the Miami Oolite. Kwader (1986) observed a range in the cementation factor, $1.3-2.3$, for Tertiary carbonate aquifers of the Coastal Plain in the southeastern USA. The low end (1.3-1.4) represented unconsolidated or poorly consolidated sediments and the high end represented well-cemented rock formations. Verwer et al. (2011) found that larger pore spaces with simple pore structures had higher cementation factors than smaller pores with more complex pore structures. This would suggest that the Key Largo Limestone may have a larger cementation factor and, assuming the porosity is the same, the formation factor would be higher.

Compared to studies from other regions, the values obtained here are not unreasonable. Using cores for formation factors is best for formations with small-scale porosity. Verwer et al. (2011) conducted their analysis on a set of 71 carbonate cores from different areas around the world. They found formation factors ranging from $10^{1}-$ $10^{3}$. The cores with larger porosities $(\sim 30 \%)$ had smaller formation factors, around 10 , which is close to the one derived in this study. For larger scale porosity, the best option is to determine it in the field. Swarzenski et al. (2006) determined the formation factor through a similar method as this study with an electrode array in the field and known pore water salinities. They found a range of formation factors from 8 to 14, with a mean of 9.4 +/- 1.2. The lower values corresponded with sand and higher values with sandstone. While this is a different type of rock, the formation factor from this study appears to be within an appropriate range. 
Comparing the formation factor to local studies, the formation factor determined for this study (9.05) is higher than other studies in southern Florida. Greenwood et al. (2006) found formation factors at four depths in a coastal wetland of Tampa Bay using a resistivity array. A value of 3.65 was determined for mangrove soil (sandy mud) and 2.45-2.90 for the Hawthorne Formation (sandy clay). The low values for the Hawthorne Formation are due to the conductive clays. Fitterman and Deszcz-Pan (2004) determined a formation factor using induction logs and water samples pumped from wells in Southwest Florida. Everglades National Park was determined to have a formation factor of 5.5 and Big Cypress National Preserve of 2.7. The Everglades National Park wells fell within the Biscayne Aquifer. Fitterman and Deszcz-Pan (2012) determined a bulk formation factor for the Biscayne Aquifer from wells in southeastern Miami-Dade County. They determined a formation factor of 5.1 for the Biscayne Aquifer. The Biscayne Aquifer contains six stratigraphic units including the Miami Oolite and Key Largo Limestone, which would all contribute in the formation factor determination. The formation factors determined in these Florida studies suggest that the one determined in this study is high.

There are few reasons that this may be the case. The formation factor measured in this study is only for the Miami Oolite. There are no other contributing rock formations for this determination unlike the one determined for the Biscayne Aquifer. Another possible contribution was the method of data collection. The formation resistivity and pore water samples came from upper 1 to $2 \mathrm{~m}$ of the formation, very close to the water table. The porosity at this level may be different than the average for the formation. Lower porosity would contribute to a higher formation factor. 


\section{Spatial Differences in Salinity}

The static tidal profiles reveal the edge of the freshwater lens $(<1$ ppt salinity) and transition zone (Figure 31). Note that the transition zone can be anywhere between freshwater and seawater but for clarity, halinity classes (Cowardin et al. 1979) were used to describe specific ranges in salinity. Oligohaline is between 0.5 and 5 ppt salinity, mesohaline is between 5 and $18 \mathrm{ppt}$, polyhaline is between 18 and 30 , and euhaline is within natural seawater ranges between 30 and 40 ppt. Surface seawater salinity averages around $36 \mathrm{ppt}$, so values above this would be considered hypersaline.

Apparent hypersaline areas are present along the near surface of the B3 profile (Figure 31C) and during the high tide on the B1WE line (Figure 19). These areas correspond with two things: the presence of marl and flooding during high tide. Marl is much more conductive than the limestone. Therefore the formation factor would not be accurate for these areas. Even on the B1NS profile (Figure 31B), the apparent salinity is higher at the surface, where the gravel and sediment present would have a different formation factor as well. The presence of marl and sediment at the surface is the most probable cause of these apparent hypersaline areas, meaning that these areas are probably lower in salinity than they appear in the profiles. 

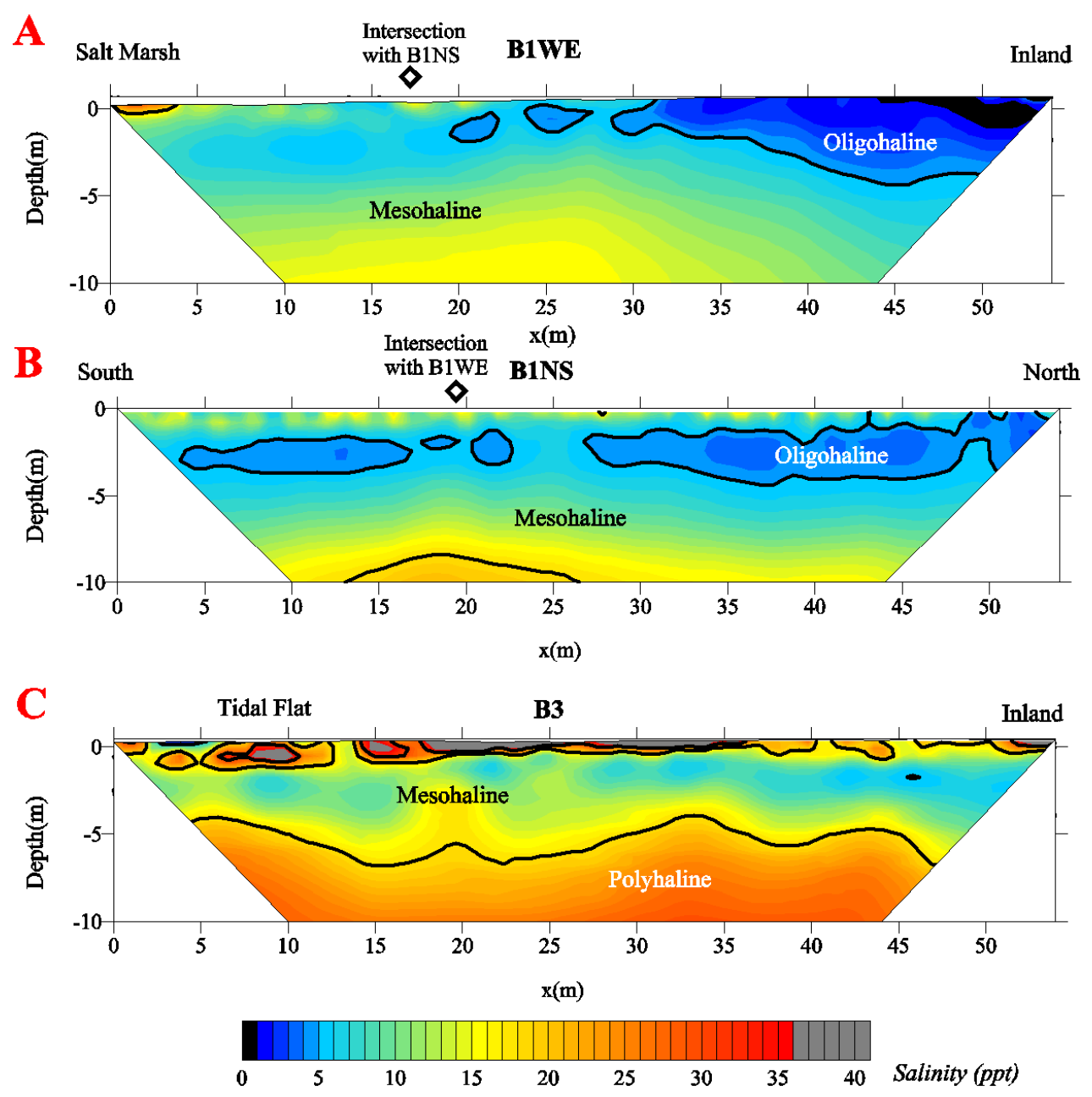

Figure 31 - Comparison of spatial differences in the salinity of each tidal profile. The A plot is from $5 / 7 / 12$ survey, $B$ is from $7 / 29 / 11$, and $C$ is from $5 / 8 / 12$. Freshwater is denoted in black, $<1$ ppt. The oligohaline zone is light in salinity $(1-5 \mathrm{ppt})$. Mesohaline is moderate in salinity (5 - 18 ppt). Polyhaline is high in salinity $(18-30 \mathrm{ppt})$. Hypersaline areas indicated in grey are due to marl not increased salinity.

The heterogeneous nature of the subsurface causes the uneven variations in the salinity zones. On the B1WE and B1NS profile the oligohaline zone is patchy and disconnected. Knowing that porosity can range significantly within a formation and that porosity affects the formation factor, this variation may not be due to changes in salinity. A solution hole or a small cavern may cause larger variations, such as the gap in the mesohaline zone on the $\mathrm{B} 3$ profile at $19 \mathrm{~m}$. Of course, higher porosities and cavernous zones may also lead to increased saltwater mixing. Much like the apparent hypersaline 
areas, these variations have to be considered with care since the converted ERT profile assumes that the whole profile has the same formation factor.

The B3 tidal profile (Figure 31C) has a different coastal setting than the B1 profiles which causes the higher salinity ranges in the groundwater at the site. Reviewing the seasonal profiles, the whole seasonal B3 profile is lower in resistivity than the B1 seasonal profile, suggesting B3 has higher levels of saltwater intrusion into the groundwater which can also be seen on the tidal profile for B3. The B1 profile starts at the edge of a small saltwater marsh with a coastal boundary of mangroves whereas a large tidal flat, interspersed with mosquito ditches, bound the B3 site. The B3 site has a smaller relief than the B1WE site by about $0.2 \mathrm{~m}$ ( Figure 32). The low relief and elevation lead to more flooding during extreme tidal events and very little gradient in the freshwater head inland to force against the seawater. The mosquito ditches remain flooded which serves as a constant source of saltwater intrusion into the groundwater. These combined issues cause the B3 site to be higher in salinity than the B1 site.

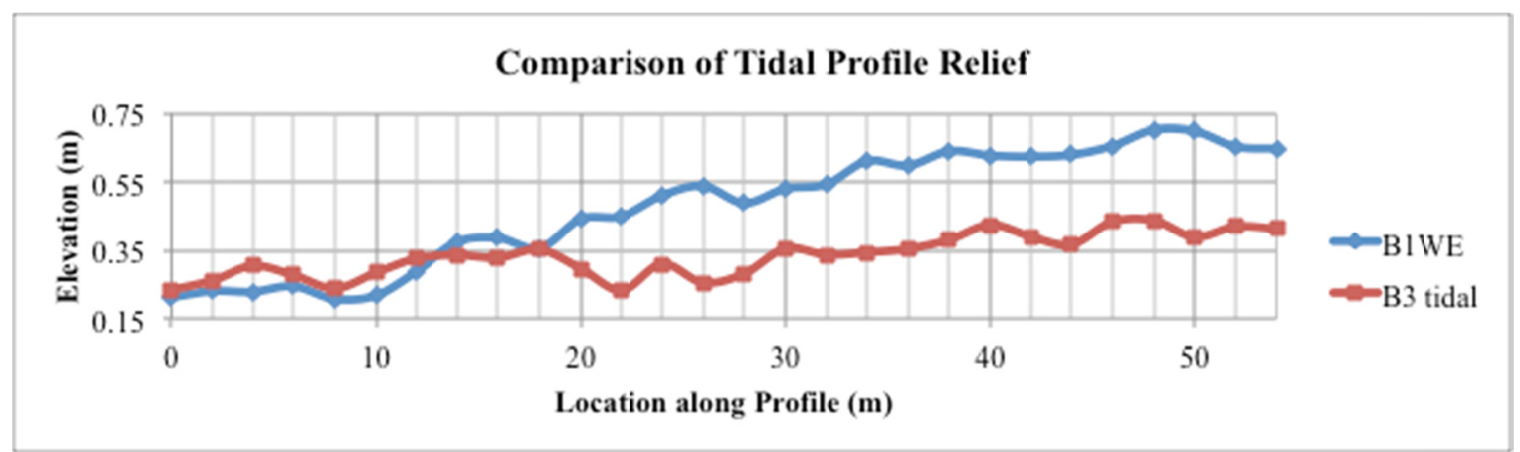

Figure 32 - Topographic relief of the B1WE and B3 tidal profiles. B3 has a relief .2 $\mathrm{m}$ smaller than the B1WE profile. The lower elevation would cause more flooding and saltwater infiltration into the groundwater. 


\section{Comparison of Groundwater Model to ERT salinity results}

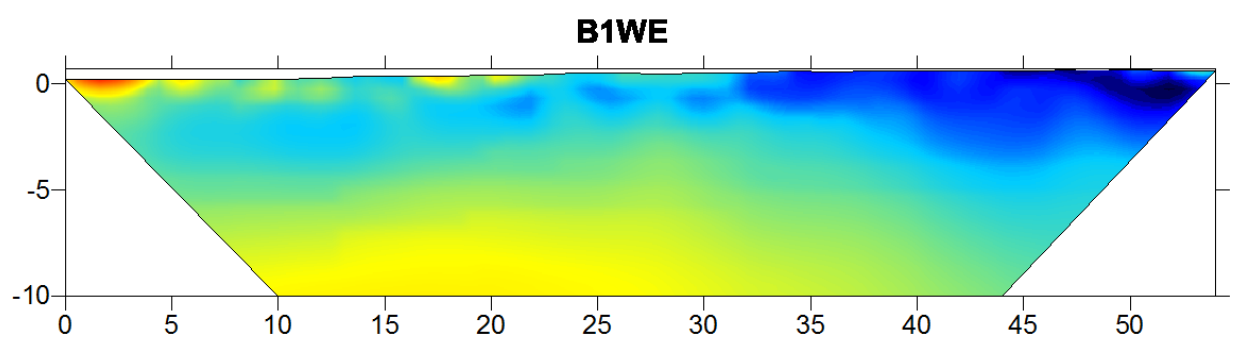

Groundwater Model

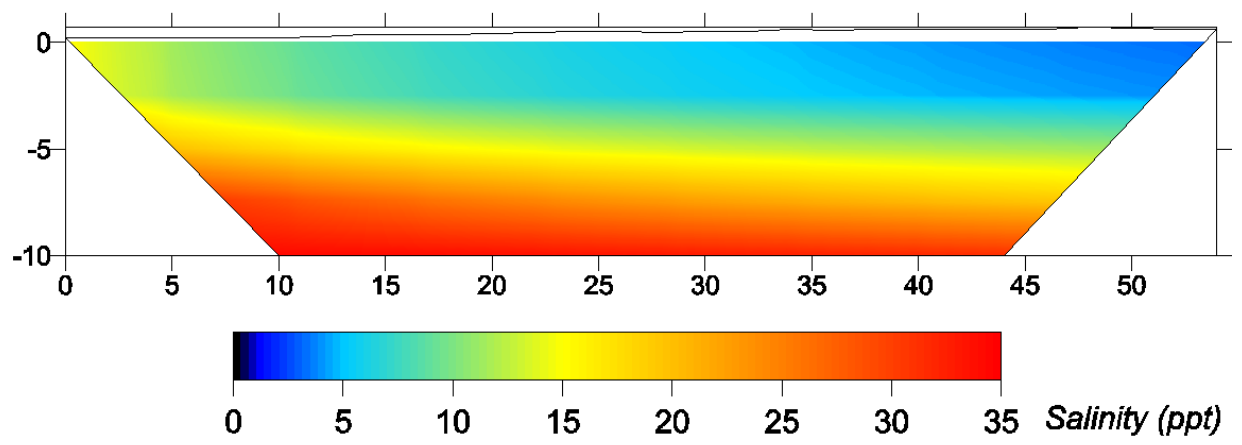

Figure 33 - Comparison of the measured salinity results from B1WE and the groundwater model result from SEAWAT after the tidal simulation.

The groundwater model does not display the same salinity below the formation contact as the ERT results (Figure 33). While the shallow well results taken during the seasonal ERT measurements for salinity agree well with the groundwater model, the salinities are too high when compared to the ERT results, especially below $4 \mathrm{~m}$. The ERT results show a thick zone of light to moderate salinity (1-15 ppt) that extends to the bottom, $10 \mathrm{~m}$, but the groundwater model shows a shorter transition with the salinities increasing to well over $15 \mathrm{ppt}$ below $5 \mathrm{~m}$. There are no wells deep enough or close enough to verify which method was more correct. The formation factor conversion applied to the Key Largo Limestone might not be very accurate and could be one reason for this difference. The regularization process of inversion imposes smoothing on sharp boundaries, which may also contribute to the issue since the contact between the two 
formations and the change in resistivity between them is likely a small but sharp change. Another factor may be that the groundwater model is inaccurate. Since the recharge rate used based on Wightman (1990) had to be increased, the hydraulic conductivity may need correcting.

The formation factor determined in this study was for the Miami Oolite and not the underlying Key Largo Limestone. If a formation factor were determined for the Key Largo Limestone, it would have to be much higher to have the ERT salinity results match the groundwater model results. For example, two points were selected below $5 \mathrm{~m}$ on one of the tidal resistivity profiles and the formation factor was recalculated for those two points to fit the same salinity as the corresponding location of the groundwater model (Figure 34). The point corresponding to $25 \mathrm{~m}$ at $7.5 \mathrm{~m}$ depth had a formation factor of 13.3 and the second point corresponding to $10 \mathrm{~m}$ at $7.5 \mathrm{~m}$ depth had a formation factor of 17.0. The formation factor of 17.0 appears to match the salinity results below $5 \mathrm{~m}$ better than the original. A formation factor of 17.0 is equates to a porosity of $24 \%$. Assuming the porosity remains $33 \%$ and that the cementation factor for Miami Oolite is 2 , this would equate to a cementation factor of 2.6. The porosity decreases significantly which would be unlikely given the increased hydraulic conductivity of the Key Largo Limestone and the porosity estimates given by other studies. While the cementation factor could increase, it is also well outside of the range found by Kwader (1986) for Tertiary carbonates in Florida. A formation factor of 17.0 is a large deviation from the formation factor for the Miami Oolite and those determined by Fitterman and Deszcz-Pan (2004 and 2012). Considering this as well as the relating porosity and cementation factor, it appears that the SEAWAT model itself may play a part in the discrepancy below $5 \mathrm{~m}$. 

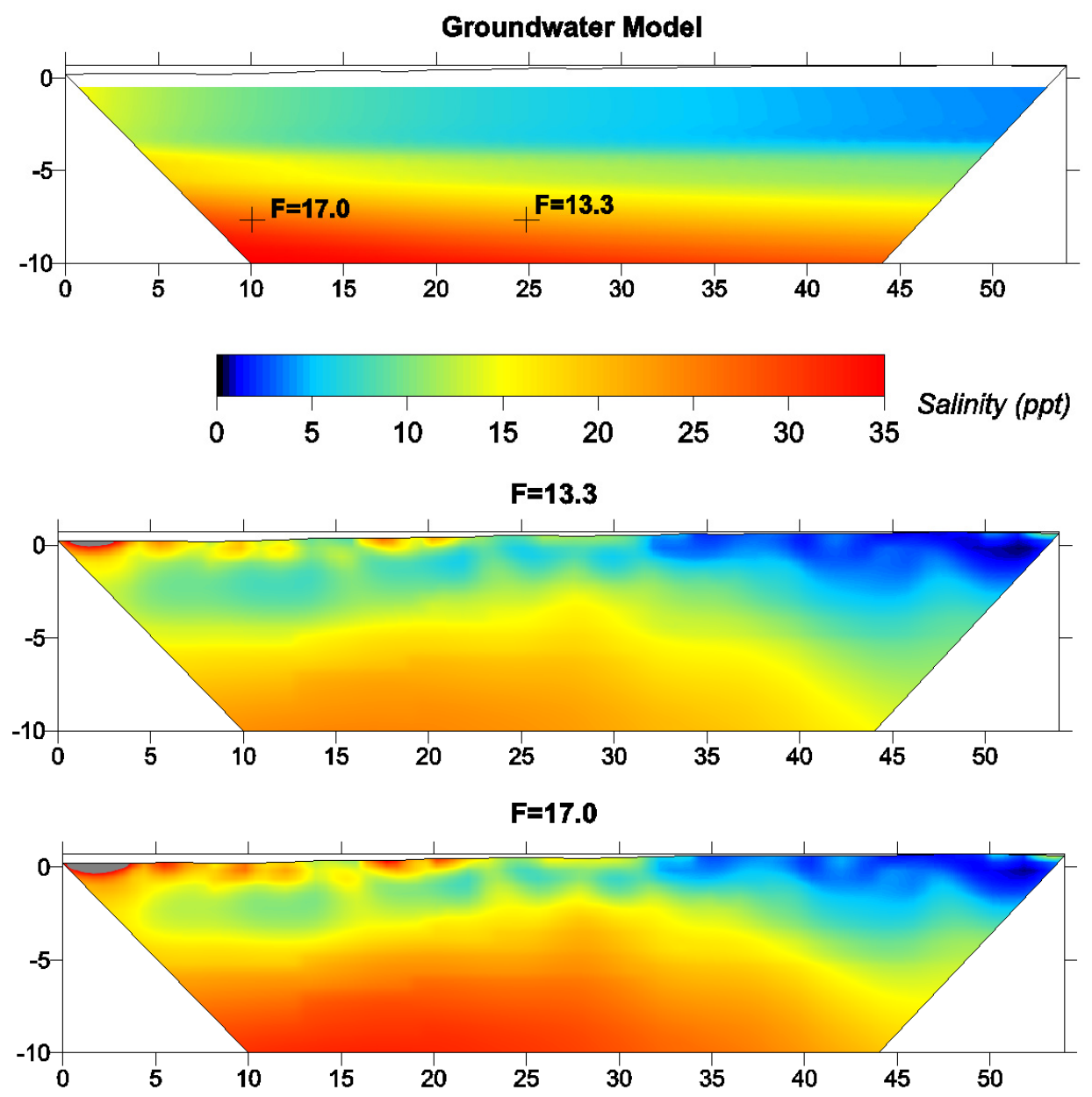

Figure 34 - Possible formation factors for the Key Largo Limestone. Two resistivity points from B1WE 5/8/12 at 01:20 were picked, at $25 \mathrm{~m}$ and $10 \mathrm{~m}$ at a depth of $7.5 \mathrm{~m}$, to match the SEAWAT salinity results by recalculating the formation factors. The salinity results based on those formation factors are displayed below.

Comparing the results to previous work suggests that the groundwater model may be inaccurate. Wightman (2010) and Hanson (1980) collected conductivity data from wells at various depths. Unfortunately, neither study conducted measurements as close to the coast as what is addressed in this study, so only the groundwater model results from this study can be compared. Both studies found many of the wells did not have very fresh water even close to the surface but normally there was a thick zone of this fresher water (between .5 and $4 \mathrm{ppt}$ ) that extended several meters down, 1-3 $\mathrm{m}$ below the formation 
contact (a total average depth of $7 \mathrm{~m}$ ). Then a sharp change in the salinities marked the transition zone that extended further down than could be measured in the wells (Wightman's wells reached a maximum of about $12 \mathrm{~m}$ and Hanson's only reached a maximum of $10 \mathrm{~m}$ ). The beginning of this sharp change also corresponds with saltwater/freshwater interface that Wightman (2010) determined with the EM method. The groundwater model transition zone for the inland portion of the island is not as thin as observed in the well data from these previous studies. This in combination with the discrepancies of the groundwater model and ERT results at the edge of the lens suggests that the parameters used from Wightman (1990) were likely inaccurate for the groundwater model in this study.

The recharge estimate is an example of the problems with the parameters from Wightman (1990) used in the groundwater model for this study. For the steady state model, the recharge from Wightman (1990) had to be increased in order to reach the salinity ranges that were observed in the wells from the seasonal profiles. A similar result came from Caballero et al. (2004) when modeling a nearby island, Little Torch Key. It required a larger recharge of $0.002 \mathrm{~m} /$ day for wet season modeling and $0.0006 \mathrm{~m} /$ day for the dry season. This came to a total recharge of $\sim 80 \%$ of the precipitation. The method utilized by Wightman (1980) relied on obtaining the freshest water available of the lens to use the chloride ratio $\left(\mathrm{Cl}_{\text {rainfall }} / \mathrm{Cl}_{\text {groundwater }}\right)$ to determine the recharge. If the water has any chloride contribution aside from the rainfall then the ratio will be too small and the recharge estimate will be too low. Considering the canals, mosquito ditches, and the wells in use on the island, the groundwater is easily contaminated by saltwater intrusion and 
that would have led to a poor estimate. If the recharge estimate is incorrect, this may mean that the hydraulic conductivity used for the groundwater model is incorrect.

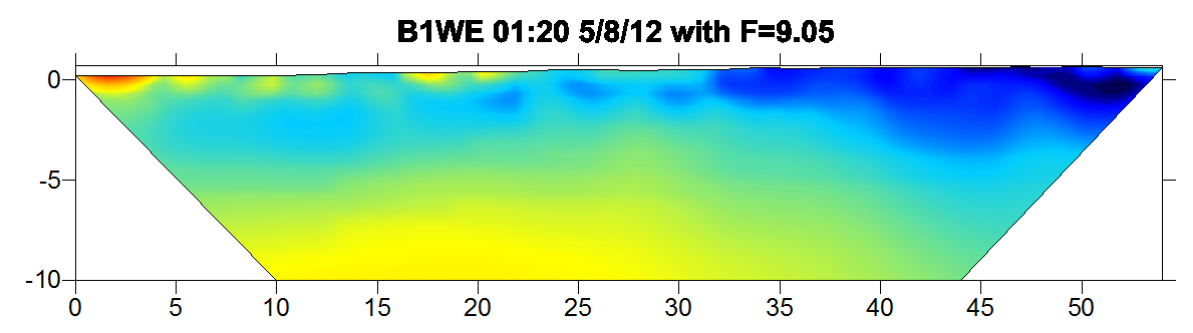

Original Groundwater Model - 2 Hydraulic Conductivity Layers
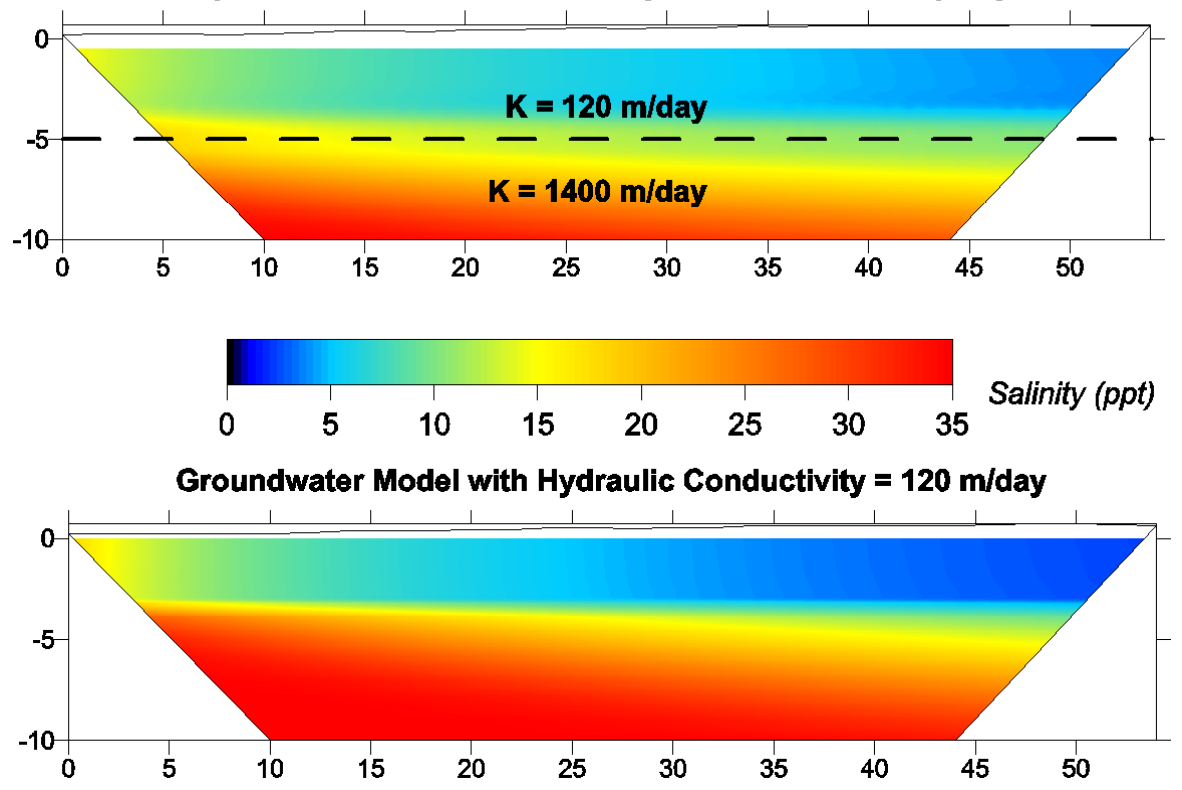

Figure 35 - Comparison of tidal ERT results, the original groundwater model results and new groundwater model with an even hydraulic conductivity of the Miami Oolite for all layers.

Based on the assumption that the hydraulic conductivity may be incorrect, a new steady-state and tidal simulation was conducted with the Key Largo Limestone zone set to the same hydraulic conductivity of the Miami Oolite, $120 \mathrm{~m} /$ day (Figure 35). The new groundwater model has a sharper interface between the freshwater and seawater. This is the opposite of what the ERT salinity results suggest. The hydraulic conductivity of the Key Largo Limestone may need to be increased, $>1400$ m/day, to match the ERT results. Due to the uncertainty of the formation factor and consideration of the contribution of 
high variability in porosity in the Key Largo Limestone, an accurate recalculation of the hydraulic conductivity would require more information which is unavailable with no deep wells near the coast.

\section{Tidal Effects on the Lens}

The tidal changes in the salinity of the groundwater are limited to within $20-30$ $\mathrm{m}$ of the coastline and the results suggest that the primary cause of this is from overland tidal flow. The May 2012 tidal survey on B1WE is the only tidal survey where this was clearly observed. The flooding along the first $14 \mathrm{~m}$ caused by the high tide can be seen as a thin saltwater wedge at the surface that moves inland and back out with the change in tide (Figure 36). As the high tide comes in, a decrease in the salinity takes place a few meters below the wedge and to the east of the wedge but it increases in salinity again as the tide goes out. This fresher water feature may not be real and may be instead be an artifact of the regularization scheme of the inversion algorithm, which has a bias towards a smooth solution.

The saltwater wedge is much more pronounced on the May, 2012 profile compared to the July, 2011 profile because of a greater tidal range. For example, at the Vaca Key tide gauge, the range was $0.1 \mathrm{~m}$ higher during the May, 2012 survey compared to the July 2012 survey (Figure 37). The freshwater in the system increased, too, based on the increase in the well level. At the low tide, the May 2012 measurement is about $0.15 \mathrm{~m}$ higher than the July 2011 survey. This increased freshwater has no clear impact on the tidal changes in salinity but the small increase in the tidal range does have a significant impact. A $10 \mathrm{~cm}$ rise in the tidal range allowed the overland flow to reach over $10 \mathrm{~m}$ 
further inland than the July 2011 survey. The low topographic relief of the island means that small increases in the sea level lead to significant flooding.
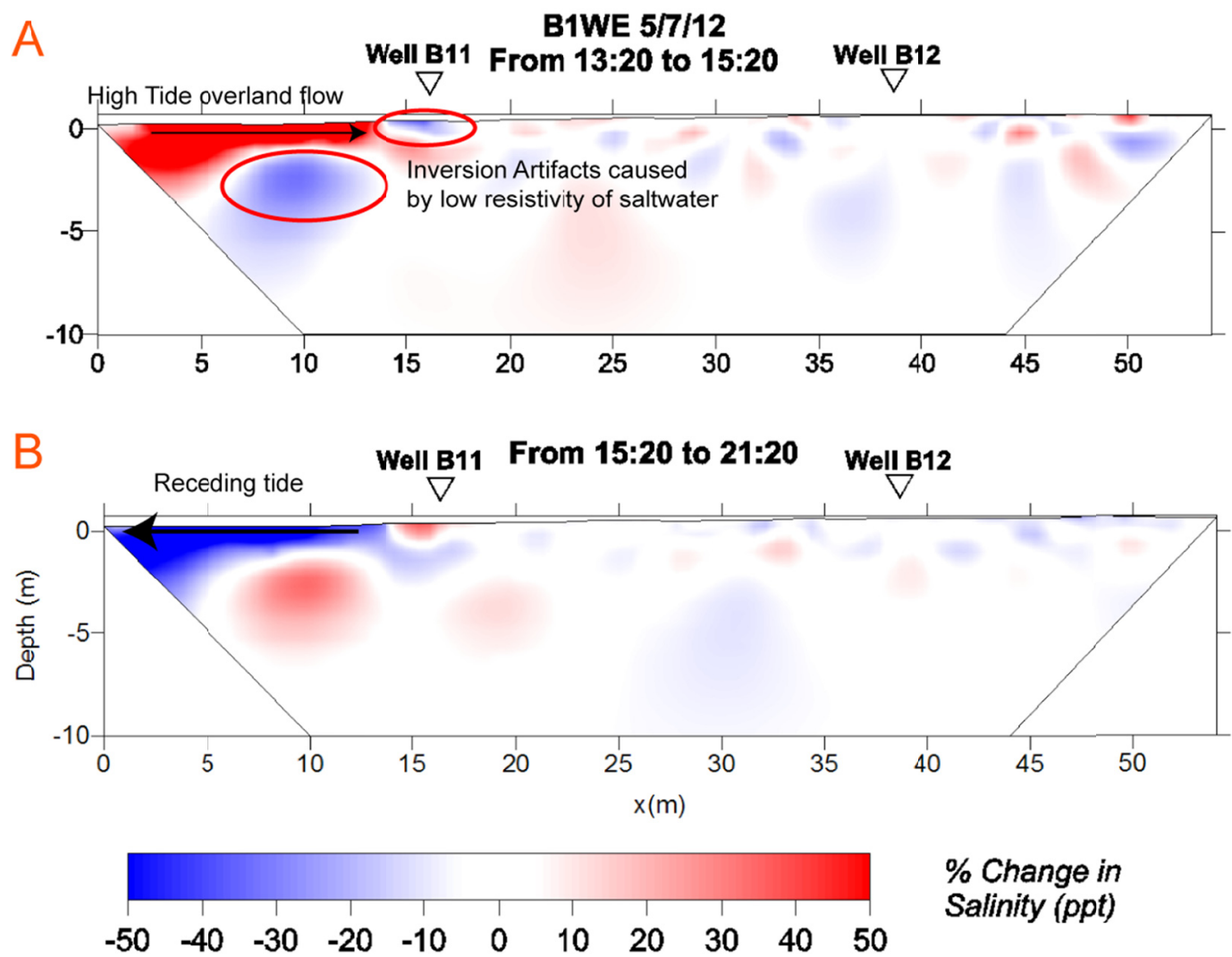

Figure 36 - $A$ is the percent change over the two hours leading up to high tide at 15:20 and $B$ is the percent change from high tide to low tide on 5/7/12 on B1WE. 

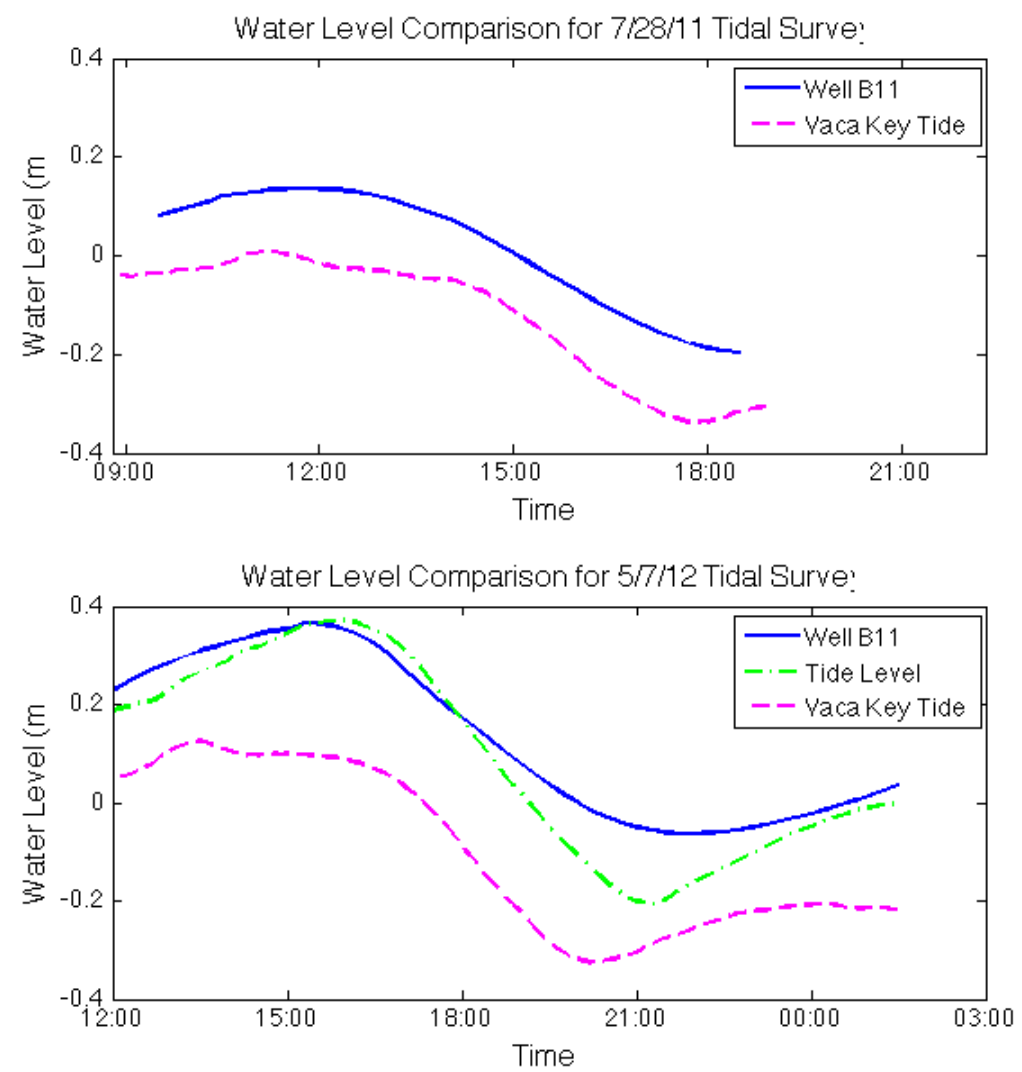

Figure 37 - A comparison of the tide and well water level results for the two B1WE tidal surveys. The tidal range increased for the May 2012 survey by $30 \%$ and the well water level increased $\sim 0.15 \mathrm{~m}$.

In addition to the thin surficial saltwater wedge, a small change in the concentration can be observed in the well conductivity measurements in Well B11 that suggests other tidal mixing. Figure 38 is an example of one of these measurements from the May 2012 survey converted to salinity but Figures 22 and 24 display the same pattern. The salinity follows the groundwater/tide level, increasing and decreasing along with the water level, suggesting a very small shift in the interface follows the tide moving in and out. Then about half way along the tide receding $(\sim 18: 00)$, the salinity reaches its minimum and begins to increase again. This well is located along $16 \mathrm{~m}$ on the profile but, as can be seen on Figure 6, is actually $15 \mathrm{~m}$ south of the profile. This area flooded with the high tide during the surveys in May 2012 and July 2011, which is the likely source of 
the increased salinity. The brackish water from high tide overland flow percolated down with the receding of the tide. Flooding leads to saltwater contamination since the low relief and high porosity/permeability allow some of the saltwater to seep into the ground instead of flowing back out to the ocean. This helps understand why true freshwater, which is usually less than $0.5 \mathrm{ppt}$, was close to non-existent in the previous studies by Hanson (1980) and Wightman (1990 and 2010).

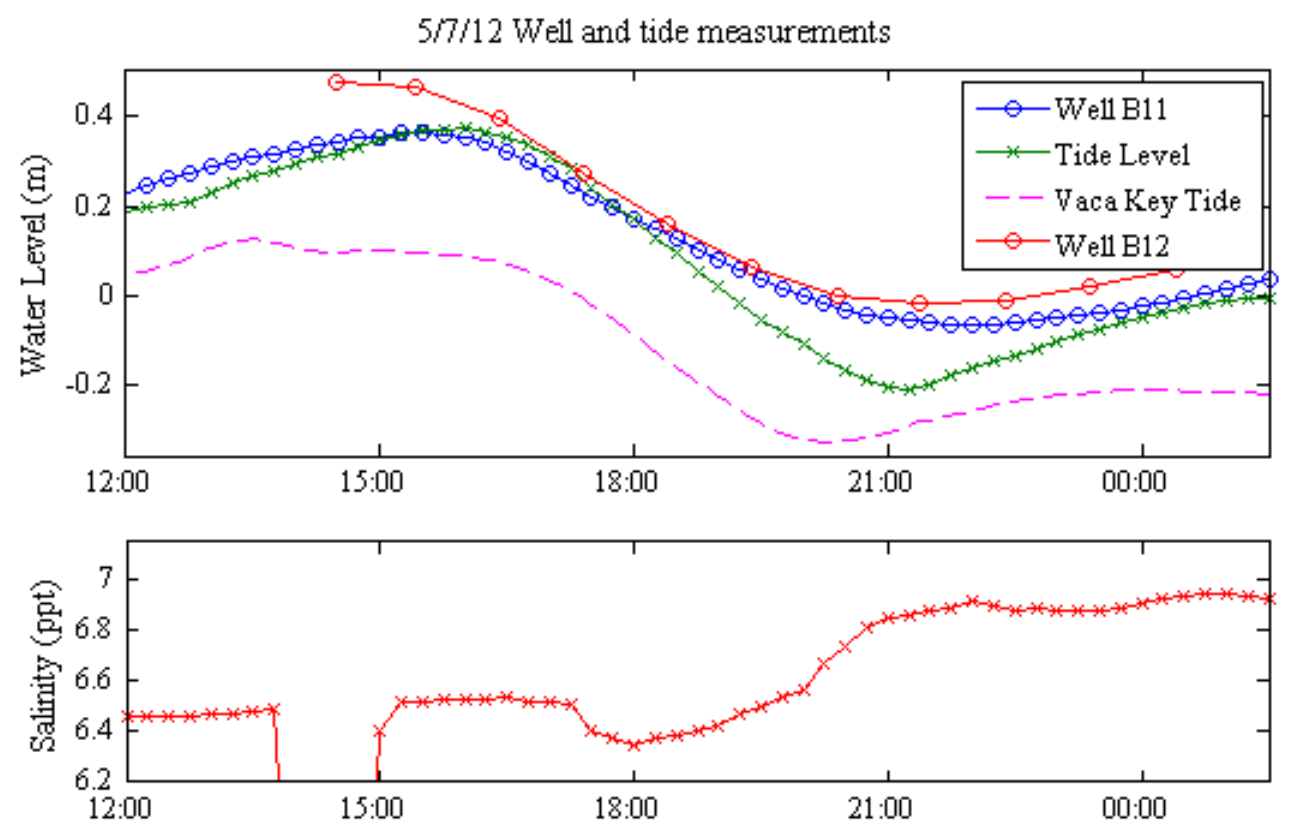

Figure 38 - Well and tide level measurements during the May 2012 tidal survey. The salinity is converted from the conductivity measurements from Well B11.

The computer groundwater model does not compare well with the July 2011 and May 2012 measurements on B1WE. The largest problem with the groundwater model was that the overland flow at high tide was not simulated. The May 2012 high tide does show that the saltwater boundary intrudes a little further inland than the July 2011 high tide measurement but only by $\sim 3 \mathrm{~m}$ (Figure 37 ). The overland flow is clearly what 
contributes to the saltwater wedge observed in the ERT salinity profiles but was not simulated in the groundwater model. The increase in freshwater available in the May 2012 survey was not taken into account for these groundwater models. This might account for why the model shows that the lens was pressed upwards with the high tide on the May 2012 simulation compared to the July 2011 simulation. This was not observed in the ERT salinity profile, which is likely due to the larger inland freshwater head for this measurement.
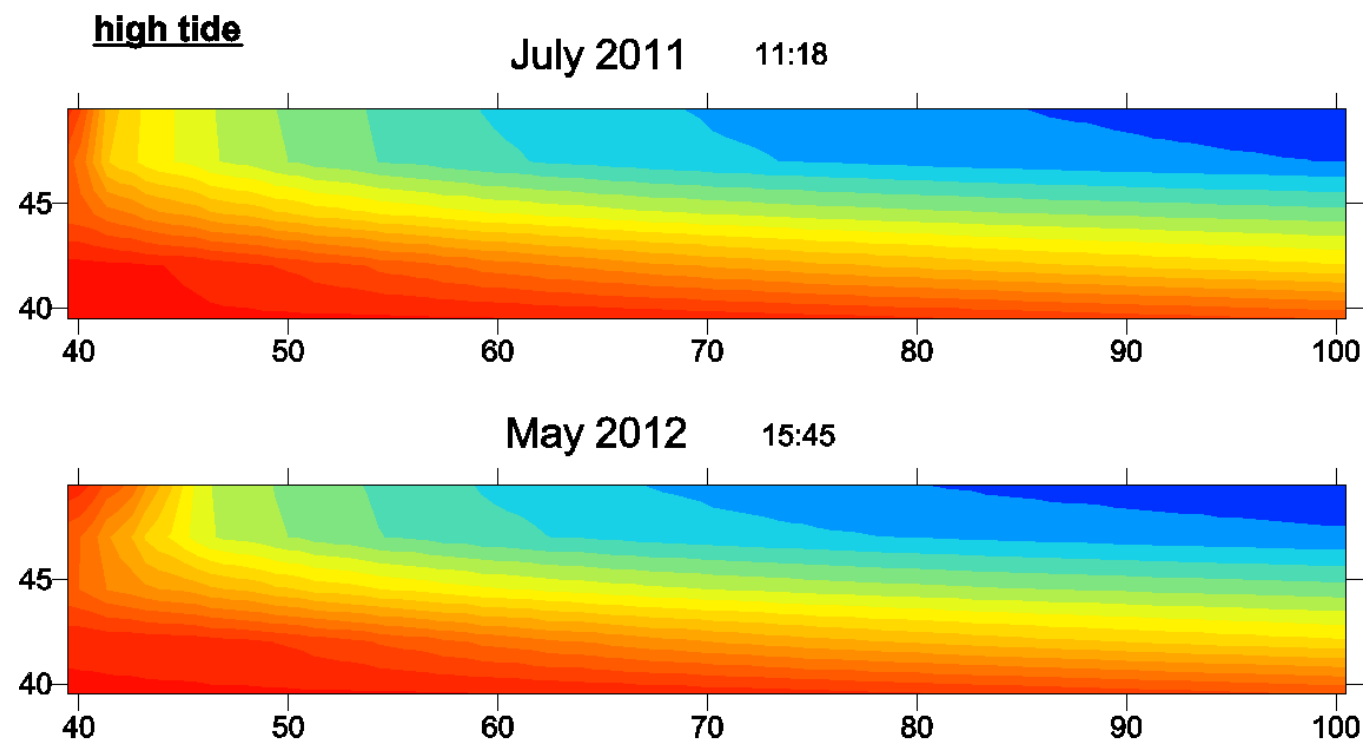

Figure 39 - High tide comparison of the two SEAWAT simulations of the B1WE tide measurements.

\section{Comparison of Separate Inversion and Difference Inversion}

The results of separate and time-lapse inversion were compared for the May 2012 B1WE profiles to determine which inversion scheme worked best. The first few ERT inversion results can be seen in Figure 40 and the full set of both can be found in Appendix A. The starting model for each was the same. The first two time steps with both inversion schemes are very similar with the exception of some small changes that 
can be seen in the percent difference of the time-lapse inversion. Then at the 14:20 timestep, the separate inversion deviates greatly from the previous time-step, while the timelapse inversion stays similar to the previous time-step model. A similar thing happens with the following time-step except that the separate inversion output does not deviate as strongly from the first time-step. These deviations occurred a few times for the remainder of the separate inversions. All of the separate inversions with large deviations took more time to converge and more iterations than the ones with small deviation from the first two time-steps.

These differences between the separate inversion and difference inversion could be due to a few reasons. LaBrecque et al. (1996) noted that the first set of measurements for permanently installed electrodes tends to be the noisiest. Due to the decreased $\mathrm{a}_{\text {weight }}$ and $b_{\text {weight }}$ used for the difference inversion, the first time step percent change in resistivity is a more sensitive to this noise than the percent change in the separate inversion model. This is reflected in all of the other time-lapse surveys for the percent change between the first two time steps, as can be seen in Appendix A. The larger weighting used in the separate inversion decreases that effect whereas the difference inversion does not. For the remainder of the time steps the difference inversion was more sensitive to the small tidal changes. The difference inversion profiles did not deviate much since the inversion had a background model of the previous time-step. Separate inversion uses a homogenous background model and attempts to converge to a local minimum between that background model and the final model. This can lead to small or large deviations depending on the measurements. The large deviation at 14:20 may be from the tide that began to flood the first few meters of the profile. The inversion over- 
compensated for the extreme low in resistivity at the surface at the beginning of the profile with a high resistivity region immediately below it. The other deviations are smaller and are likely due to noise in the measurement. Difference inversion seems to be the better choice for discerning smaller changes.

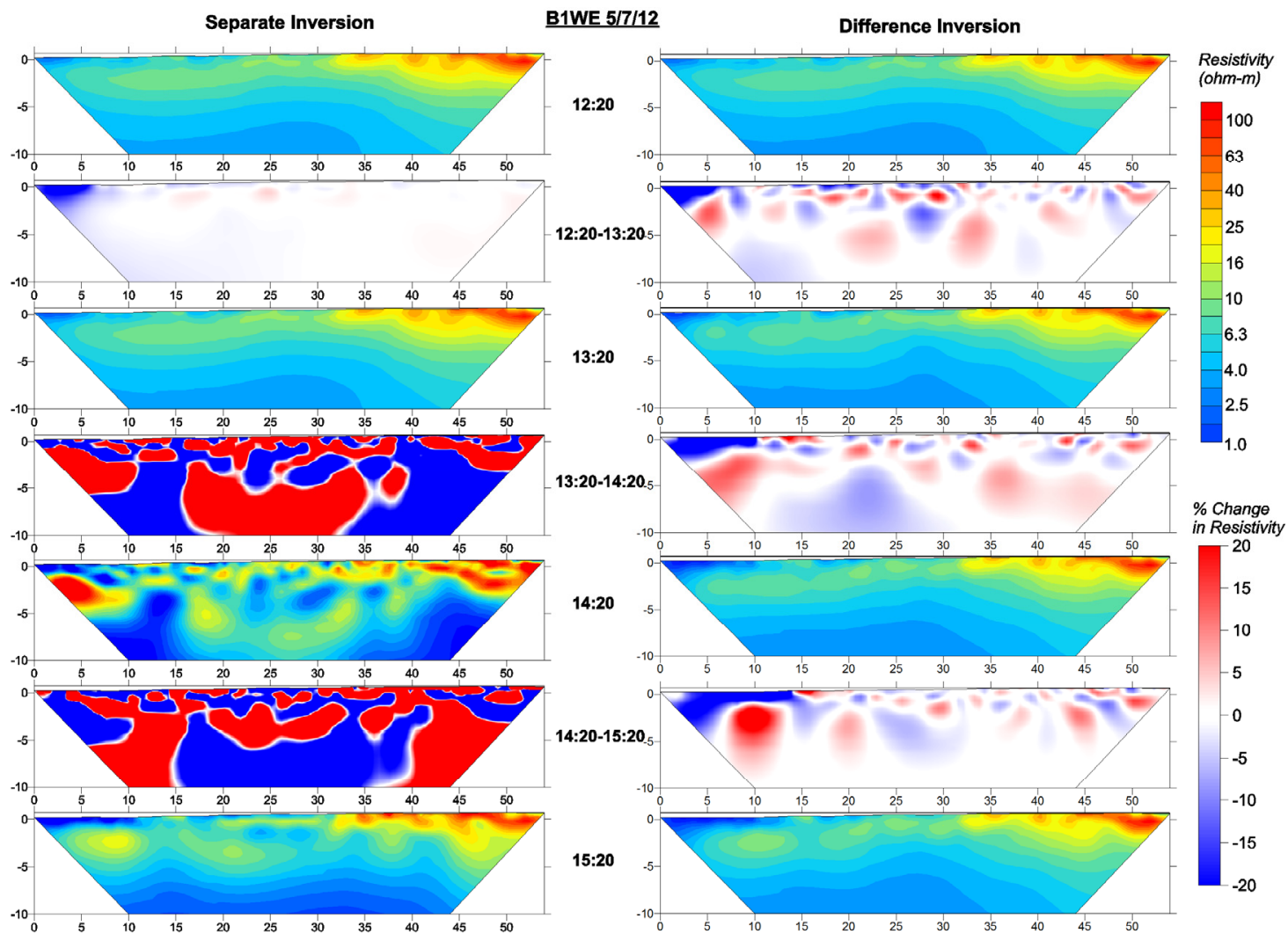

Figure 40 - Comparison of the two ERT inversion results leading up to high tide from 12:20 to 15:20. The separate inversions produce different models which makes smaller changes difficult to see.

The separate and time-lapse inversions produced for the Big Pine Key seasonal profiles are a little different. Along B1 (Figure 8) and B3 (Figure 10), both inversion types produced a similar percent difference. Yet, the inversion results for B2 do not show the same percent change (Figure 9). The difference between the December models is visible without the aid of the percent difference plot. The difference model result for December produced a resistivity distribution with the least difference from the starting 
model, the May results. Without the starting model, the separate inversion determines the best distribution based on a homogenous forward model. It does not mean that the modeled resistivity is any less correct since the May result could be incorrect but the amount of change that occurred over the season will be more accurate with the difference inversion.

The difference inversion provides the best results for analyzing the amount of change over a time series for both the seasonal and tidal results. The separate inversions do not always deviate far from the difference inversions but when they do, the percent change between the time-steps is most likely inaccurate. For the small changes that occur in these time-series, the difference inversion is the best option. If an accurate starting model were used, the separate inversions could be made more accurate. A starting model for ERT measurements would be difficult to produce and possibly inaccurate, though. Wightman's two studies from 1990 and 2010 show that there is a great deal of deviation in the lens between the seasons and on a yearly basis, which is a problem for the seasonal profiles. The tidal profiles are located on the transition zone with no sharp boundaries to easily create a forward model from. The groundwater model results would be a good basis for a forward model if the groundwater model had produced more accurate results. Therefore in the case of this study, the difference inversion was the best choice. 


\section{CONCLUSIONS}

Tidal changes to the groundwater salinity on Big Pine Key are small and limited to within 20 to $30 \mathrm{~m}$ of the coast. The changes are caused by thin saltwater wedge at the surface caused by the overland flow of the tide. The extent of this overland flow is dictated by the magnitude of the tide. Due to the low topographic relief of the island, a small change in the magnitude causes a large increase in the inland extent of this tidal flooding. The low relief and the permeable nature of the rock allow some of this saltwater to seep down into the groundwater before receding with the tide.

The groundwater model did a not replicate the ERT salinity tidal surveys. The largest problem may be that no attempt was made to model the overland flow caused by the high tide. The groundwater model predicted higher salinities at depth than the ERT salinity profiles indicated as well. This discrepancy is most likely due to inaccuracies in the input parameters for the groundwater model based on Wightman (1990). If the recharge estimate was inaccurate when producing the DGH model by Wightman, then the hydraulic conductivities likely need to be changed to compensate. Additionally, finer gridding may aid in addressing the tidal groundwater dynamics along the coastal boundary.

Difference inversion proved to be superior method for change analysis for both the tidal and seasonal profiles. While the separate inversion did work for some of the seasonal profiles and for a few of the tidal profiles, the deviations caused large, unrealistic changes where none were present in the difference inversion. A good starting model would help the separate inversions. Starting models can be derived from groundwater models but the groundwater model developed in this study may be 
insufficient. With no starting model and small changes to detect, the difference inversion is the best even when the surveys are taken months apart.

This study suggests that the normal tidal mixing along the natural coastline of this island, and likely the rest of the Lower Keys, is small and relatively insignificant. Yet, the tidal effect is highly sensitive to small increases in the magnitude. This has broader implications when applied to storm surge and sea level rise. Storm surge would easily cause significant saltwater contamination and may be why freshwater is difficult to find even in the center of the island. Sea level rise impact can already be seen on the island in areas of vegetation die off. The tide associated with the sea level rise creates a brackish boundary of over $20 \mathrm{~m}$ beyond the mid-tide level. 


\section{REFERENCES}

Beaudoin, C. M. (1990). "Effects of Dredge and Fill Canals on Fresh-water Resources of a Small Oceanic Island, Big Pine Key, Florida.” M.S. thesis, University of South Florida, Tampa, Fl.

Binley, A., (2011). R2: 2-D inversion of resistivity data. Summary. Available from http://www.es.lancs.ac.uk/people/amb/Freeware/R2/R2 summary.htm (verified 23.01.12) Lancaster University, Lancaster, UK.

Binley, A. and Kemna., A. (2005). "DC Resistivity and Induced Polarization Methods." Hydrogeophysics. Ed. Y. Rubin and S.S. Hubbard. Netherlands: Springer, 129-156. Print.

Constable, S. C., Parker, R. L., \& Constable, C. G. (1987). “Occam's inversion: A practical algorithm for generating smooth models from electromagnetic sounding data." Geophysics, 52(3), 289-300.

Coniglio, M., and Harrison, R. S. (1983). "Facies and diagenesis of late Pleistocene carbonates from Big Pine Key, Florida." Bulletin of Canadian Petroleum Geology 31.3 : 135 -147. Print.

Cowardin, L. M., Carter, V., Golet, F. C., and LaRoe, E. T. (1979). "Classification of wetlands and deepwater habitats of the United States. "U.S. Department of the Interior, Fish and Wildlife Service, Washington, D.C. Jamestown, ND: Northern Prairie Wildlife Research Center Online. http://www.npwrc.usgs.gov/resource/wetlands/classwet/index.htm

Cunningham, K. J., Sukop, M. C., Huang, H., Alvarez, P. F., Curran, H. A., Renken, R. A., and Dixon, J. F. (2009). "Prominence of ichnologically influenced macroporosity in the karst Biscayne aquifer: Stratiform 'super-K' zones." Geological Society of America Bulletin 121.1-2 : 164-180.

Fitterman, D.V., Deszcz-Pan, M., and Prinos, S.T. (2012). "Helicopter electromagnetic survey of the Model Land Area, Southeastern Miami-Dade County, Florida." U.S. Geological Survey Open-File Report 2012-1176, 77 p.

Guo, W., and Langevin, C. D. (2002). "User's guide to SEAWAT: A computer program for simulation of three-dimensional variable-density ground-water flow", U.S. Geological Survey Open File, 01-434.

Halley, R. B., Vacher, H.L. and Shinn, E. (1997). "Geology and Hydrogeology of the Florida Keys." Geology and hydrogeology of carbonate islands. Ed. H. Leonard Vacher and Terrence M. Quinn. Amsterdam ; New York : Elsevier,: 217-248 
Hanson, C E. (1980). "Freshwater Resources of Big Pine Key, Florida." Tallahassee, Fla: U.S. Dept. of the Interior, Geological Survey, Print.

Hayley, K., Pidlisecky, A. and Bentley, L.R. (2011). "Simultaneous time-lapse electrical resistivity inversion." Journal of Applied Geophysics 75.2: 401-411.

Hoffmeister, J. E. (1974). The Florida Keys: Land From the Sea. Coral Gables, FL: University of Miami Press.

Hurt, G. W., Noble, C. V. and Drew, R. W. (1995). "Soil survey of Monroe County, Keys Area, Florida." University of Florida Digital Collections. http://ufdc.ufl.edu/UF00025712/00001

Kwader, T. (1986). "The Use of Geophysical Logs for Determining Formation Water Quality." Ground Water 24.1: 11-15.

LaBrecque, D. J., Miletto, M., Daily, W., Ramirez, A. and Owen, E. (1996). "The effects of noise on Occam's inversion of resistivity tomography data": Geophysics, 61, 538548.

LaBrecque, D. J., and Yang, X. (2001). "Difference Inversion of ERT Data: a Fast Inversion Method for 3-D In Situ Monitoring." Journal of Environmental and Engineering Geophysics 6.2: 83-89.

Langevin, C.D., and Beaudoin, C.M. (1998). "Effects of sea water canals on fresh water resources: an example from Big Pine Key, Florida." Ground Water 36.3: 503+. Academic ASAP. Web. 2 Mar. 2011.

Meadows, D. G., Caballero, J.P., Kruse, S. E., and Vacher, H. L. (2004). "Variation of salinity in brackish-water lenses of two Florida Keys." Journal of Coastal Research 20: $386+$.

Morrow, F.J., Ingham, M.R. and McConchie, J.A. (2010). "Monitoring of tidal influences on the saline interface using resistivity traversing and cross-borehole resistivity tomography." Journal of Hydrology 389.1-2: 69-77.

Mulligan, A. E., Langevin, C., and Post, V.E.A. (2011). "Tidal Boundary Conditions in SEAWAT." Ground Water 49.6: 866-879.

Ogurcak, D. (2010). “The Influence of Disturbance, Seasonality, and Hydrogeologic Controls on Plant Communtiy Boundary Dynamics in the Lower Florida Keys." Unpublished manuscript, Florida International University, Miami, Fl.

Pidlisecky, A., and Knight, R. (2008). "FW2_5D: A MATLAB 2.5-D electrical resistivity modeling code." Computers \& Geosciences 34.12: 1645-1654. 
De Franco, R., Biella, G., Tosi, L., Teatini, P., Lozej, A., Chiozzotto, B., ... \& GasparettoStori, G. (2009). "Monitoring the saltwater intrusion by time lapse electrical resistivity tomography: The Chioggia test site (Venice Lagoon, Italy)" Journal of Applied Geophysics 69: 117-130

Radtke, D.B., Davis, J.V., and Wilde, F.D., eds. (2005), "Specific electrical conductance (version 1.2)": U.S. Geological Survey Techniques of Water-Resources

Investigations, book 9, chap. A6, section 6.3, 22 p. http://water.usgs.gov/owq/FieldManual/Chapter6/6.3_contents.html

Randazzo, A. F., and Halley, R. B. (1997). "Geology of the Florida Keys." The Geology of Florida. Ed. Anthony F. Randazzo and Douglas S. Jones. Gainesville, FL : University Press of Florida: 251-259.

Robbin, D. M., and Stipp, J.J. (1979). "Depositional rate of laminated soilstone crusts, Florida Keys.” Journal of Sedimentary Research 49.1: 175 -178.

Robinson, R. B. (1967). "Diagenesis and Porosity Development in Recent and Pleistocene Oolites from Southern Florida and the Bahamas." Journal of Sedimentary Research 37.2: 355-364.

Stewart, M. (1988). "Electromagnetic Mapping of Fresh-Water Lenses on Small Oceanic Islands." Ground Water 26.2: 187-191.

Swarzenski, P. W., Burnett, W. C., Greenwood, W. J., Herut, B., Peterson, R., Dimova, N., .. \& Weinstein, Y. (2006). "Combined time-series resistivity and geochemical tracer techniques to examine submarine groundwater discharge at Dor Beach, Israel." Geophys. Res. Lett. 33.24: L24405.

Tiab, D., and Donaldson, E. C. (2004). Petrophysics: Theory and Practice of Measuring Reservoir Rock and Fluid Transport Properties. Boston: Gulf Professional Pub. Print

Vacher, H. L. and Wallis, T.N. (1992). "Comparative Hydrogeology of Fresh-Water Lenses of Bermuda and Great Exuma Island, Bahamas.” Ground Water 30: 15-20.

Vacher, H. L. and Ayers, J. F. (1980). "Hydrology of small oceanic islands - Utility of an estimate of recharge inferred from chloride concentration of the fresh-water lenses." Journal of Hydrology v.39: 21-37

Wagner, R.J., Boulger, R.W., Jr., Oblinger, C.J., and Smith, B.A., (2006). “Guidelines and standard procedures for continuous water-quality monitors-Station operation, record computation, and data reporting": U.S. Geological Survey Techniques and Methods 1-D3, 51 p. +8 attachments; http://pubs.water.usgs.gov/tm1d3

Whitaker, F. F. and Smart, P. L. (1997) "Hydrogeology of the Bahamian Archipelago." Geology and hydrogeology of carbonate islands. Ed. H. Leonard Vacher and Terrence M. Quinn. Amsterdam ; New York : Elsevier: 183-216 
Wightman, M. J. (1990). "Geophysical Analysis and Dupuit-Ghyben-Herzberg Modeling of Fresh-water Lenses on Big Pine Key, Florida.” M.S. thesis, University of South Florida, Tampa, Fl.

Wightman, M. J. (2010). "Geophysical and Hydrogeological Study of Freshwater Lenses of Big Pine Key, FL.” St. Petersburg, FL: GeoView, Inc. 
APPENDIX A: Tidal ERT Results

\section{Line B1WE 7/28/11 Difference Inversion Results}

ERT results are plotted in $\log 10$ scale. Percent change in the resistivity over the time steps is plotted between each ERT result. 


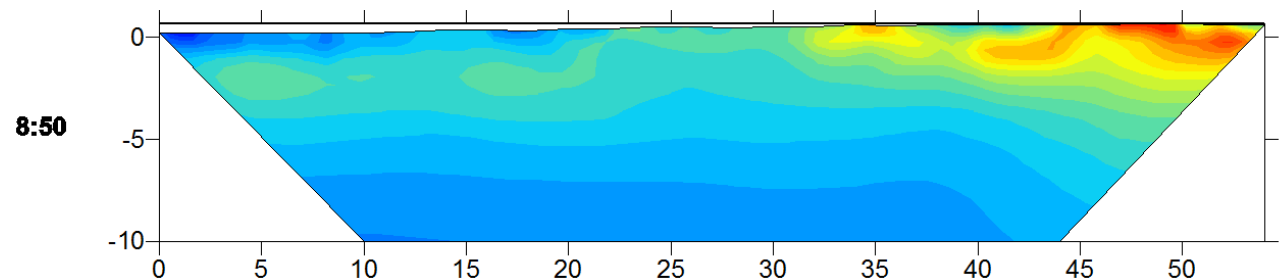

Resistivity
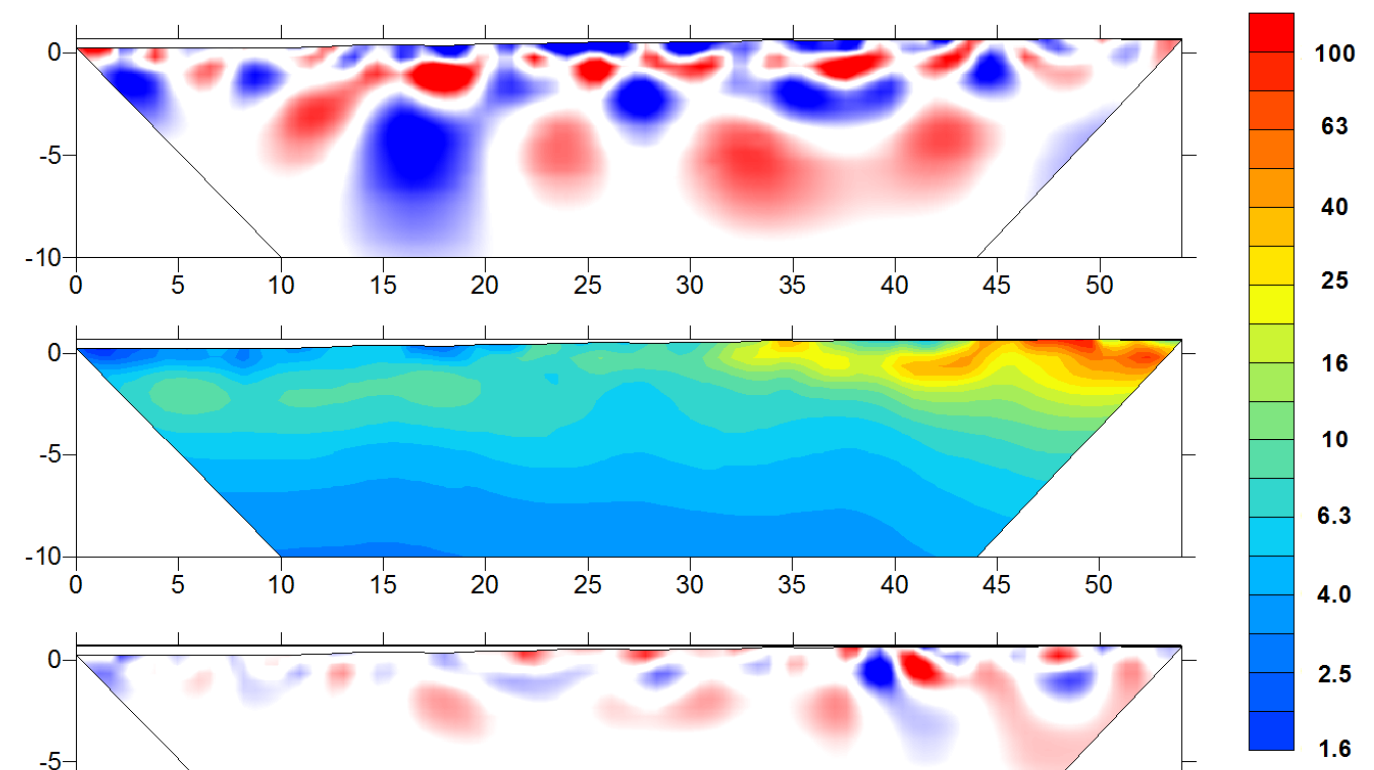

9:50
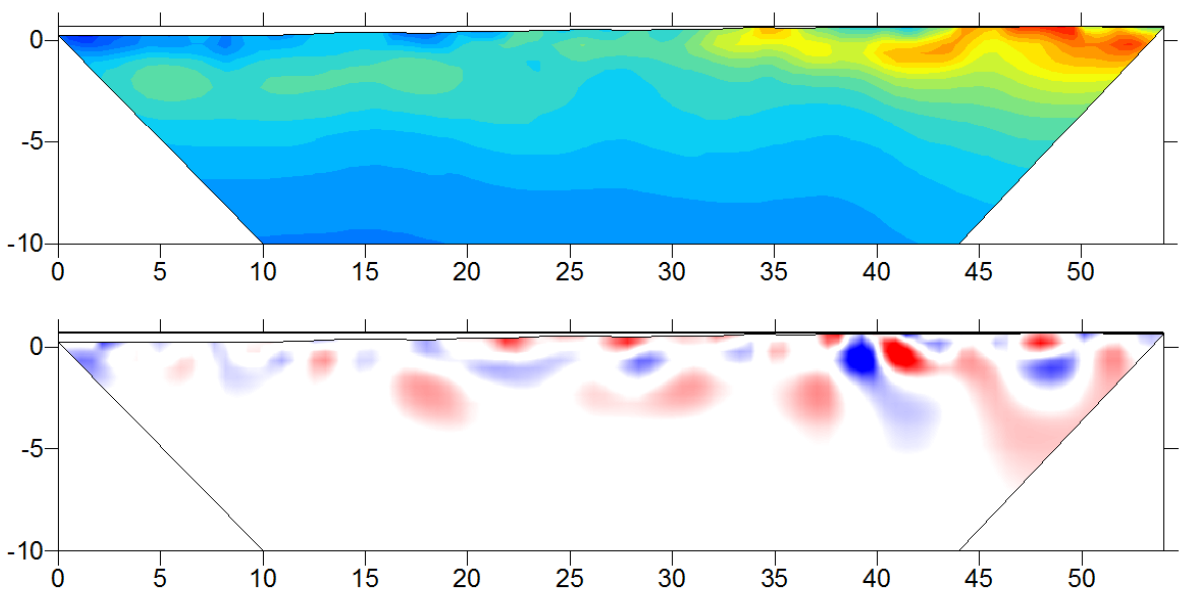

\% change in Resistivity

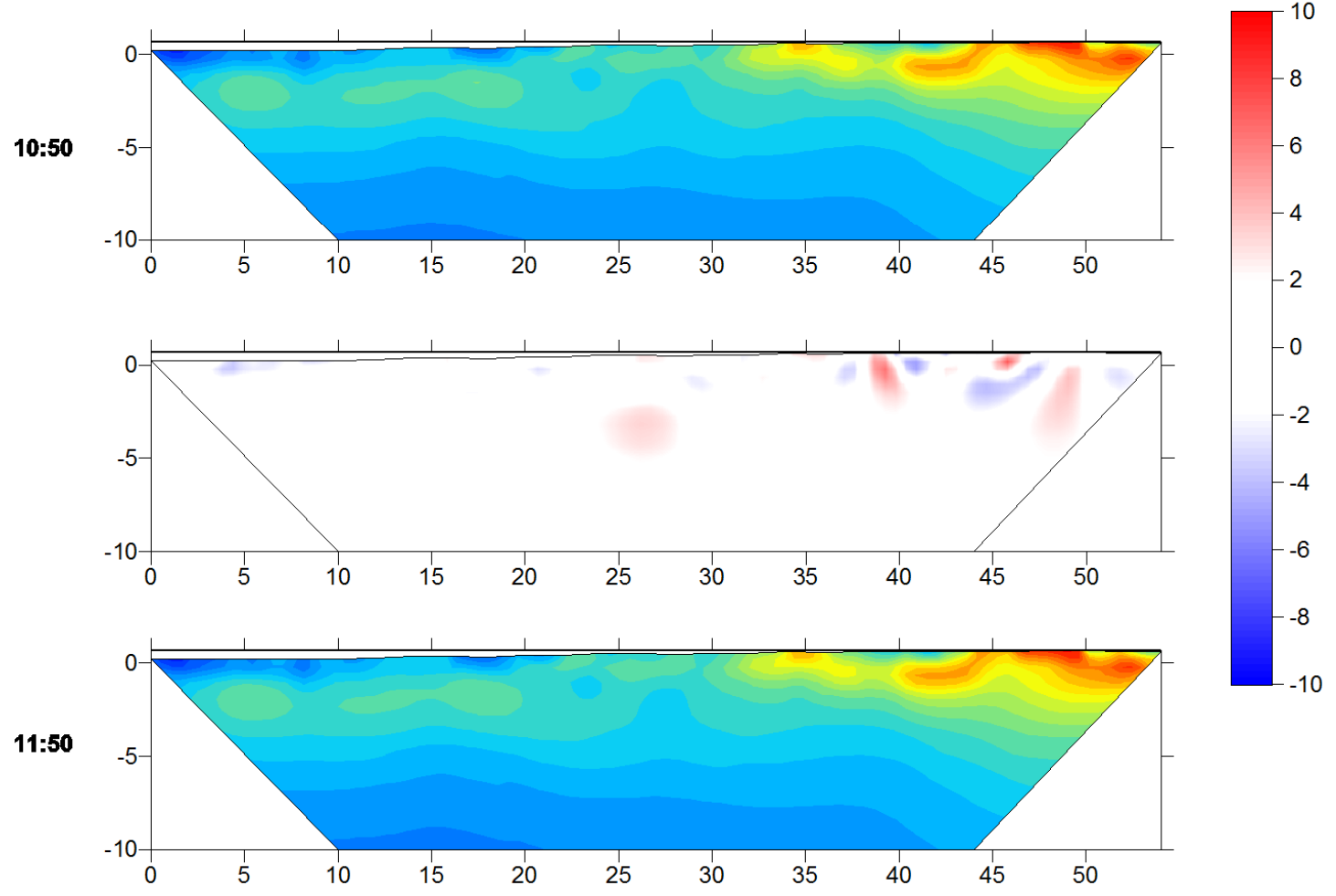




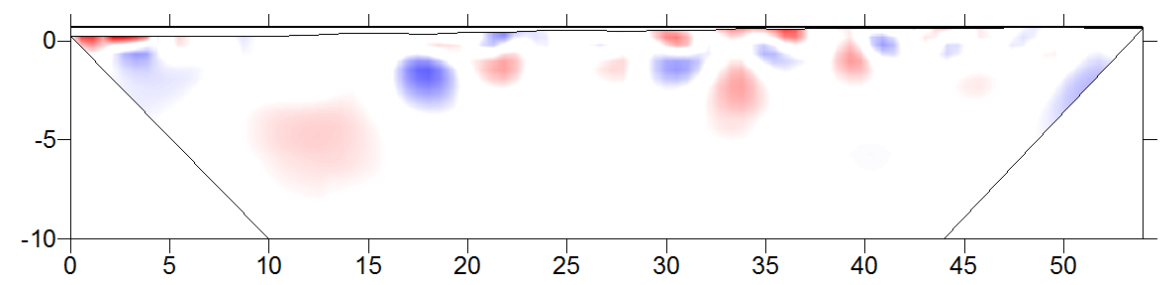

$12: 50$

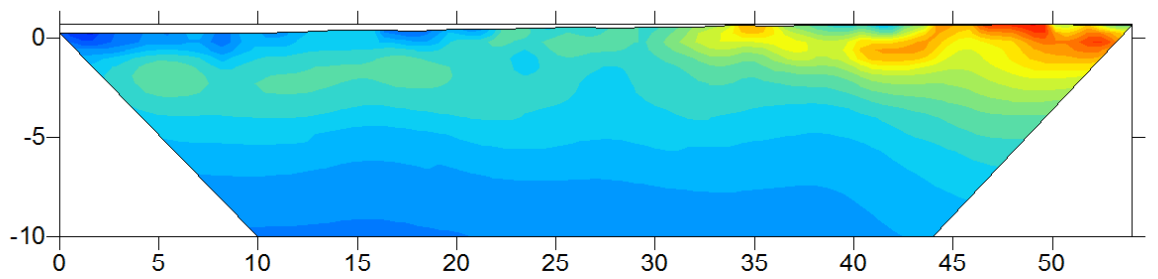

Resistivity

(ohm-m)

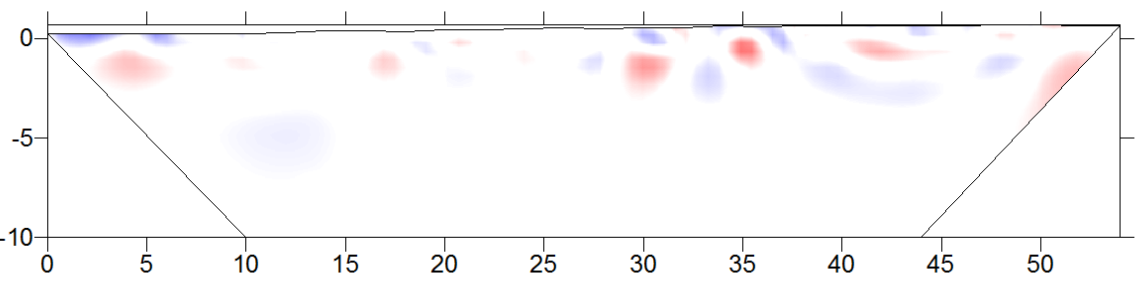

13:50
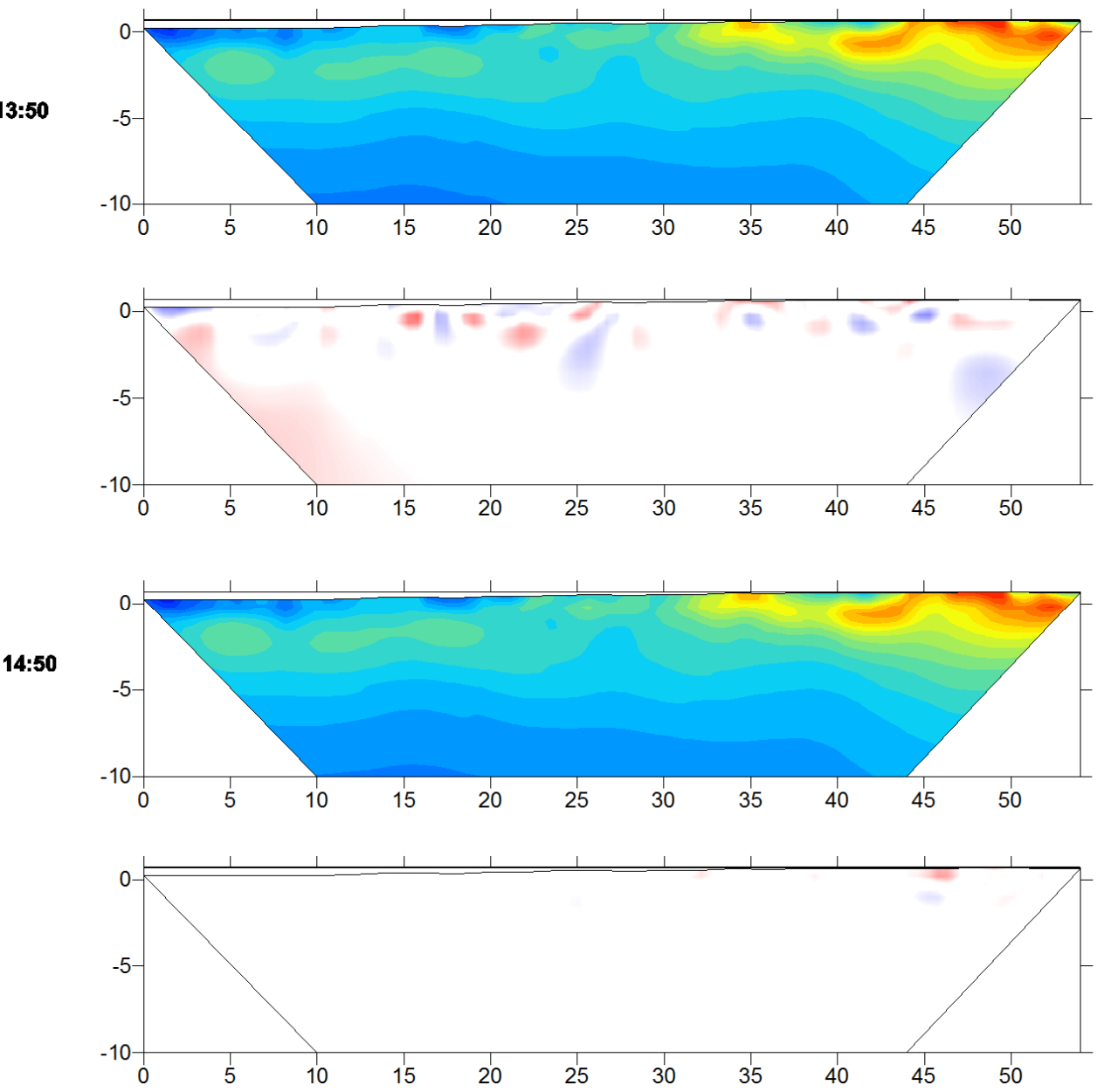

$\%$ change

in Resistivity

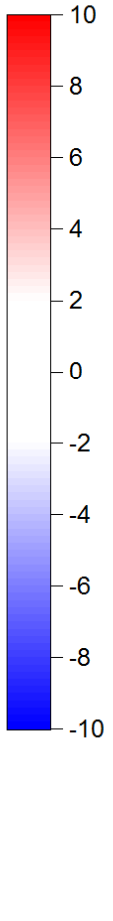




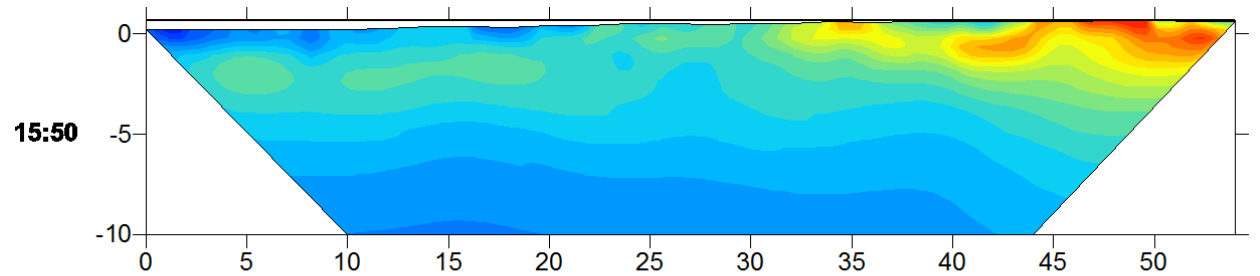

Resistivity
(ohm-m)
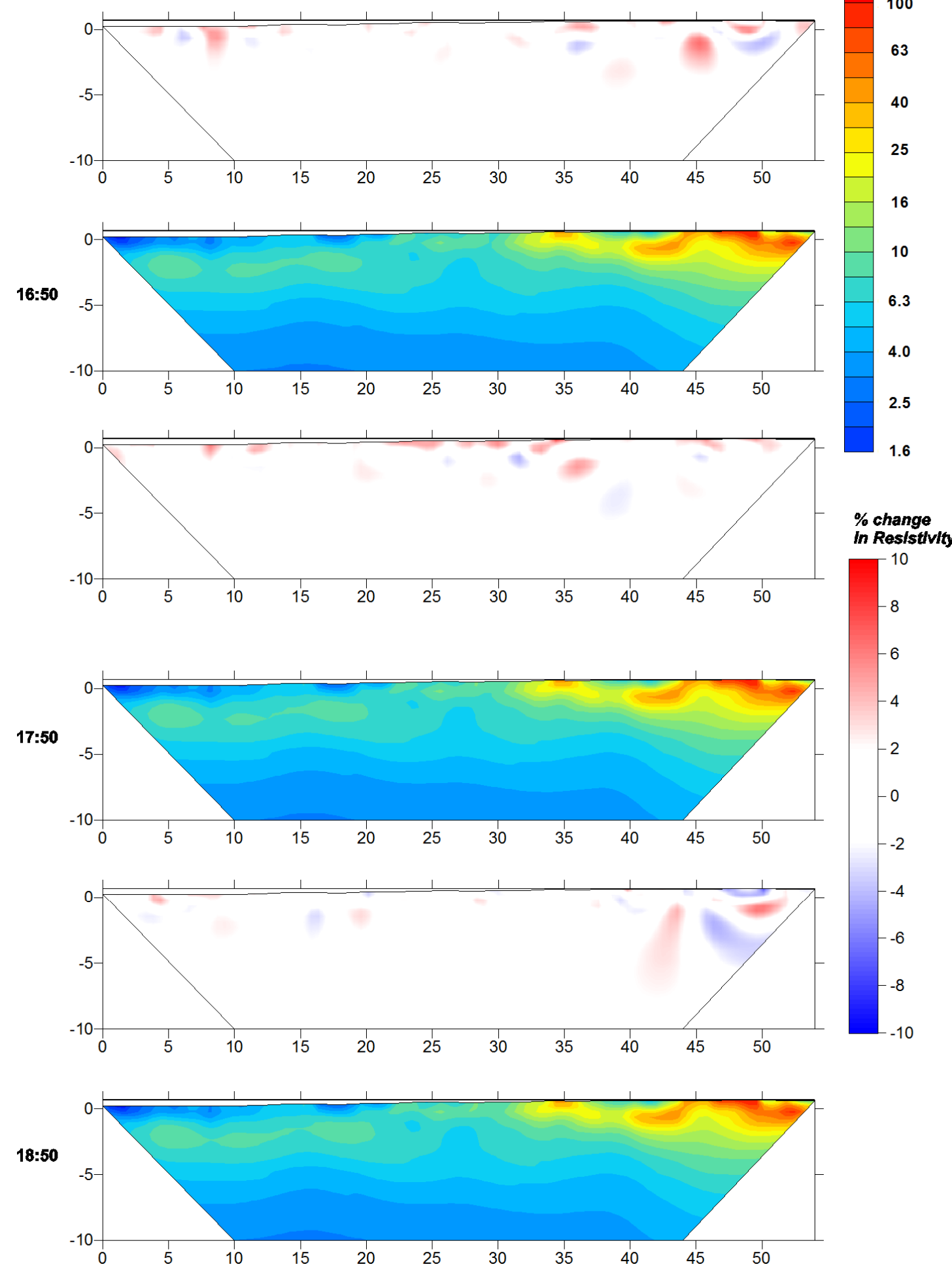


\section{Line B1NS 7/29/11 Difference Inversion Results}

ERT results are plotted in $\log 10$ scale. Percent change in the resistivity over the time steps is plotted between each ERT result. 


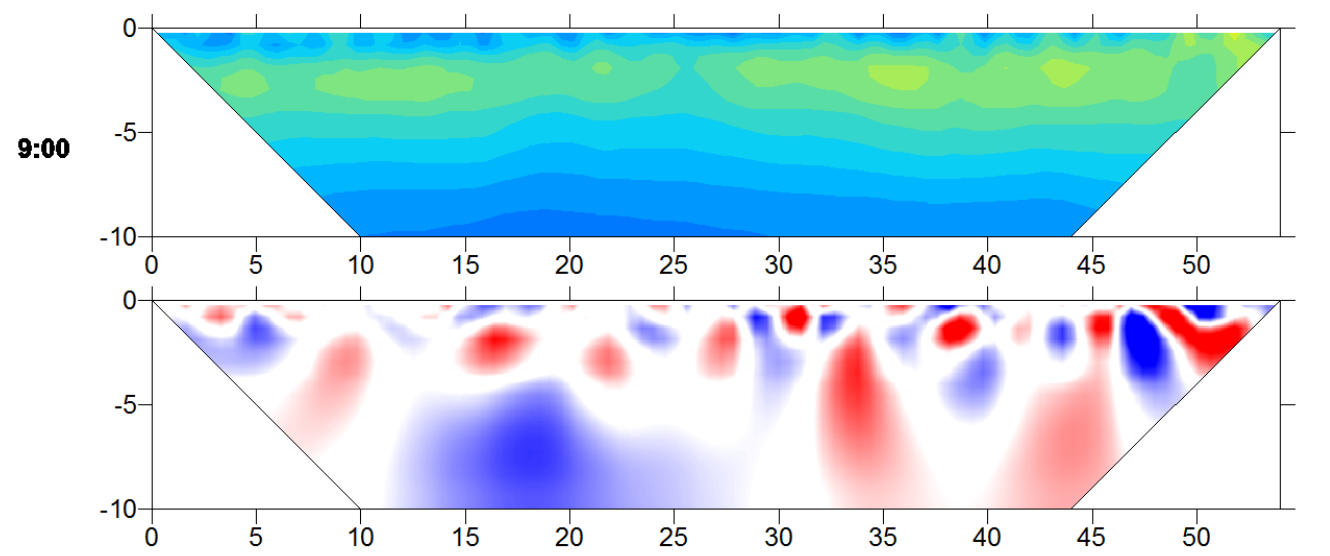

Resistivity

(ohm-m)
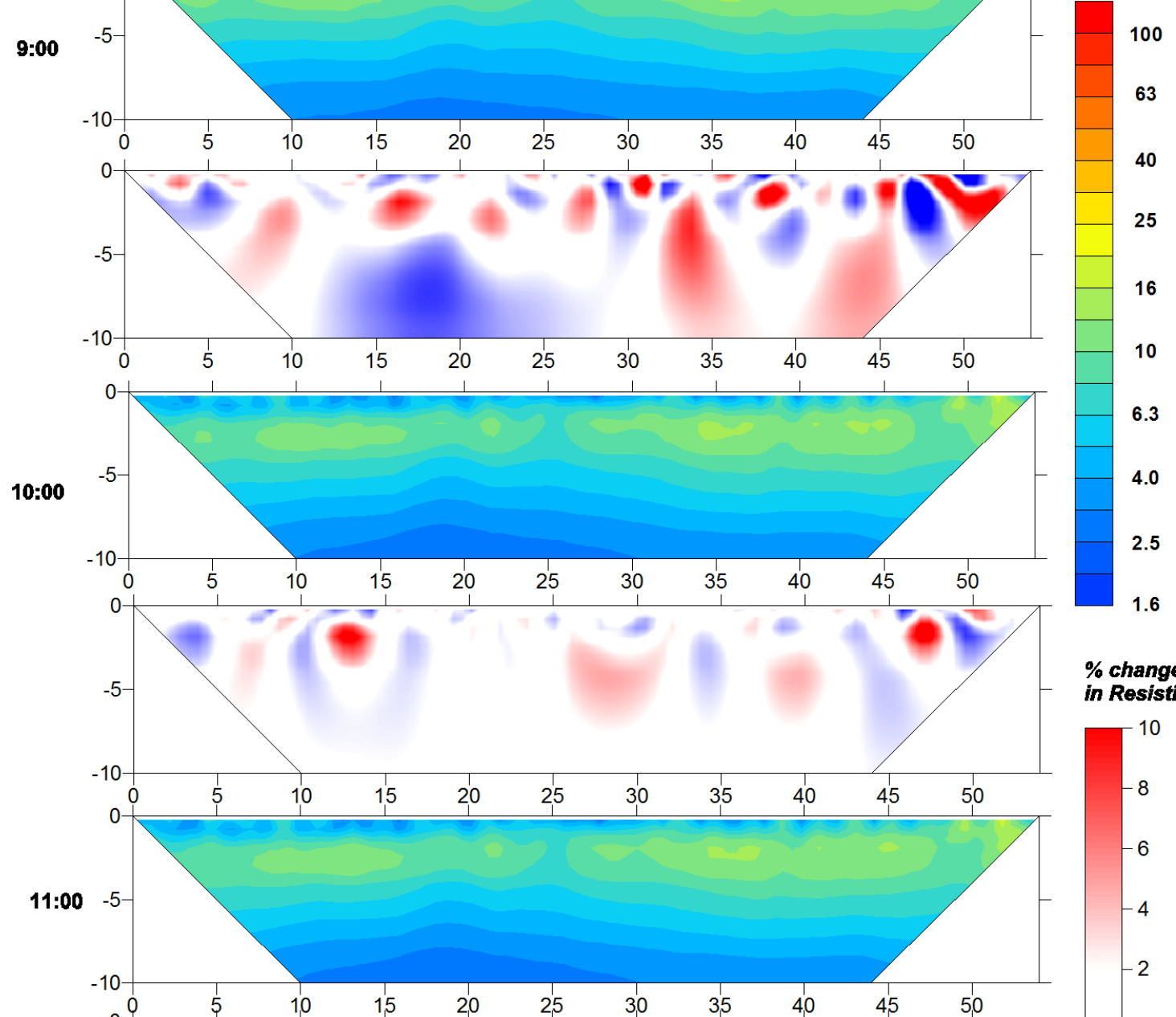

\section{$\%$ change} in Resistivity

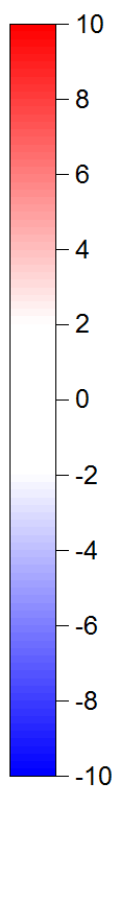




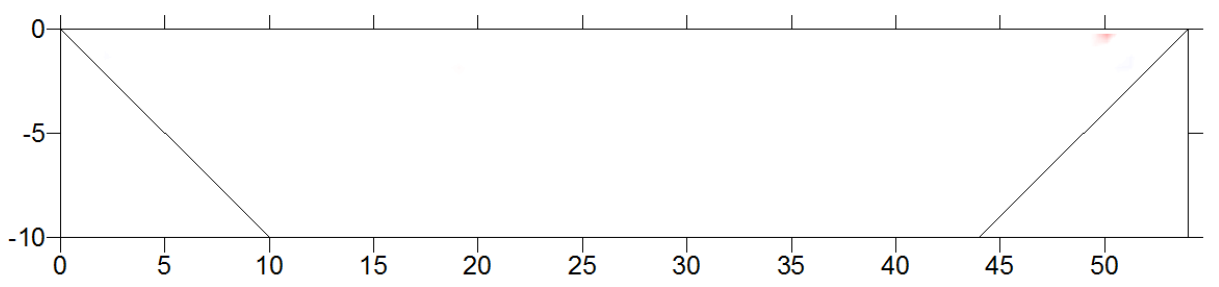

Resistivity

(ohm-m)

100

63

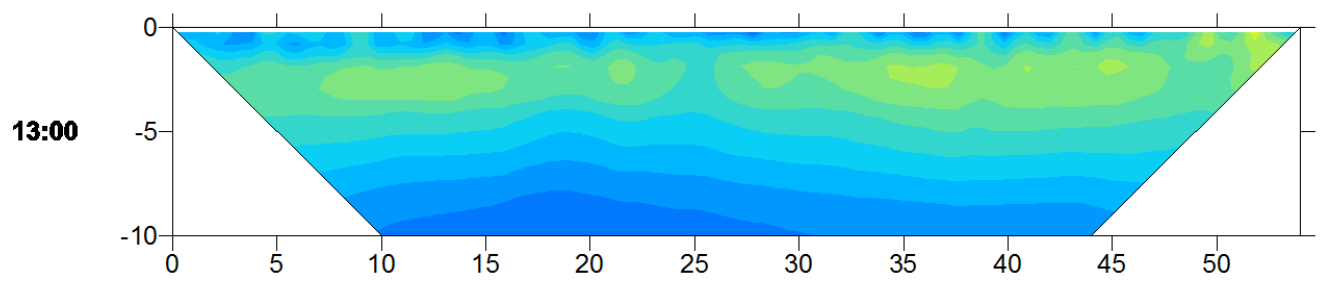

40

25
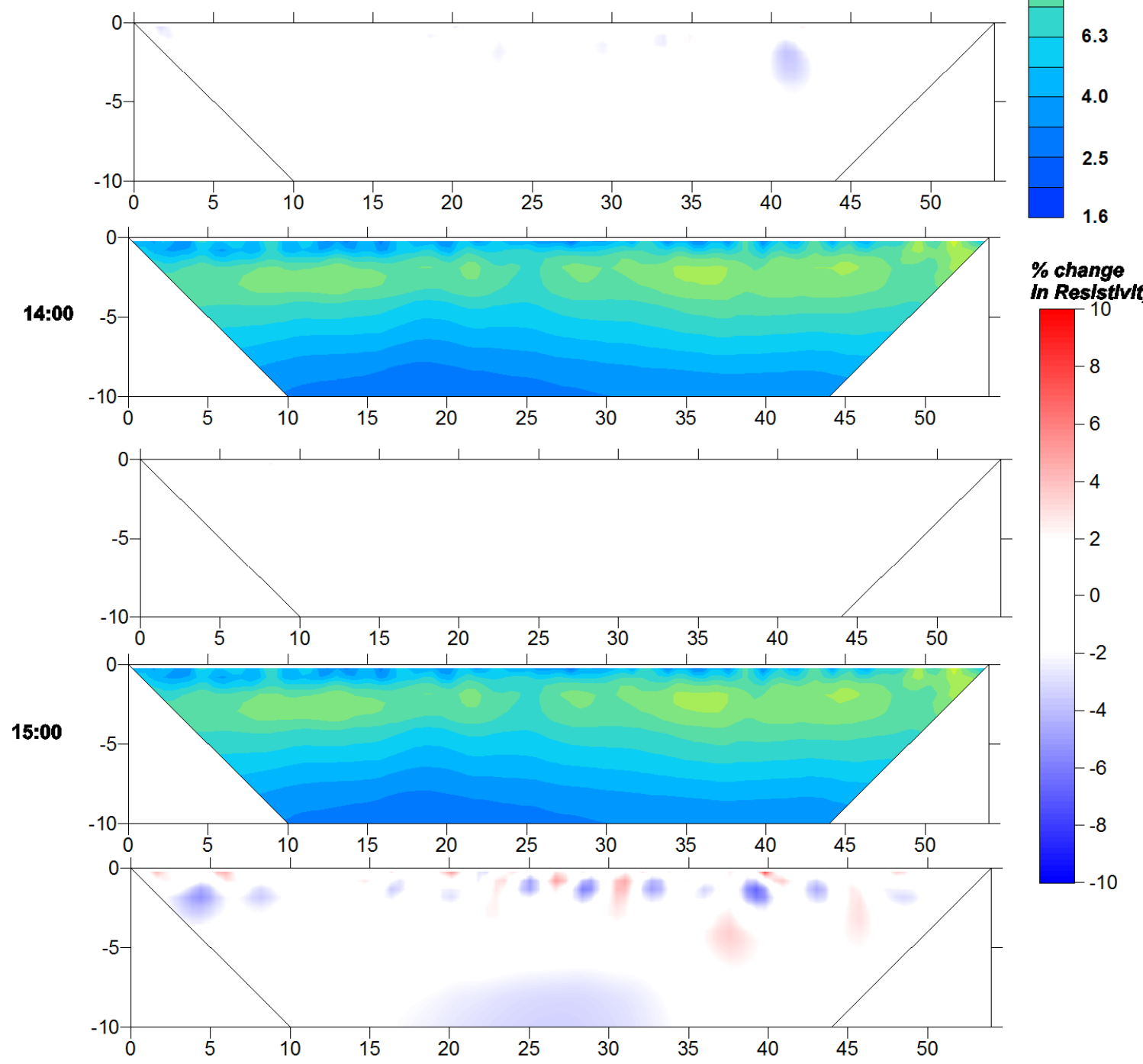

$\%$ change

In Resistlvity 


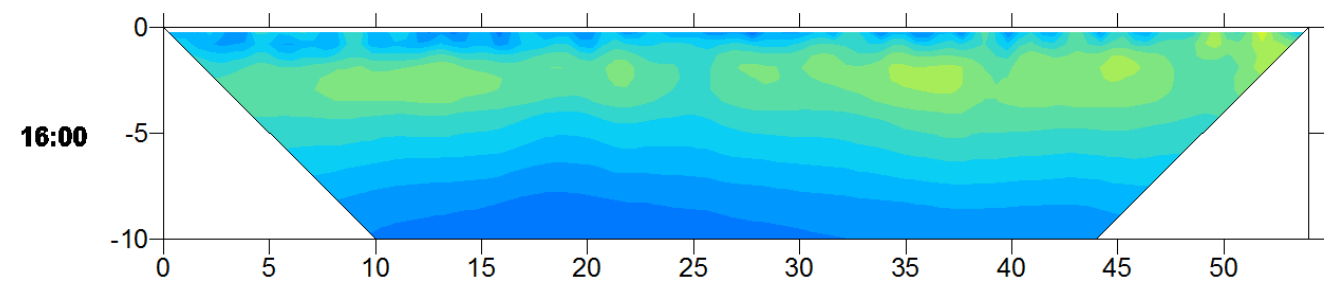

Resistivity

(ohm-m)
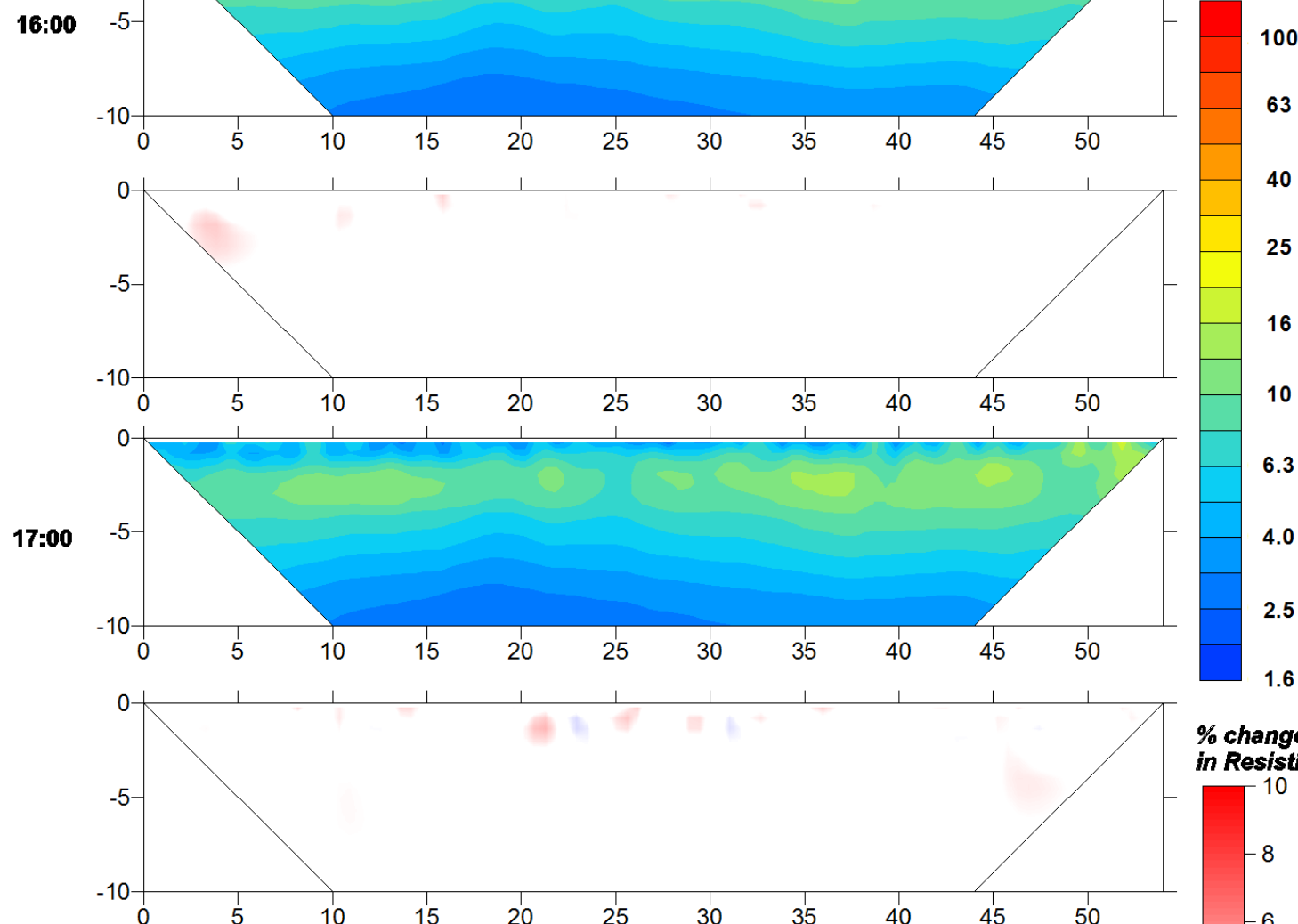

$\%$ change

in Resistivity

T 10

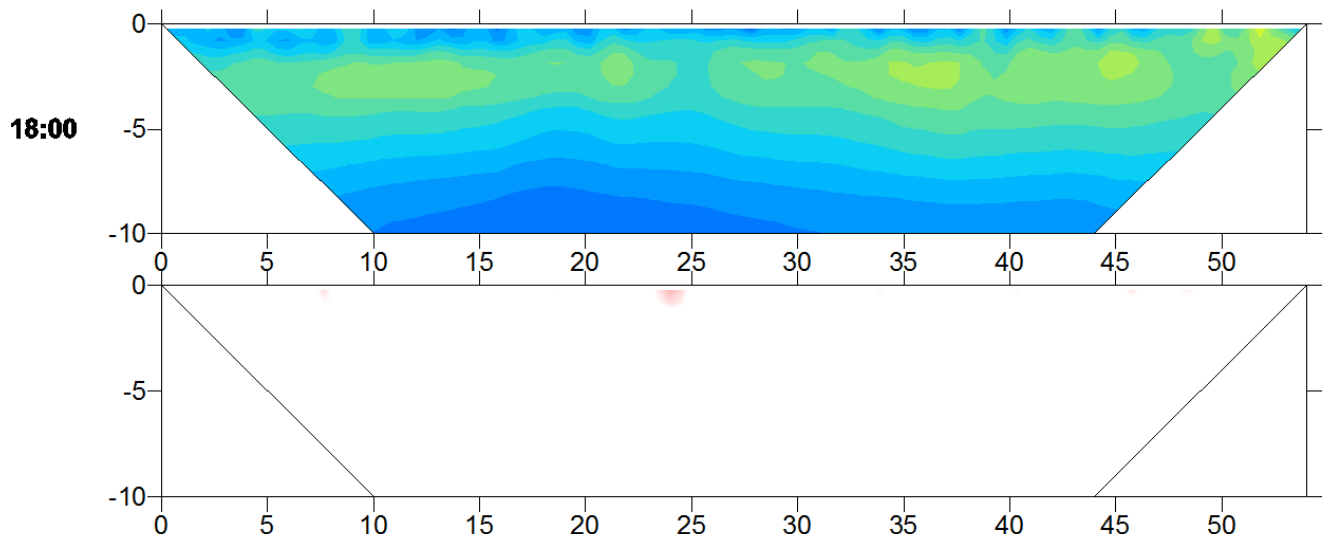

$-8$

$-6$

$-4$

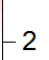

$-0$

$-2$

$-4$

$-6$

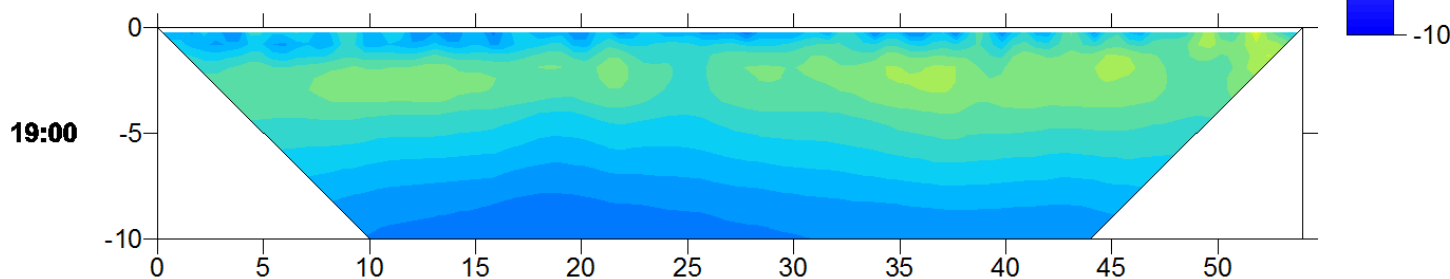




\section{Line B1WE 5/7/12 Separate Inversion Results}

ERT results are plotted in $\log 10$ scale. Percent change in the resistivity over the time steps is plotted between each ERT result. 


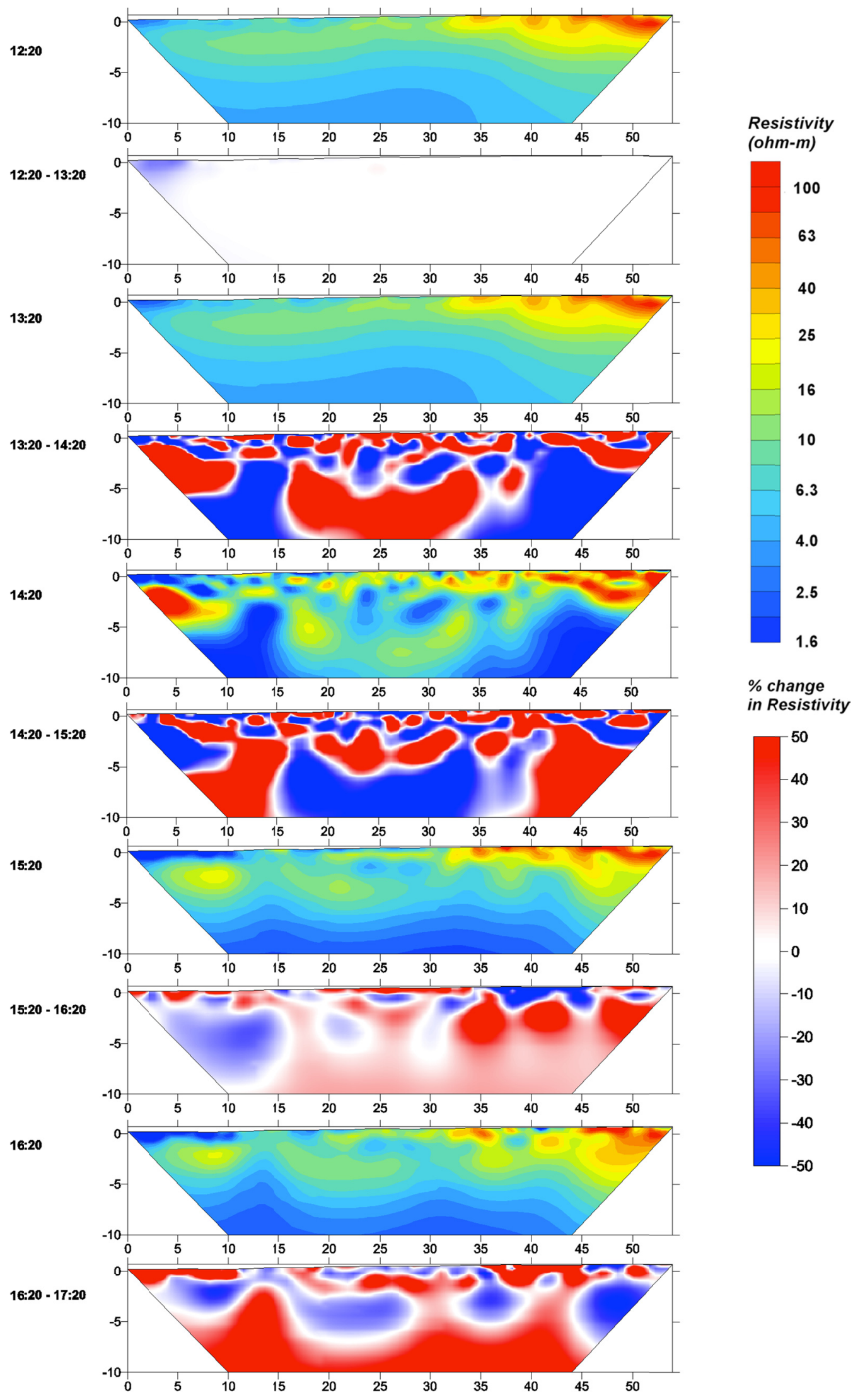



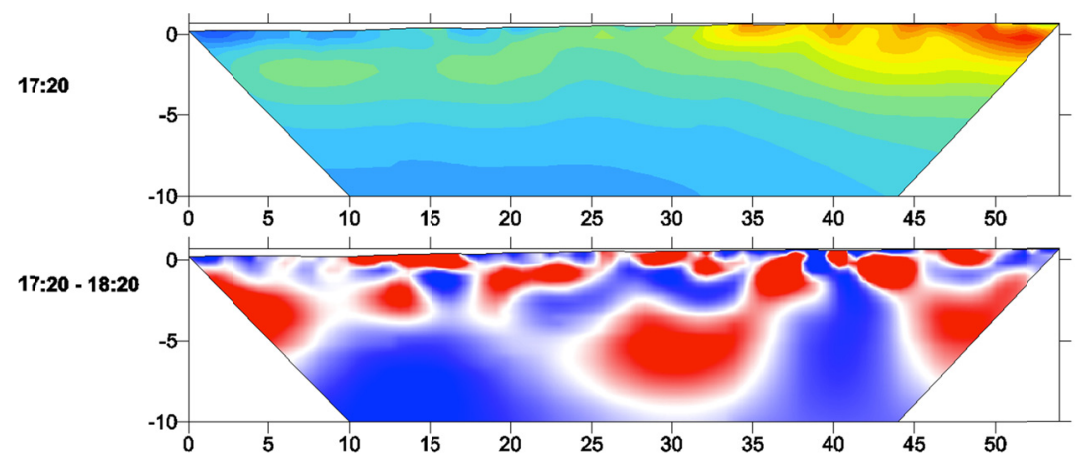

Resistivity

(ohm-m)

18:20
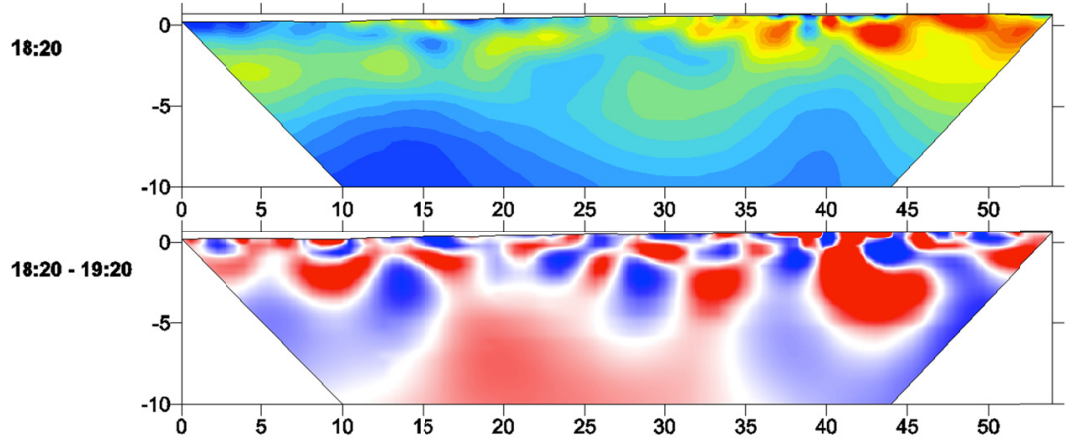

19:20
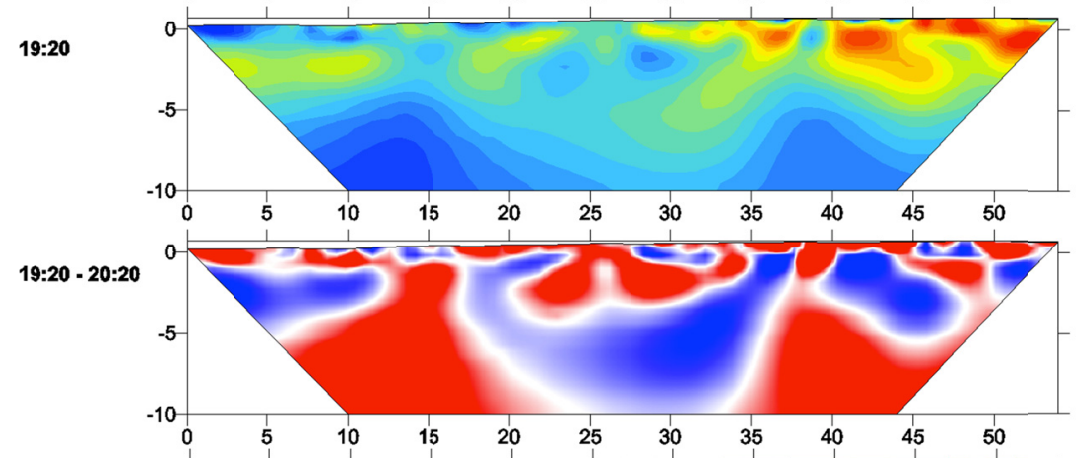

20:20
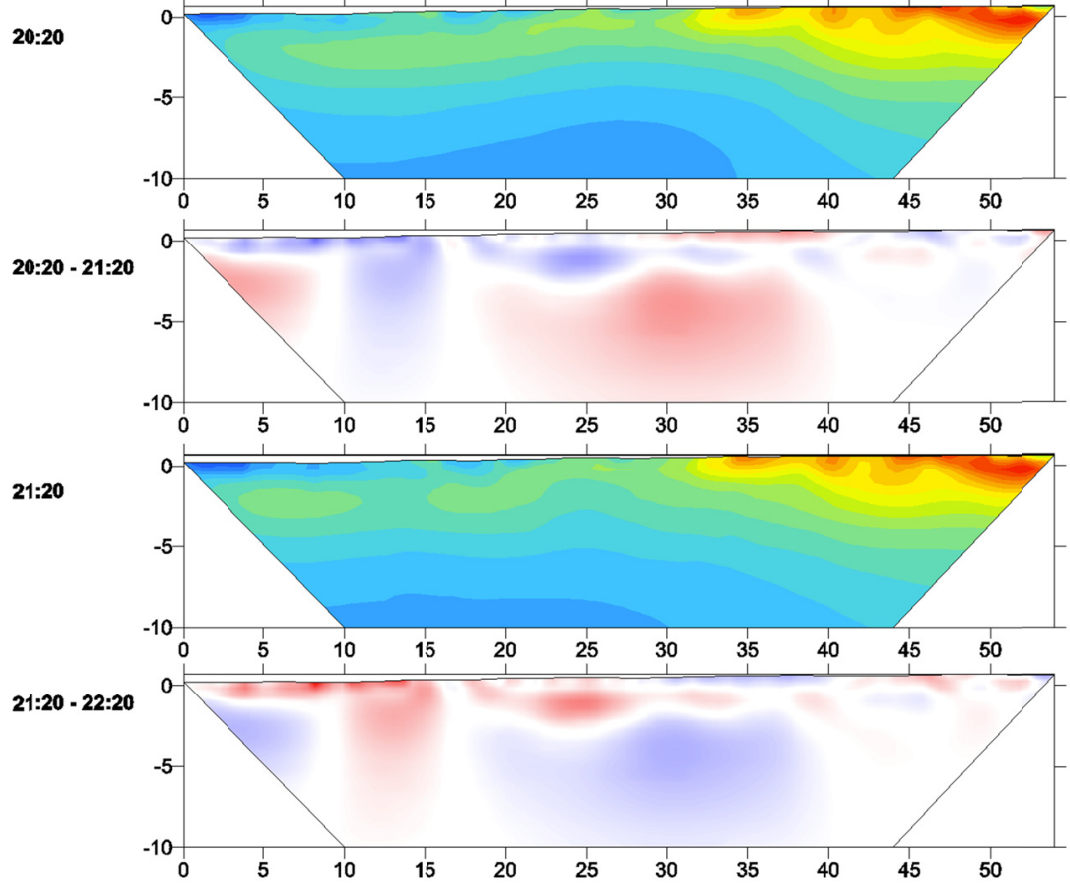

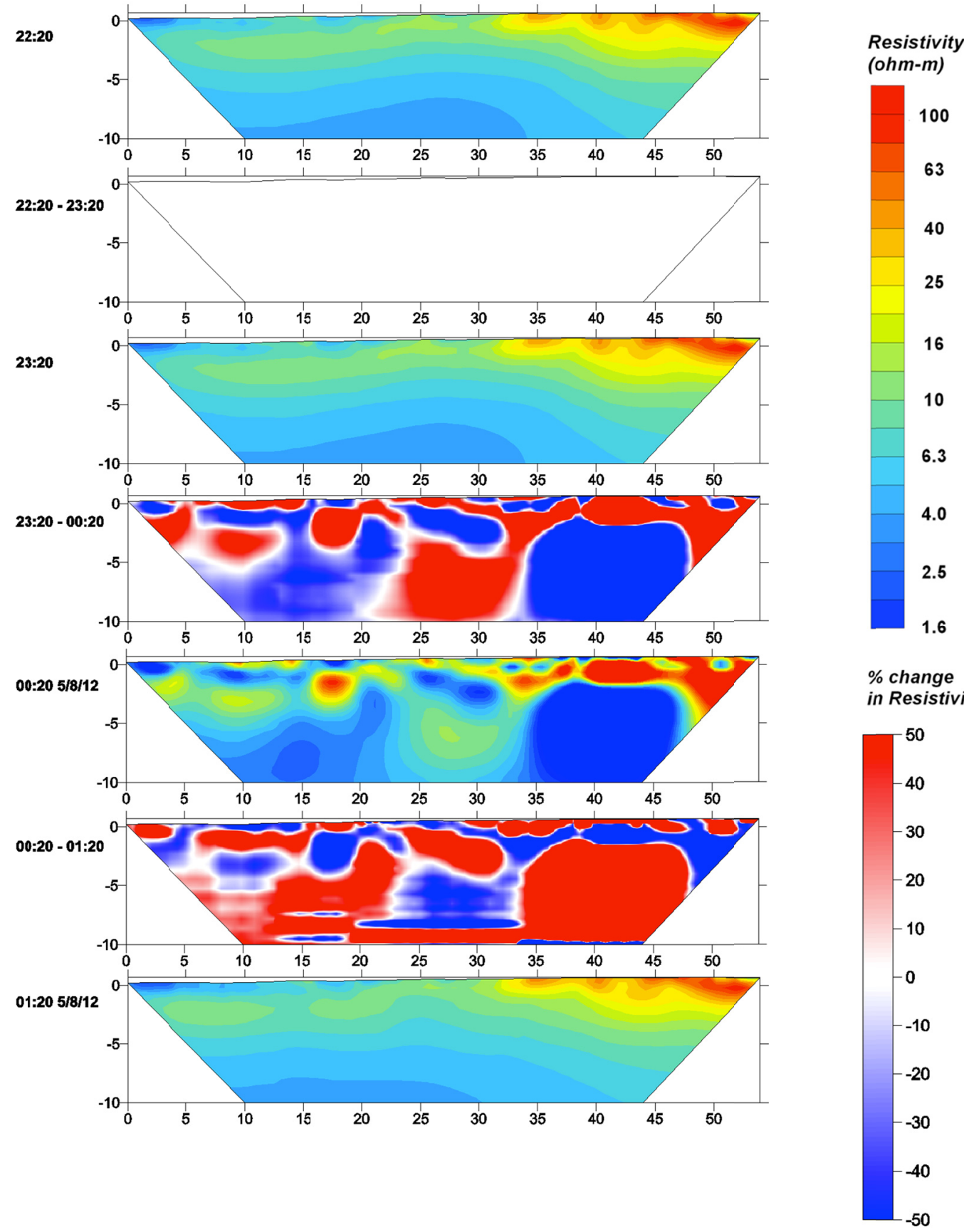


\section{Line B1WE 5/7/12 Difference Inversion Results}

ERT results are plotted in $\log 10$ scale. Percent change in the resistivity over the time steps is plotted between each ERT result. 


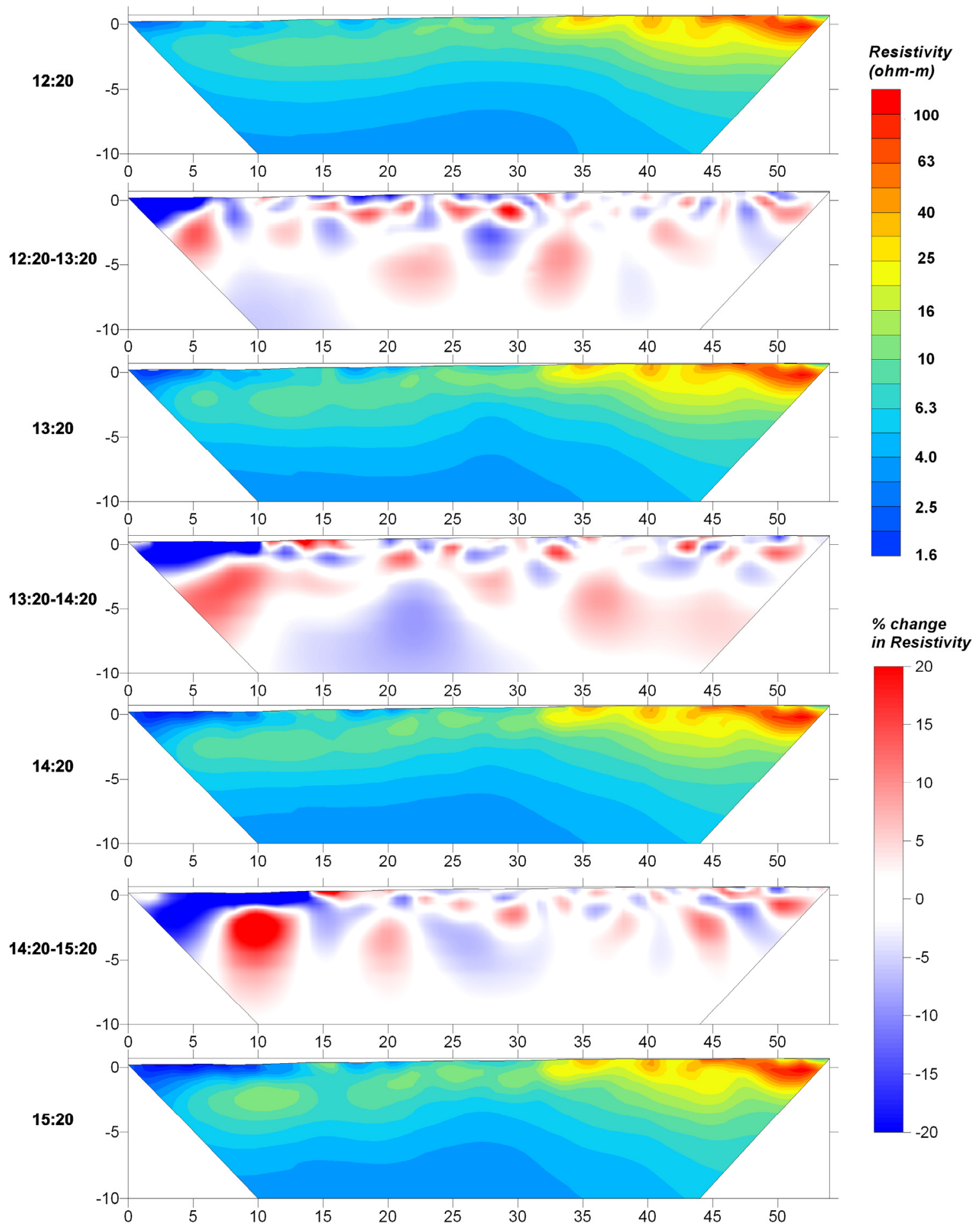




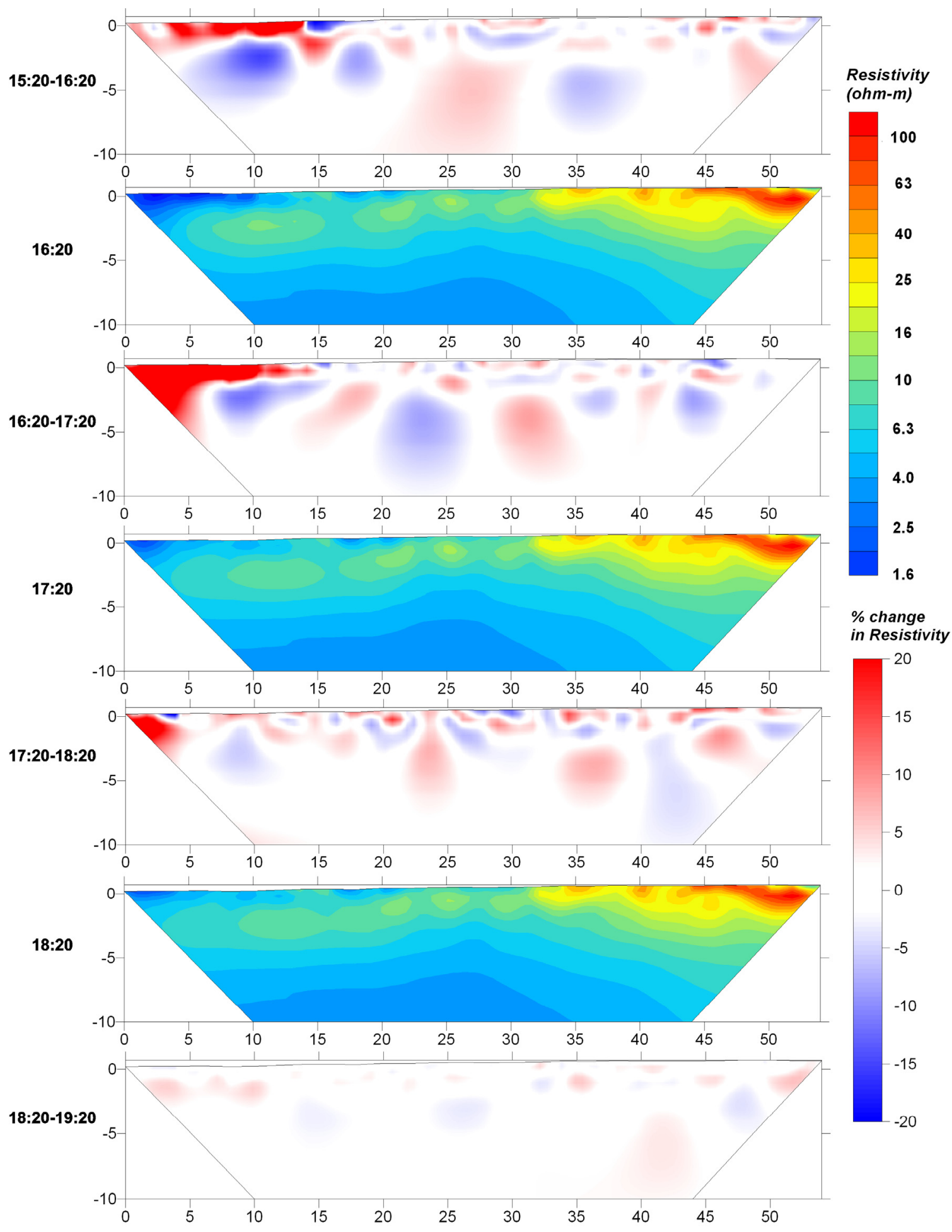




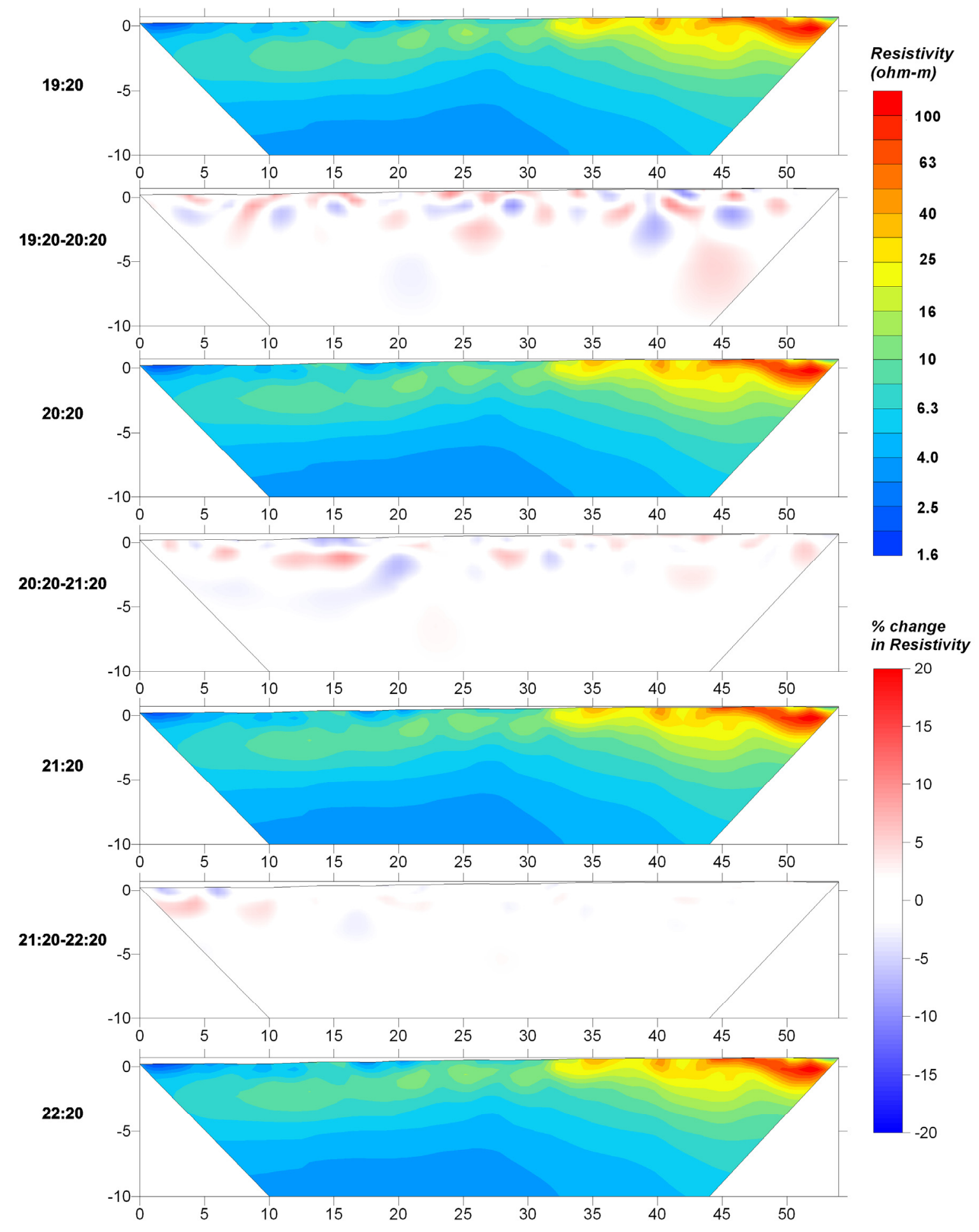




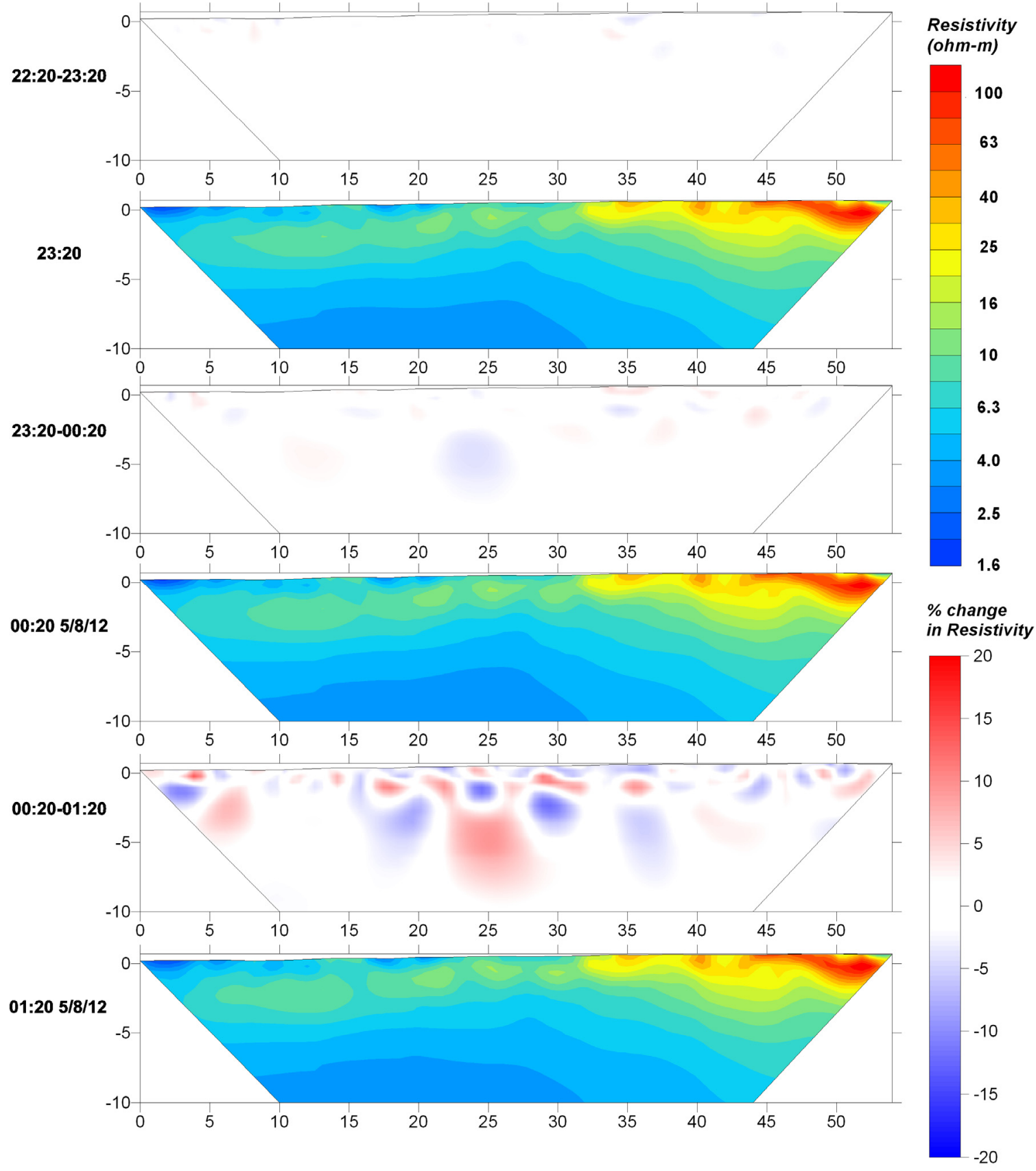




\section{Line B3 5/8/12 Difference Inversion Results}

ERT results are plotted in $\log 10$ scale. Percent change in the resistivity over the time steps is plotted between each ERT result. 


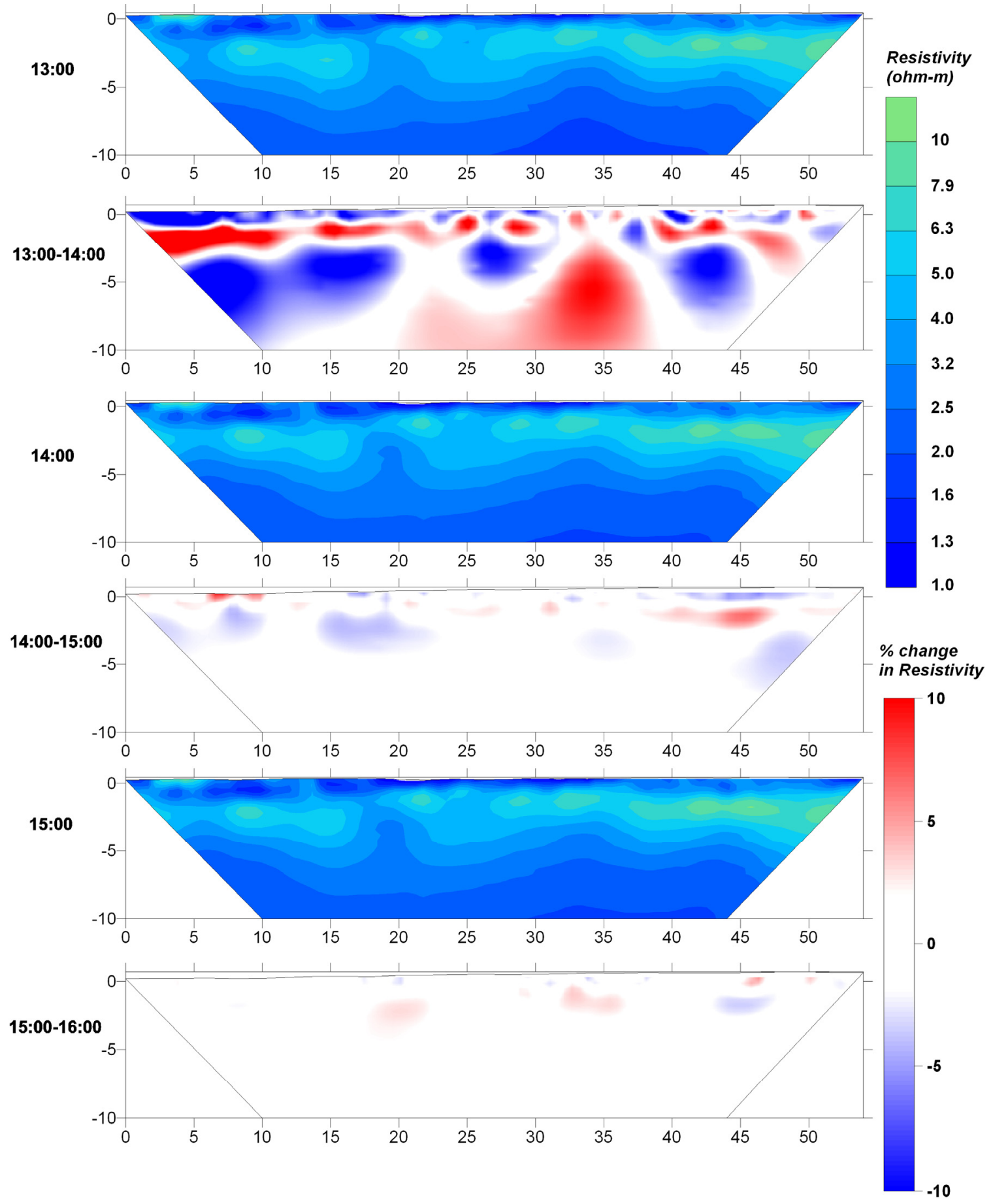




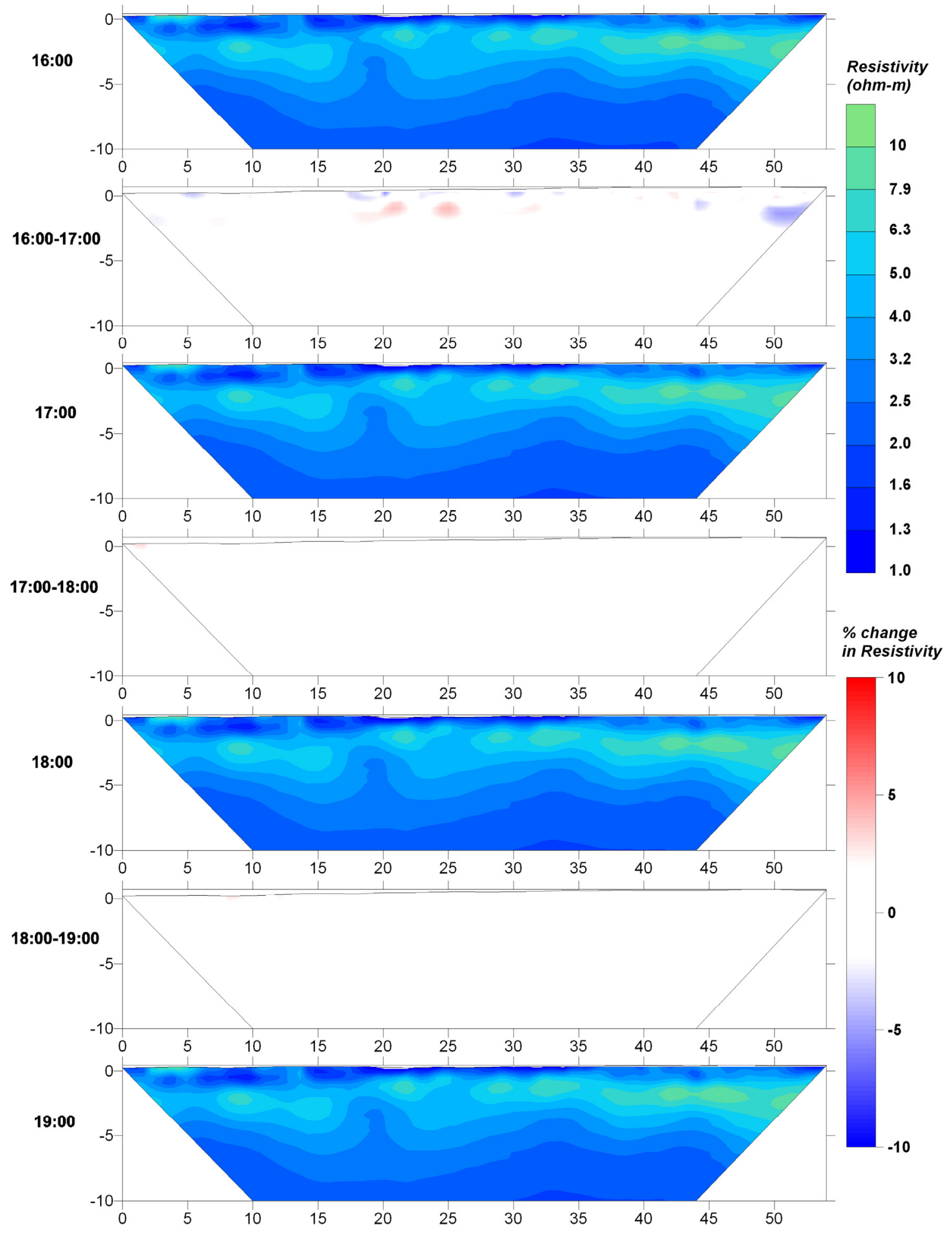


APPENDIX B: Seasonal Well Data and Corresponding Resistivity Values

\begin{tabular}{|c|c|c|c|c|c|c|c|c|}
\hline $\begin{array}{l}\overline{0} \\
\overline{3}\end{array}$ & $\frac{\stackrel{\Xi}{ \pm}}{0}$ & $\underset{\Xi}{\stackrel{\Xi}{\Xi}}$ & 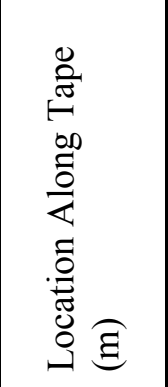 & 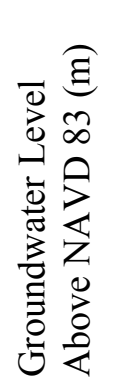 & $\begin{array}{l}0 \\
0 \\
0 \\
\stackrel{0}{0} \\
\stackrel{\bullet}{\bullet}\end{array}$ & 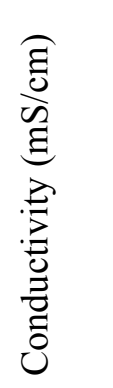 & 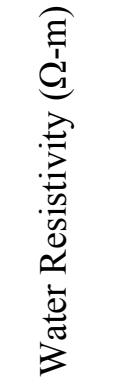 & 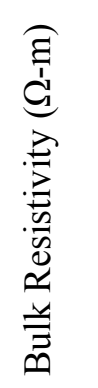 \\
\hline B11 & $5 / 20 / 11$ & $10: 37 \mathrm{a}$ & 16 & -0.038 & 26.4 & 14.02 & 0.713 & 8.4 \\
\hline B12 & $5 / 20 / 11$ & $10: 45 a$ & 38 & 0.028 & 26.7 & 4.374 & 2.286 & 14.7 \\
\hline B13 & $5 / 20 / 11$ & $12: 40 p$ & 104 & 0.075 & 26.7 & 2.527 & 3.957 & 34.14 \\
\hline B24 & $5 / 24 / 11$ & $5: 10 p$ & $\sim 278$ & 0.401 & 28 & 2.303 & 4.342 & 85.94 \\
\hline $\mathrm{B} 25$ & $5 / 24 / 11$ & $3: 44 p$ & $\sim 190$ & -0.068 & 27.5 & 6.38 & 1.567 & 21.77 \\
\hline B26 & $5 / 24 / 11$ & $11: 07 \mathrm{a}$ & 22 & -0.398 & 28.1 & 0.836 & 11.962 & 96.45 \\
\hline B31 & $5 / 21 / 11$ & $9: 35 a$ & 18 & -0.339 & 27.7 & 23.54 & 0.425 & 5.13 \\
\hline B32 & $5 / 21 / 11$ & $10: 20 \mathrm{a}$ & 62 & -0.03 & 27.4 & 20.01 & 0.5 & 5.99 \\
\hline B33 & $5 / 21 / 11$ & $11.23 \mathrm{a}$ & 104 & -0.024 & 26.3 & 10.83 & 0.923 & 12.15 \\
\hline B34 & $5 / 21 / 11$ & $11: 31 \mathrm{a}$ & 134 & 0.014 & 26.2 & 7.44 & 1.344 & 10.97 \\
\hline B35 & $5 / 21 / 11$ & $12: 45 p$ & 192 & 0.008 & 26.8 & 6.08 & 1.645 & 20.78 \\
\hline S21 & $5 / 23 / 11$ & $10: 10 \mathrm{a}$ & 34 & -0.088 & 28.6 & 58.6 & 0.171 & 1.94 \\
\hline S22 & $5 / 23 / 11$ & $11: 42 a$ & 104 & 0.045 & 28 & 10.8 & 0.926 & 8.68 \\
\hline $\mathrm{S} 23$ & $5 / 23 / 11$ & $1: 00 p$ & $\sim 180$ & -0.092 & 27.4 & 4.604 & 2.172 & 18.9 \\
\hline S31 & $5 / 22 / 11$ & $9: 51 \mathrm{a}$ & 8 & -0.093 & 30.1 & 54.5 & 0.183 & 2.21 \\
\hline $\mathrm{S} 32$ & $5 / 22 / 11$ & $10: 01 \mathrm{a}$ & 34 & -0.075 & 28 & 19.7 & 0.508 & 5.81 \\
\hline $\mathrm{S} 33$ & $5 / 22 / 11$ & $10: 30 \mathrm{a}$ & 74 & 0.03 & 27.3 & 7.04 & 1.42 & 13.24 \\
\hline S34 & $5 / 22 / 11$ & $11: 25 \mathrm{a}$ & 121 & -0.092 & 27.8 & 2.508 & 3.987 & 36.87 \\
\hline S35 & $5 / 22 / 11$ & $2: 14 p$ & 219 & 0.029 & 27.1 & 2.616 & 3.823 & 27.99 \\
\hline B11 & $11 / 13 / 11$ & $1: 20 p$ & 16 & 0.114 & 26.1 & 12.41 & 0.806 & 7.95 \\
\hline B12 & $11 / 13 / 11$ & $2: 00 p$ & 38 & 0.223 & 25.5 & 6.5 & 1.538 & 20.34 \\
\hline B13 & $11 / 13 / 11$ & $3: 20 p$ & 104 & 0.295 & 26 & 3.253 & 3.074 & 36.9 \\
\hline B31 & $11 / 11 / 11$ & $10: 20 \mathrm{a}$ & 18 & 0.021 & 25.9 & 24.86 & 0.402 & 4.62 \\
\hline B32 & $11 / 11 / 11$ & $11: 30 \mathrm{a}$ & 62 & 0.122 & 26.3 & 23.58 & 0.424 & 5.94 \\
\hline B33 & $11 / 11 / 11$ & $12: 04 p$ & 104 & 0.126 & 25.9 & 9.15 & 1.093 & 12.48 \\
\hline B34 & $11 / 11 / 11$ & $12: 40 p$ & 134 & 0.24 & 26.6 & 2.532 & 3.949 & 11.09 \\
\hline B35 & $11 / 11 / 11$ & $1: 50 p$ & 192 & 0.088 & 25.7 & 5.46 & 1.832 & 23.69 \\
\hline S21 & $11 / 13 / 11$ & $8: 55 a$ & 34 & -0.036 & 25.5 & 36.09 & 0.277 & 2.81 \\
\hline
\end{tabular}




\begin{tabular}{|l|l|l|r|r|r|r|r|r|} 
S22 & $11 / 13 / 11$ & $9: 55 \mathrm{a}$ & 104 & 0.056 & 25.8 & 8.61 & 1.161 & 9.42 \\
\hline S23 & $11 / 13 / 11$ & $11: 00 \mathrm{a}$ & $\sim 180$ & -0.007 & 25.2 & 4.567 & 2.19 & 23.92 \\
\hline S31 & $11 / 12 / 11$ & $9: 40 \mathrm{a}$ & 8 & -0.089 & 26.4 & 38.58 & 0.259 & 3.24 \\
\hline S32 & $11 / 12 / 11$ & $10: 20 \mathrm{a}$ & 34 & -0.07 & 26 & 6.96 & 1.437 & 9.72 \\
\hline S33 & $11 / 12 / 11$ & $11: 10 \mathrm{a}$ & 74 & 0.094 & 26.6 & 1.157 & 8.643 & 50.73 \\
\hline S34 & $11 / 12 / 11$ & $11: 50 \mathrm{a}$ & 121 & 0.039 & 27 & 0.971 & 10.299 & 75.11 \\
\hline S35 & $11 / 12 / 11$ & $2: 50 \mathrm{a}$ & 219 & 0.207 & 26.2 & 1.126 & 8.881 & 114.62 \\
\hline B26 & $12 / 10 / 11$ & $10: 10 \mathrm{a}$ & 22 & 0.1 & 26 & 0.91 & 10.989 & 77.1 \\
\hline B25 & $12 / 10 / 11$ & $1: 22 \mathrm{p}$ & $\sim 190$ & 0.11 & 26.5 & 3.66 & 2.732 & 25.02 \\
\hline B24 & $12 / 10 / 11$ & $2: 30 \mathrm{p}$ & $\sim 278$ & 0.118 & 25.7 & 1.122 & 8.913 & 64.86 \\
\hline
\end{tabular}


APPENDIX C: Salinity Distribution Plots

B1WE tidal survey on 7/28/11

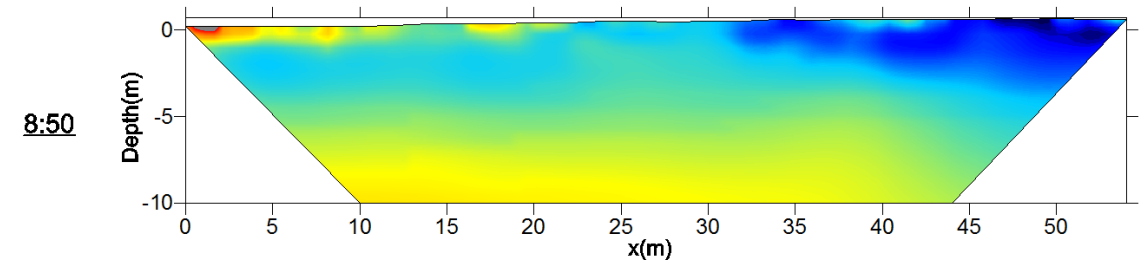

$\underline{9: 50}$

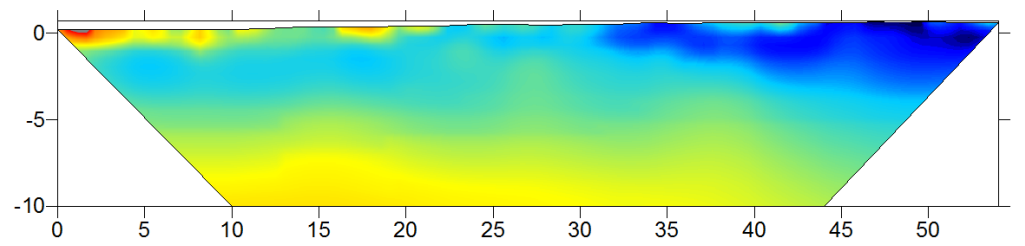

10:50

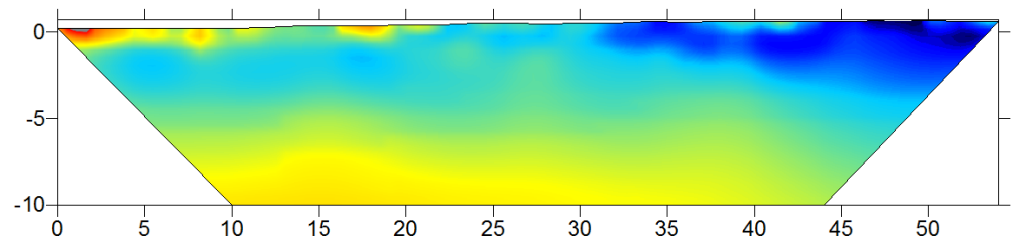

$\underline{11: 50}$
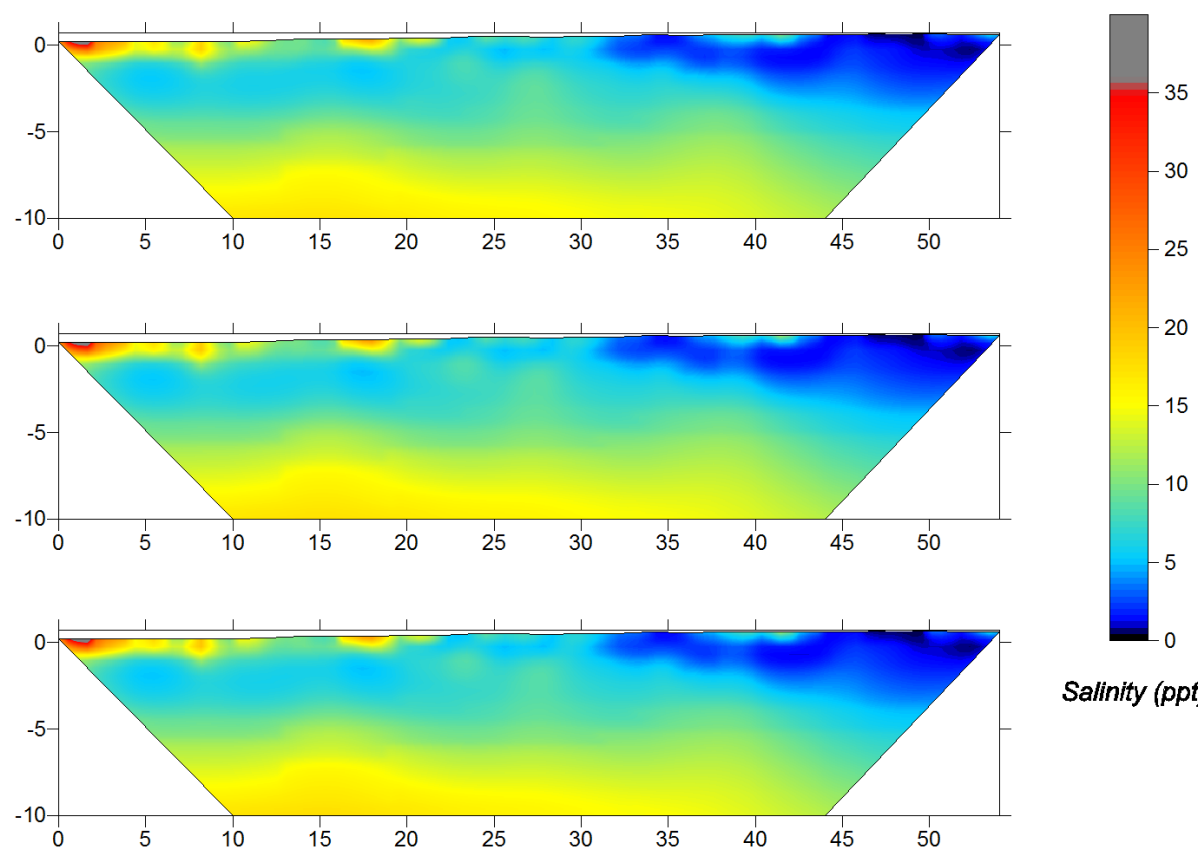

Salinity (ppt)

$\underline{12: 50}$

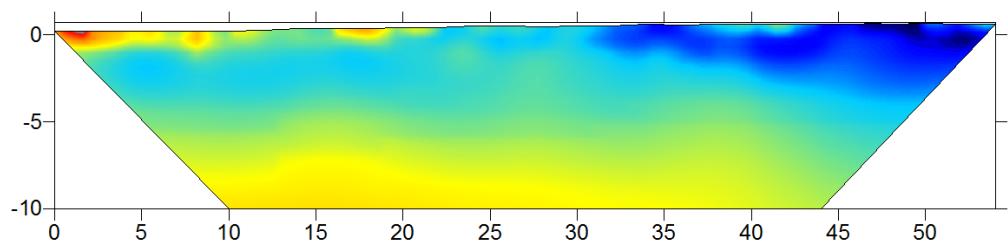

13:50

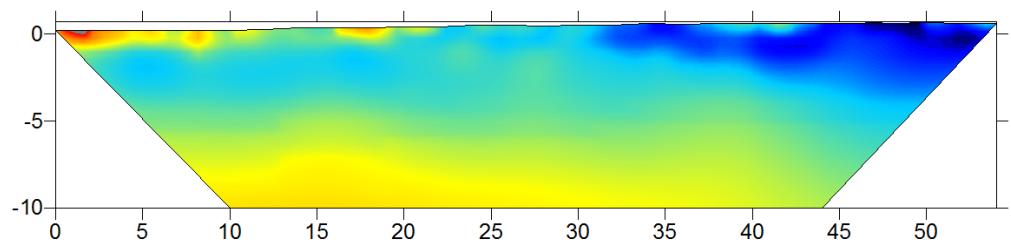



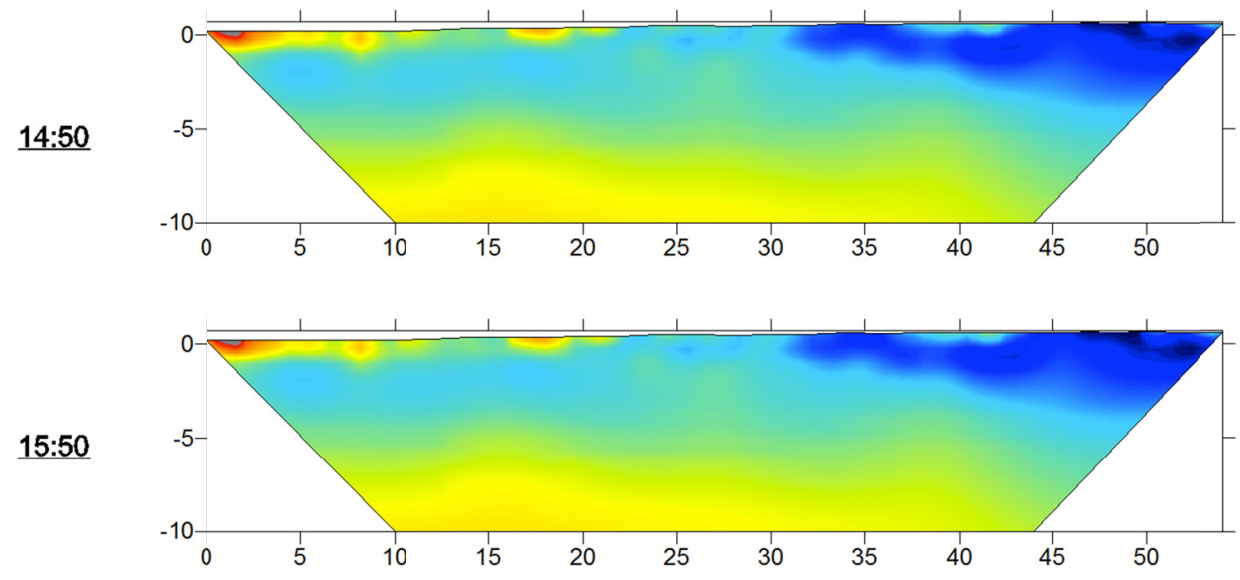

16:50

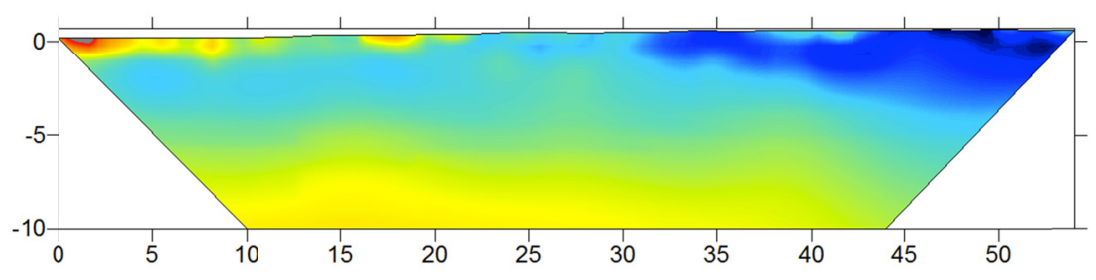

$17: 50$

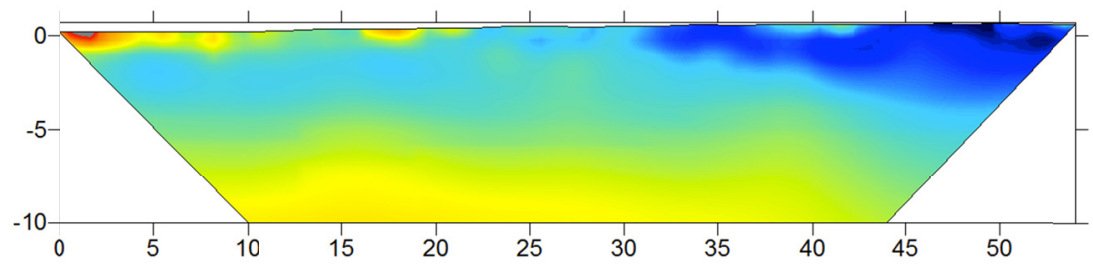

18:50

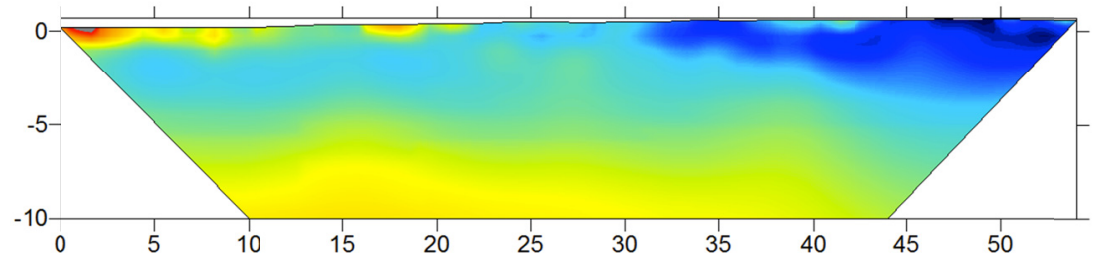


B1NS tidal survey on 7/29/11
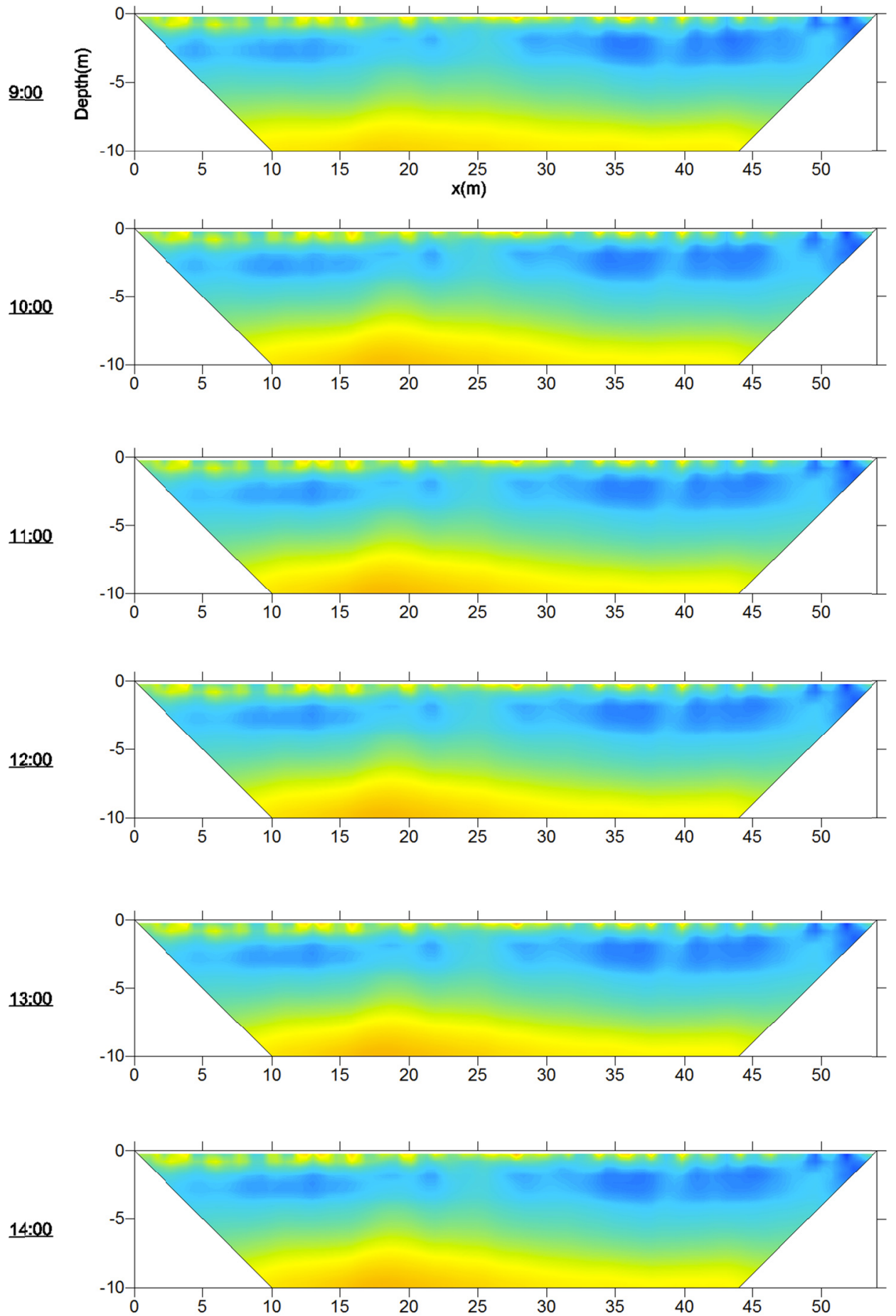

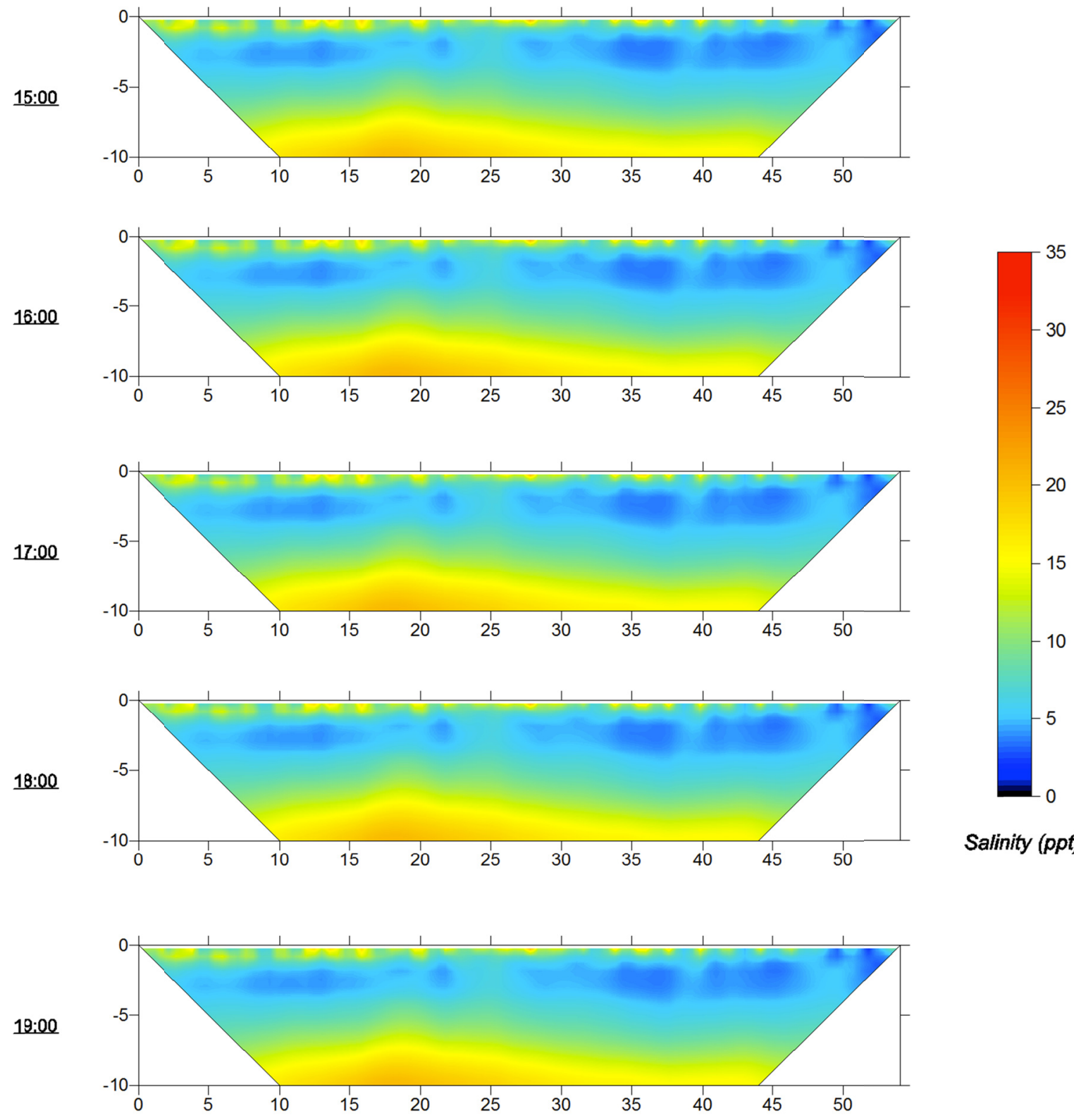

Salinity (ppt) 
B1WE tidal survey on 5/7/12
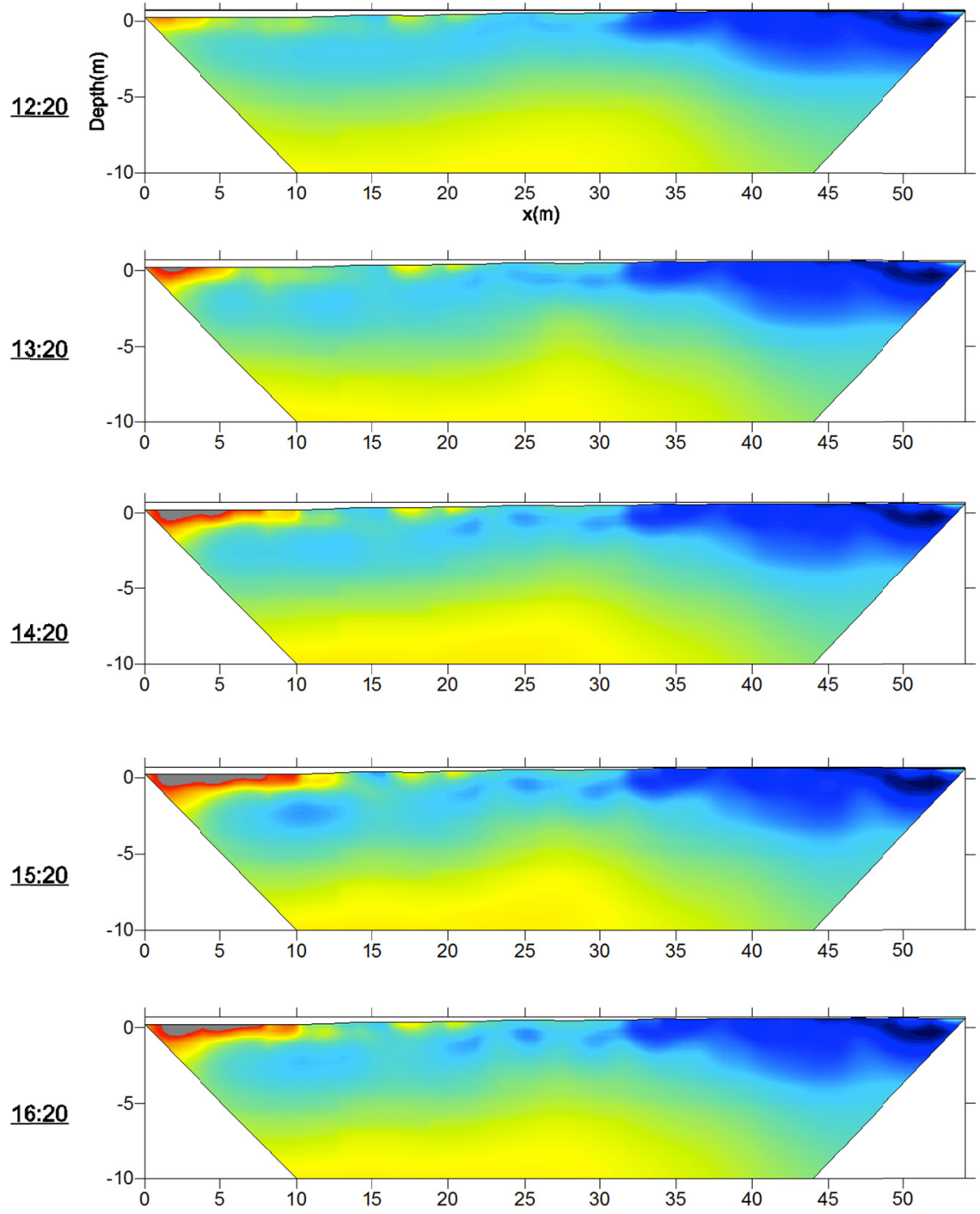

Salinity (ppt)

$17: 20$

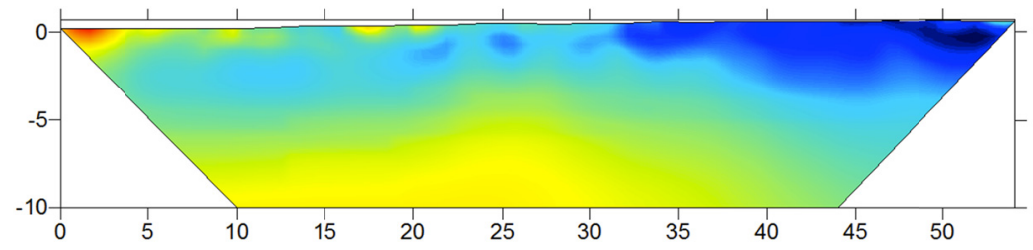

18:20

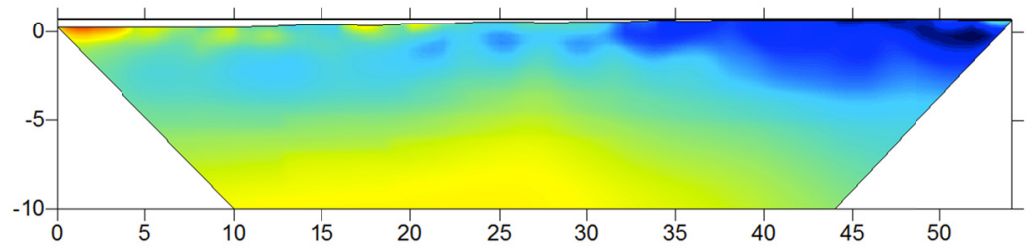



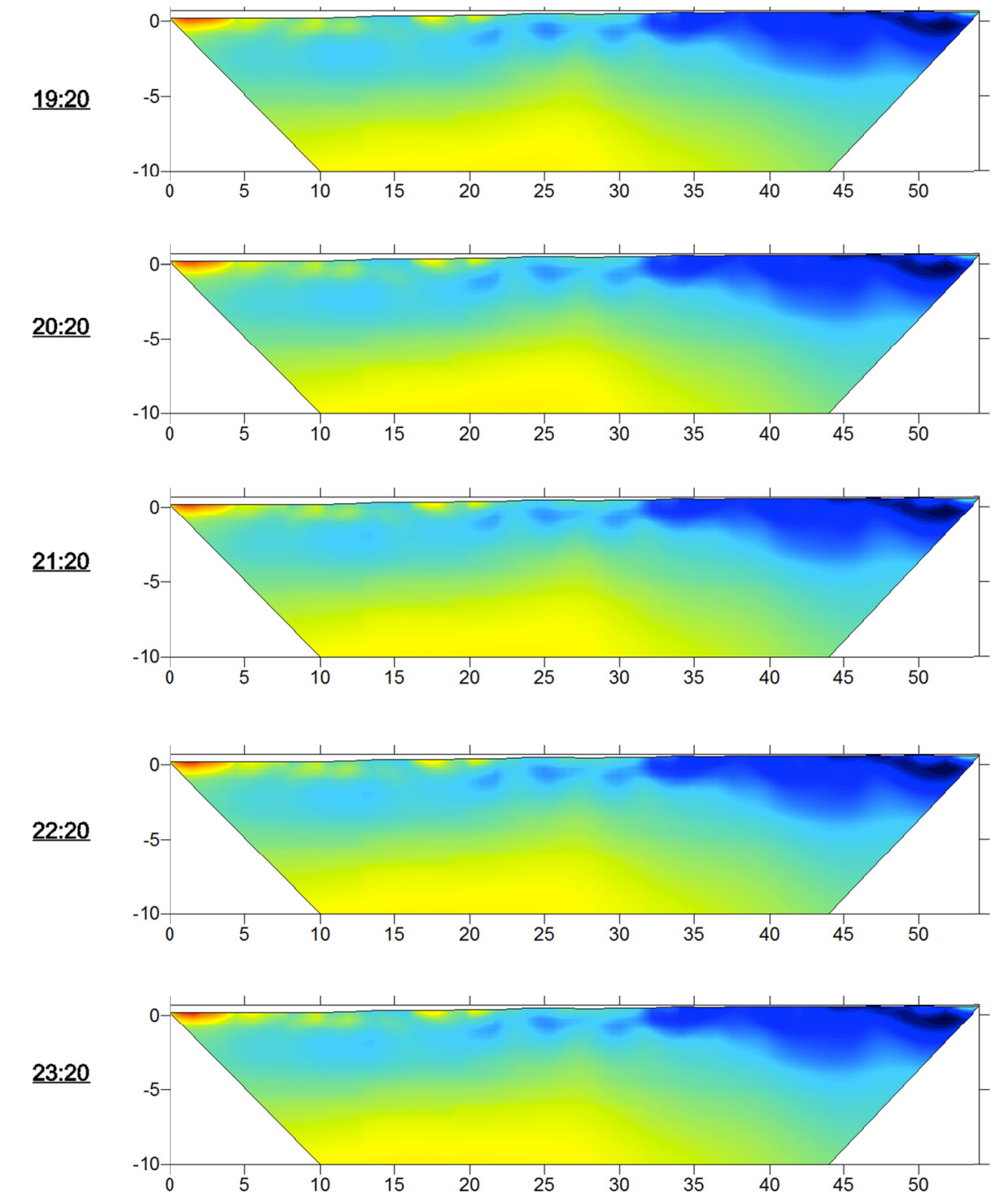

Salinity (ppt)
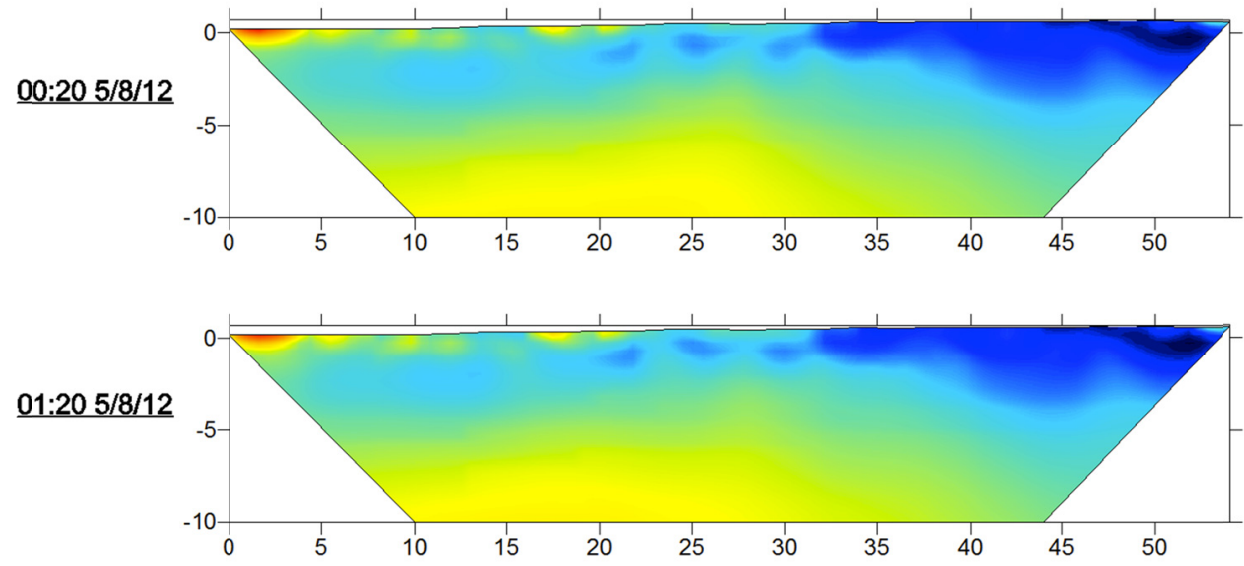


\section{B3 tidal survey on 5/8/12}

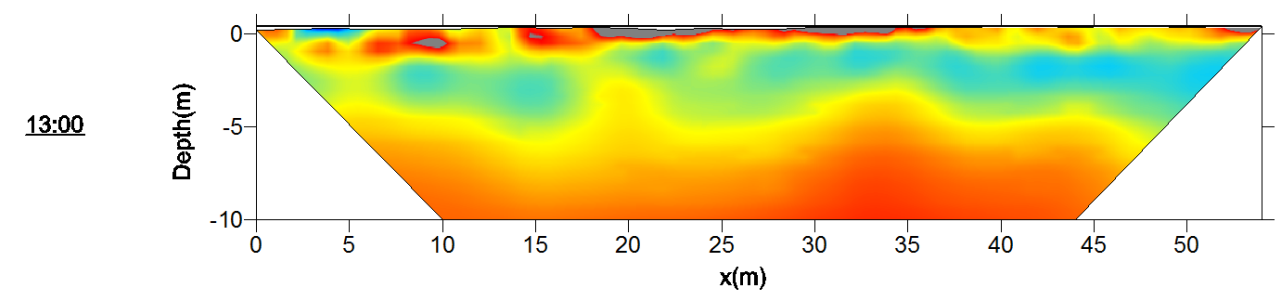

14:00

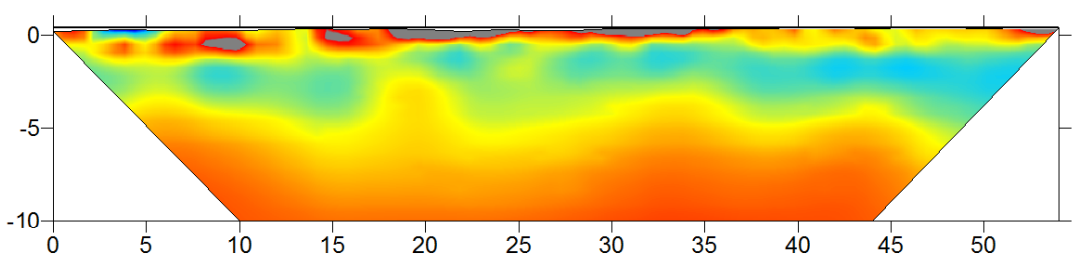

15:00

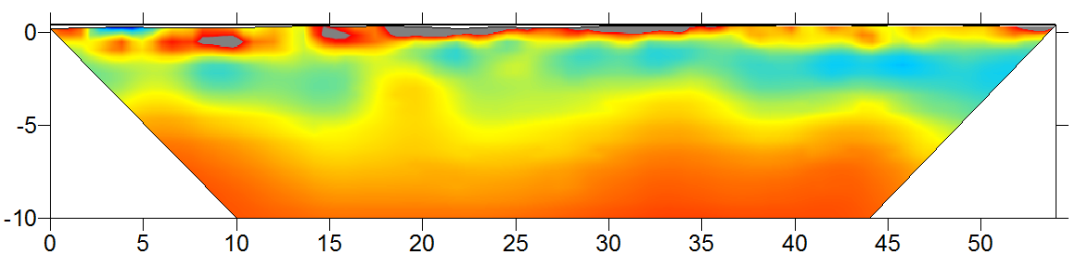

16:00

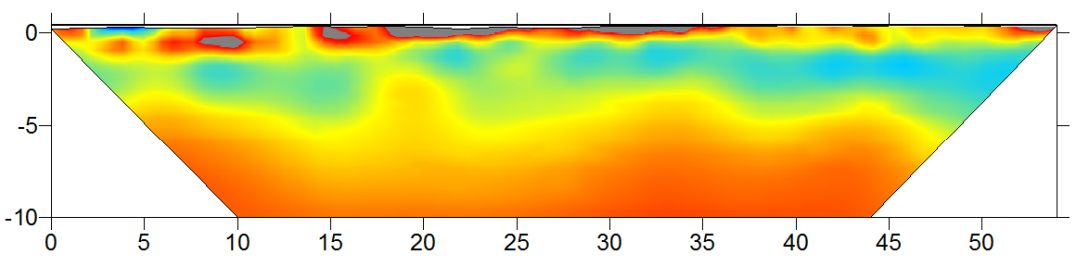

Salinity (ppt)

17:00

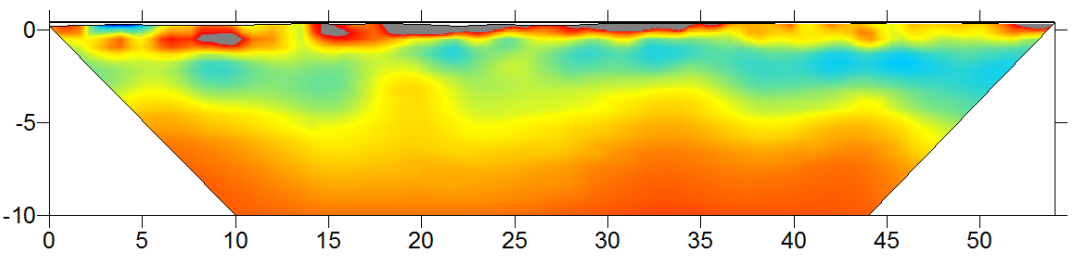

18:00

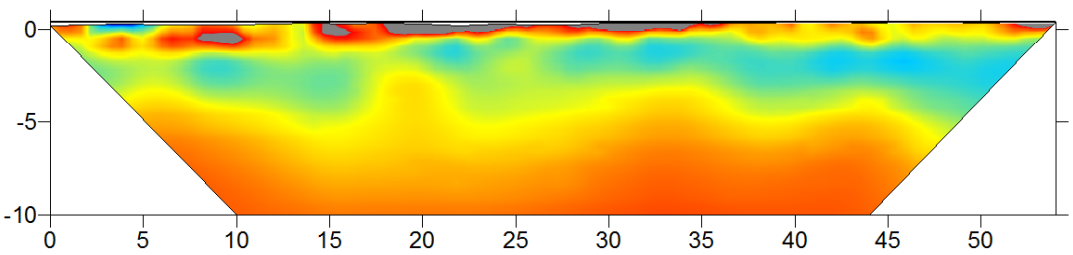

19:00

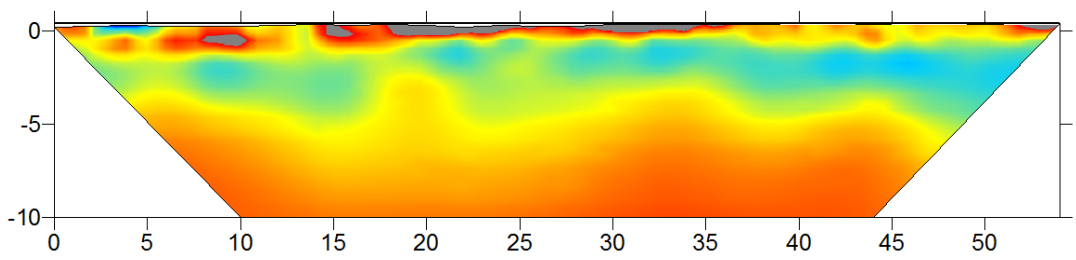


APPENDIX D: Tidal Head Boundary Conditions

\begin{tabular}{|c|c|c|}
\hline Stress Period & Jul-11 & May-12 \\
\hline 1 & 49.879 & 50.016 \\
\hline 2 & 49.891 & 50.028 \\
\hline 3 & 49.903 & 50.04 \\
\hline 4 & 49.915 & 50.054 \\
\hline 5 & 49.934 & 50.067 \\
\hline 6 & 49.953 & 50.078 \\
\hline 7 & 49.962 & 50.092 \\
\hline 8 & 49.968 & 50.108 \\
\hline 9 & 49.976 & 50.121 \\
\hline 10 & 49.974 & 50.136 \\
\hline 11 & 49.973 & 50.15 \\
\hline 12 & 49.979 & 50.163 \\
\hline 13 & 49.991 & 50.179 \\
\hline 14 & 50.004 & 50.193 \\
\hline 15 & 50.007 & 50.196 \\
\hline 16 & 50.012 & 50.217 \\
\hline 17 & 50.015 & 50.224 \\
\hline 18 & 50.022 & 50.231 \\
\hline 19 & 50.025 & 50.238 \\
\hline 20 & 50.026 & 50.246 \\
\hline 21 & 50.030 & 50.267 \\
\hline 22 & 50.032 & 50.288 \\
\hline 23 & 50.032 & 50.302 \\
\hline 24 & 50.034 & 50.314 \\
\hline 25 & 50.035 & 50.327 \\
\hline 26 & 50.038 & 50.347 \\
\hline 27 & 50.041 & 50.352 \\
\hline 28 & 50.038 & 50.365 \\
\hline 29 & 50.038 & 50.382 \\
\hline 30 & 50.037 & 50.396 \\
\hline 31 & 50.048 & 50.402 \\
\hline 32 & 50.053 & 50.406 \\
\hline 33 & 50.054 & 50.408 \\
\hline 34 & 50.054 & 50.401 \\
\hline 35 & 50.059 & 50.389 \\
\hline 36 & 50.073 & 50.372 \\
\hline 37 & 50.073 & 50.348 \\
\hline
\end{tabular}




\begin{tabular}{|r|r|r|}
\hline 38 & 50.076 & 50.317 \\
\hline 39 & 50.085 & 50.277 \\
\hline 40 & 50.091 & 50.241 \\
\hline 41 & 50.098 & 50.206 \\
\hline 42 & 50.106 & 50.166 \\
\hline 43 & 50.107 & 50.133 \\
\hline 44 & 50.111 & 50.089 \\
\hline 45 & 50.116 & 50.058 \\
\hline 46 & 50.120 & 50.02 \\
\hline 47 & 50.118 & 49.985 \\
\hline 48 & 50.124 & 49.956 \\
\hline 49 & 50.130 & 49.927 \\
\hline 50 & 50.131 & 49.898 \\
\hline 51 & 50.128 & 49.872 \\
\hline 52 & 50.129 & 49.85 \\
\hline 53 & 50.125 & 49.835 \\
\hline 54 & 50.124 & 49.829 \\
\hline 55 & 50.129 & 49.838 \\
\hline 56 & 50.130 & 49.858 \\
\hline 57 & 50.133 & 49.875 \\
\hline 58 & 50.138 & 49.89 \\
\hline 59 & 50.138 & 49.903 \\
\hline 60 & 50.142 & 49.918 \\
\hline 61 & 50.148 & 49.933 \\
\hline 62 & 50.158 & 49.948 \\
\hline 63 & 50.170 & 49.963 \\
\hline 64 & 50.174 & 49.977 \\
\hline 65 & 50.175 & 49.988 \\
\hline 66 & 50.168 & 49.999 \\
\hline 67 & 50.162 & 50.01 \\
\hline 68 & 50.153 & 50.019 \\
\hline 69 & 50.146 & 50.026 \\
\hline 70 & 50.141 & 50.031 \\
\hline 71 & 50.139 & 50.033 \\
\hline 72 & 50.136 & 50.031 \\
\hline 73 & 50.136 & 50.029 \\
\hline 74 & 50.132 & 50.023 \\
\hline 76 & 50.126 & 50.012 \\
\hline 77 & 50.122 & 49.998 \\
\hline & 50.119 & 49.983 \\
\hline & & \\
\hline
\end{tabular}




\begin{tabular}{|c|c|c|}
\hline 78 & 50.118 & 49.976 \\
\hline 79 & 50.115 & 49.974 \\
\hline 80 & 50.105 & 49.979 \\
\hline 81 & 50.096 & 49.982 \\
\hline 82 & 50.080 & 49.997 \\
\hline 83 & 50.061 & 50.012 \\
\hline 84 & 50.045 & 50.03 \\
\hline 85 & 50.026 & 50.047 \\
\hline 86 & 50.008 & 50.065 \\
\hline 87 & 49.987 & 50.078 \\
\hline 88 & 49.964 & 50.087 \\
\hline 89 & 49.943 & 50.088 \\
\hline 90 & 49.919 & 50.086 \\
\hline 91 & 49.903 & 50.078 \\
\hline 92 & 49.886 & 50.066 \\
\hline 93 & 49.873 & 50.05 \\
\hline 94 & 49.859 & 50.033 \\
\hline 95 & 49.844 & \\
\hline 96 & 49.836 & \\
\hline 97 & 49.829 & \\
\hline 98 & 49.829 & \\
\hline 99 & 49.832 & \\
\hline 100 & 49.839 & \\
\hline 101 & 49.850 & \\
\hline 102 & 49.857 & \\
\hline 103 & 49.860 & \\
\hline 104 & 49.863 & \\
\hline 105 & 49.869 & \\
\hline 106 & 49.868 & \\
\hline 107 & 49.871 & \\
\hline 108 & 49.871 & \\
\hline 109 & 49.872 & \\
\hline 110 & 49.874 & \\
\hline 111 & 49.878 & \\
\hline 112 & 49.875 & \\
\hline 113 & 49.875 & \\
\hline 114 & 49.869 & \\
\hline 115 & 49.872 & \\
\hline 116 & 49.868 & \\
\hline 117 & 49.865 & \\
\hline
\end{tabular}




\begin{tabular}{|l|l|l|}
\hline 118 & 49.862 & \\
\hline 119 & 49.859 & \\
\hline 120 & 49.852 & \\
\hline 121 & 49.848 & \\
\hline 122 & 49.848 & \\
\hline 123 & 49.851 & \\
\hline 124 & 49.861 & \\
\hline 125 & 49.859 & \\
\hline 126 & 49.843 & \\
\hline 127 & 49.853 & \\
\hline 128 & 49.870 & \\
\hline 129 & 49.888 & \\
\hline 130 & 49.907 & \\
\hline 131 & 49.892 & \\
\hline 132 & 49.892 & \\
\hline 133 & 49.901 & \\
\hline
\end{tabular}

